\title{
Kapitel 3: Besichtigen
}

\section{Auf Exkursion im Kriegsmuseum}

Im sowjetischen Museum waren die Besucherinnen und Besucher »[...] nicht sich selbst überlassen, sondern wurde[n] gleichsam an die Hand genommen [...]. Die Exkursion war vollgepackt mit Informationen, die sich keiner merken konnte, auch wenn manche mitschrieben - ein intensiver Belehrungsvorgang, der große Selbstdisziplin verlangte «. ${ }^{1}$ Der sowjetische Museumsbesuch unterschied sich von seinem westeuropäischen Gegenstück in erster Linie durch seine Konzeption als geleiteter Gruppenbesuch. Die Ausstellungsinszenierung war nicht auf den Individualbesuch ausgerichtet, sondern setzte einen gemeinsamen Rundgang, eine sogenannte »Exkursion« (ékskursija) mit den Museumsführerinnen und Museumsführern voraus.

\section{Das russische Exkursionswesen im sowjetischen Museum}

Das russische Exkursionswesen (ékskursionistik, èkskursiologija) entwickelte sich aus der theoretischen Disziplin der Regionalwissenschaften (kraevedenie) und prägte die pädagogischen Reformbewegungen des ausgehenden Zarenreiches. ${ }^{2}$ Die theoretischen Curricula der Schulen sollten um lebendige und lebensnahe Ausflüge in die Umgebung erweitert werden. Die Bezeichnung »Exkursion« weist auf den didaktischen Ansatz des Lernens durch Entdeckung hin. Nach der Oktoberrevolution von 1917 formte das Narkompros die neue Methode des Bildungsausfluges zu einer wissenschaftlichen Disziplin und gründete in Petrograd ein »Institut für Exkursionen « (Petrogradskii èkskursionnyj institut). Die prägenden Figuren des vorrevolutionären Exkursionswesens und ihrer akademischen Weiterentwicklung in der jungen Sowjetunion waren der Historiker Ivan Michailovič Grevs (1860-1941) und sein Schüler Nikolaj Pavlovič Anciferov (1889-1959). ${ }^{3}$ Nach der Russischen Revolu-

1 Schlögel, Karl: Museumswelten im Umbruch, S. 15.

2 Johnson, Emily: How St. Petersburg Learned to Study itself, S. 97-123.

3 Ivan Grevs erste Abhandlung über die Theorie und Praxis der »Exkursion « als Mittel der universitären Lehre erschien 1910: K teorij i praktike »èkskursii«, kak orudija naučnogo izučenija 
tion, als die Paläste, Gutshäuser und Landsitze des Adels für das allgemeine Publikum geöffnet wurden, führten die sogenannten Exkursionisten (ékskurzovody) das Volk durch die Welt der ehemaligen Herrscher, um den Menschen an den authentischen Orten eine lebendige Vorstellung von den sozialen und kulturellen Verhältnissen der Zarenzeit zu geben. ${ }^{4}$ Diese Politik des Bewahrens und Ausstellens der Kunst- und Kulturgüter der gestürzten Elite in den sogenannten »Palast-Museen« (dvorec-muzej) prägte die sowjetische Museologie während der Zeit des Kriegskommunismus und der »Neuen Ökonomischen Politik« (1918-1928). ${ }^{5}$ Im Kontext der »Kulturrevolution« des ersten Fünfjahresplans wurde im Dezember 1930 der erste Kongress für muzejščiki abgehalten. ${ }^{6}$ Er leitete eine Museumsreform ein, die das sowjetische Museumswesen zu einem eigenständigen Modell werden ließ, das sich stark von seinem westeuropäischen Gegenpart unterschied. Diese Reform hatte in erster Linie Folgen für das Exkursionswesen. Die Auswahl- und Interpretationskriterien westlicher Museen, in denen Nationalität, Chronologie oder die Biografien einzelner Künstler und Künstlerinnen die Ausstellungsinszenierungen bestimmten, wurden als Beweis einer bourgeoisen Ideologie kritisiert. Die führenden sowjetischen Museologinnen und Museologen, die der »neuen Generation von radikal marxistischen Kuratoren« angehörten, propagandierten ein Ausstellungsmodell, in dem (Kunst-)Geschichte als Klassenkampf gezeigt wurde. ${ }^{7}$ Dieses »rigoros ideologische Ausstellungsmodell« war durch zwei Merkmale gekennzeichnet, die die Inszenierung und die Sammlungspolitik beeinflussten und sich damit auch auf die Führungspraxis der Museen auswirkten. Die dezidierte Favorisierung des Textes gegenüber dem Objekt sollte eine unzweideutige Interpretation der Ausstellung sicherstellen. Die großformatigen Textbanner, die wie Spruchbänder mit didaktischen Slogans über den Exponaten angebracht wurden, führten zu dem zeitgenössischen Begriff des "von selbst sprechenden Museums« (samogovoriaščij muzej), das einer individuellen Interpretation und Aneignung der Ausstellung möglichst keinen Raum lassen sollte, da es die Deutung aus sich selbst heraus vorgab. ${ }^{8}$

Die Dominanz der Texte, die die Exponate mitunter zu einer reinen Illustration des Diskurses werden ließ, führte zu einer Abwertung des Ausstellungsstücks,

istorij v universitetach. 1925 gab I. Grevs einen wegweisenden Sammelband zur Rolle der Exkursionistik in der Kultur heraus: »Ėkskursij v kul'ture«. Sein Schüler Nikolaj Anciferov griff diese Ansätze auf und publizierte Schriften und Lehrgänge zur Exkursionistik. Vgl. Anciferov, Nikolaj: Teorija i praktika èkskursij po obščestvovedeniju, Leningrad 1926.

4 Schlögel, Karl: Museumswelten im Umbruch, S. 25.

5 Für das Jahrzehnt der »preservationist policy« (1918 und 1928) vgl. Akinsha, Konstantin/Jolles, Adam: On the Third Front, The Soviet Museum and its Public during the Cultural Revolution, in: Canadian American Slavic Studies, Nr. 43, 2009, S. 195-212.

6 Fitzpatrick, Sheila (Hg.): Cultural Revolution in Russia 1928-1931, Bloomington 1978.

7 Ebd. S. 198.

8 Jolles, Adam: Stalin's Talking Museums, in: Oxford Art Journal, Vol. 28, Nr. 3, 2005, S. 431-455. 
das heißt des Originals. Eine auf die Exponate bezogene Museologie wurde als westlicher »Objekt-Fetischismus« (veščnyj fetišizm) diskreditiert und die Produktion von Repliken und Kopien wurde gefördert. An die Stelle des einzigartigen Originals sollte das austauschbare Museumsobjekt mit der immer gleichen politischen Botschaft treten. ${ }^{9}$ Diese idealtypische Vorstellung wurde von der Vorgabe des unionsweiten Objekttransfers gefördert und hatte starken Einfluss auf die Museumssammlungen. Mit dem Ziel der Angleichung der Ausstellungen wurden Bestände ohne Rücksicht auf die Einheit der Sammlungen auseinandergenommen und auf die Museen der Sowjetunion verteilt. Häuser, die nicht in den Besitz der benötigten Objekte kamen, sorgten selbständig für Ersatz, indem sie die Exponate reproduzierten oder Fotos der Originale ausstellten. ${ }^{10}$ Die Historiker Akinsha und Jolles werten diese Ausstellungspraxis als »Ent-Sakralisierung der Objekte«. Sie sei Ausdruck einer »Ikonophobie« der sowjetischen Kuratoren, die »tiefes Misstrauen« gegenüber der Fähigkeit des Museumspublikums hegten, die Geschichte ohne Texthilfen zu verstehen. ${ }^{11}$

$\mathrm{Zu}$ Beginn der 1930er Jahre entstand eine zweite Generation von sowjetischen Ausstellungen, die den Fokus der Vermittlungsarbeit auf die diskursive Denunziation legte. ${ }^{12}$ Diese Praxis, die in erster Linie gegen die orthodoxe Kirche und die Avantgardekunst gerichtet war, sollte das ungebildete, proletarische Publikum mit den kulturellen Zielen der stalinistischen Interpretation des Kommunismus vertraut machen. Diese »militant marxistischen Ausstellungen« führten zu einer Machtverschiebung im Museum. Während zuvor die Werke von Künstlerinnen und Künstlern den Ausstellungsinhalt bestimmt hatten, rückten nun das Museum bzw. seine Kuratorinnen und Kuratoren an diese Stelle. ${ }^{13}$ Die denunziatorische sowjetische Museologie wird von der Forschung als Übergang zum sozialistisch-realistischen Ausstellungsmodell beschrieben. ${ }^{14}$

Das Museumsinstitut entwickelte neue Konzepte für die Führungen in den radikal umgestalteten und neu entstehenden Museen, und die ékskurzovody stellten sich die Frage, welchen Platz sie innerhalb der spannungsreichen Beziehung zwischen Text und Objekt einnehmen sollten. ${ }^{15}$ Gemäß der Theorie über die Wirkung von Ausstellungsarrangements auf große Gruppen waren sie nun nicht mehr nur

Akinsha, Konstantin/Jolles, Adam: On the Third Front, S. 198.

Ebd. S. 204.

Ebd. S. 201-202.

Jolles/Adam: Stalin's Talking Museums, S. 431.

Ebd. S. 437-439.

Ebd. S. 451. Adam Jolles weist auf das Erkenntnispotential einer noch ausstehenden Studie hin, die in einer vergleichenden transnationalen Perspektive die sowjetische Museumspraxis der 1930er Jahre in Bezug zu westeuropäischen Museen stellt. 
Lehrerinnen und Lehrer mit besonderer Qualifikation, sondern wurden als Expertinnen und Experten angesehen, die über die Gabe verfügten, wissenschaftliche Erkenntnisse emotional und intellektuell wirkungsvoll zu präsentieren. Die Historikerin Emily Johnson, die die Entstehung des russischen Exkursionswesens erforscht hat, vergleicht die Arbeit der èkskursozovody mit den Aufgaben von Schauspielern: »[...] an expert scholar with the creativity necessary to weave the results of years of study into affecting emotional and intellectual events. Transforming raw information into a polished monologue, this new master guide completed tasks analogous to a performance artist's: scripting, blocking and staging his presentation. ${ }^{16}$

Der Forschung zufolge ist die ursprüngliche Form des russischen bzw. frühsowjetischen Exkursionswesens gemeinsam mit der Disziplin der kraevedenie während der erwähnten Museumsreform in den frühen 1930er Jahren vernichtet und die Anciferov'sche Tradition der Bildungsreisen in den Untergrund gedrängt worden. Erhalten habe sich nur eine "Schwundform der Exkursion« die sich durch einen stextintensiven, fakten- und detailversessenen, weniger auf das Sehen als auf das Zuhören ausgerichteten « Typus von Führungen auszeichne. ${ }^{17}$

Die Relikte des »Großen Vaterländischen Krieges« und die im Krieg entwickelte Form der kommemorativen Ausstellungen führten zu einem Umdenken in der didaktischen Vermittlung, die im Zusammenhang mit der Aufwertung des $\mathrm{Mu}$ seumsexponates stand. Die frischen Kriegsrelikte erschienen den èkskurzovody als ideologisch legitimierte Zeugen, die sie zum Sprechen bringen konnten.

\section{Die èkskurzovody und ihre Besuchergruppen}

Die ékskurzovody diskutierten den Inhalt und die Qualität ihrer Texte mit ihren Kolleginnen und Kollegen und schrieben die Skripte ihrer Führungen in der Regel selbst. Protokolle dieser internen Sitzungen erlauben eine Rekonstruktion der zeitgenössischen Diskurse über Form, Inhalt und Ausrichtung der Ausstellungsführungen.

Im Moskauer Armeemuseum waren die Ansprüche an die zwölf èkskurzovody hoch. Die Arbeitspläne sahen vor, dass die sie einen Monat Zeit hatten, um ihre Skripte zu verfassen. Dann mussten sie in Anwesenheit ihrer Vorgesetzten und ihrer Kolleginnen und Kollegen aus der Sammlungsabteilung die konzipierten Führungen vortragen und sich der Kritik stellen. ${ }^{18}$ Der hohe politische Anspruch spie-

16 Ebd. S. 114.

17 Schlögel, Karl: Museumswelten im Umbruch, S. 24-25.

18 Ebd. S. 1. Die in den Protokollen besprochenen Führungen sind nicht erhalten. Die einzigen Führungsskripte aus dem Moskauer Armeemuseum sind zwei zufällig überlieferte, nicht archivierte Dokumente aus dem Jahr 1935: Stenogramma, èkskursija, provodimaja èkskursovodom tov. Alekseevym v Muzee Krasnoj Armii, 5. nojabrja 1935 goda. Stenogramma, èks- 
gelt sich auch in den umfassenden Schulungen, an denen die Mitarbeiterinnen und Mitarbeiter regelmäßig teilnehmen mussten. ${ }^{19}$ Damit wurde eine Professionalisierung der muzejščiki angestrebt, für die in Minsk und Tscheljabinsk keinerlei Mittel bereitstanden. Auch die direkte Anbindung des Moskauer Museums an die wichtigste politische Propagandabehörde der Roten Armee GlavPURKKA, die das Museum mit theoretischen Materialien versorgte, vergrößerte den Wissensvorsprung gegenüber anderen Museen. Theoretische Unterstützung erhielten die Moskauer èkskurzovody auch durch die politischen Vorträge, die das Haus der Roten Armee in engen Abständen organisierte und deren Besuch obligatorisch war. Das Programm war nicht nur inhaltlich anspruchsvoll - dank seiner guten Beziehungen gelang es dem Haus regelmäßig, renommierte Historiker, hohe Politiker und Militärs einzuladen -, sondern auch sehr zeitaufwendig: Nach ihren langen Arbeitstagen mussten die ékskurzovody beinahe jeden zweiten Abend Vorträge besuchen. Im Anschluss an die Vortragsreihe fand eine inhaltliche Prüfung statt. Der Kurator und stellvertretende Museumsdirektor Pëtr Loginov fragte den gerade vermittelten Stoff ab und überprüfte, ob sie in der Lage waren, die komplexen Inhalte auf die didaktische Form einer Museumsführung zu reduzieren. ${ }^{20}$

Wie jeden Winter stand auch im Dezember 1944 die Auswertung der Rede Stalins zu den Revolutionsfeierlichkeiten im Zentrum der politischen Weiterbildung und alle Mitarbeiterinnen und Mitarebeiter waren angehalten, sich den Inhalt der Rede im Selbststudium anzueignen. ${ }^{21}$ Um eine möglichst effektive Ausstellungsführung zu erreichen, wurden die Arbeitspläne der Exkursionsabteilung eng mit jenen der Ausstellungsabteilung koordiniert. Anlässlich des 27. Jubiläums der Oktoberrevolution im November 1944 hatte Stalin von den »10 vernichtenden Schlägen « gesprochen, die die Rote Armee dem Feind in diesem Jahr zugefügt hatte. ${ }^{22}$ Den ékskurzovody wurden gemäß ihren Kenntnissen und ihres Ranges (drei Lohnstufen) Themen zugeteilt, zu denen sie Führungsskripte verfassen sollten. Auf der

kursija, provodimaja èkskursovodom tov. Slavgorodskoj v Muzee Krasnoj Armii, 11. nojabrja 1935 goda, in: CMVS, nicht archivierte Bestände.

19 Alle drei Monate bekam der Leiter des Exkursionsbüros einen Arbeitsplan von dem stellvertretenden Museumsdirektor Pëtr Loginov zugestellt, der die Weiterbildung für die 12 Angestellten der Abteilung Bildung und Vermittlung festlegte. Vgl.: CMVS, op. 3, d. 26/9, I. 1.

Vom 19. bis zum 29. Dezember 1944 fanden insgesamt fünf Vorträge statt. Am 23. Dezember 1944 hielt beispielsweise der renommierte Experte zur deutschen Ceschichte Arkadij Erusalimskij einen Vortrag mit dem Titel: »Über die internationale Lage«. Vgl.: CMVS, op. 3, d. 26/9, I. 1.

21 Ebd.

22 Stalin, Josef: Der 27. Jahrestag der großen sozialistischen Oktoberrevolution, Am 6. November 1944, in: Verlag Roter Morgen (Hg.): ]. W. Stalin, Februar 1934-April 1945, Bd. 14, Dortmund 1976, S. 356-370. 
untersten Stufe sollten Skripte zu den einzelnen "Schlägen« ausgearbeitet werden. Die Ausarbeitung von anspruchsvolleren Themen, wie beispielsweise die internationale Dimension des Krieges, wurde Mitarbeiterinnen und Mitarbeitern der mittleren und obersten Lohnstufe übertragen. ${ }^{23}$

Auszüge aus dem Protokoll einer Sitzung, bei der èkskurzovody den Kuratorinnen und Kuratoren sowie ihren Vorgesetzten ihre Führungen präsentierten, geben Einblick in die Diskussionskultur der muzejščiki und zeigen, dass sich die geäußerte Kritik in erster Linie um die Frage nach der richtigen Relation zwischen Text und Objekt drehte.

\section{„Kritik und Selbstkritik» der muzejščiki}

Unter dem Titel »Das Jahr des entscheidenden Sieges«, einem Zitat aus der Rede Stalins zum 27. Jahrestag der Oktoberrevolution, hatte die Moskauer Museumsführerin Leonova einen Führungstext ausgearbeitet, der im Juli 1945 im Museum lebhaft diskutiert wurde. ${ }^{24}$ Frau Artemova, eine der älteren Museumsführerinnen, eröffnete die Diskussion:

»Mein Eindruck der Führung ist nicht schlecht. Aber die Führerin nennt nur Operationen und Zahlen [...] deswegen kann die Führung nur für ein militärisches Publikum verwendet werden. Die Führerin hat überhaupt keine Bilder oder Objekte miteinbezogen. Sie hat zu wenig über den Dritten Schlag gesagt, ein Thema, mit dem die Genossin Leonova vertraut ist. $\ll^{25}$

Die erfahrene Museumsführerin begann ihre Wortmeldung mit einem Lob für die grundsätzlich gute Qualität der Führung ihrer Kollegin. Ihre anschließende Kritik betraf zwei zusammenhängende Bereiche: Die Führung sei für ein breites Publikum ungeeignet, da sie zu zahlen- und faktenlastig sei. Deshalb seien solche technischen Führungen, wenn überhaupt, nur für ein militärisch versiertes Publikum

23 Der Plan teilte den Angestellten Pachman, Rajt, Leonova und Mosesova je zwei bis drei der von Stalin beschriebenen »Schläge« zu. Dabei wurden jeder Museumsführerin geografisch zusammenhängende Kriegsereignisse zugewiesen. Beispielsweise sollte die Führerin Pachman eine Führung zu den »Schlägen Nr. 1, 4 und 10 «schreiben, die zur Befreiung des Leningrader Gebietes, der Befreiung Kareliens und zu dem Angriff auf Nordfinnland führten. Die Führerin Marija Nazarova, die zur mittleren Gehaltsstufe gehörte, sollte hingegen eine Führung zu der Thematik »Die Angriffsoperationen unserer Alliierten« verfassen. CMVS, op. 3, d. 26/9, I. 1.

24 CMVS, op. 3, d. 26/9, I. 10-12. Die wissenschaftlichen Mitarbeiterinnen und Mitarbeiter des Museums (Abteilung Bildung \& Vermittlung und Ausstellungen/Sammlungen) waren in drei aufeinander aufbauenden Lohnstufen angestellt: Im Jahr 1944 verdienten die Angestellten der unteren Stufe zwischen 450-600 Rubel/Monat, die der mittleren Lohnstufe 600 Rubel und die der oberen zwischen 600 und 800 Rubel. Vgl.: CMVS, op. 3, d. 35/18, I. 27-27ob. 
geeignet. Der Fehler liege in der Gestaltung der Führung, die keinen Bezug auf die Exponate nähme. Damit hatte sie eine offene Frage angesprochen. Wegen der Kritik am »Objektfetischismus« der muzejščiki zu Beginn der 1930er Jahre bestanden bei manchen ékskurzovody offenbar Hemmungen vor einem zu expliziten Einbezug der Objekte. Die abschließende Bemerkung zur mangelhaften politischen Ausrichtung der Führung in Bezug auf die Thematik des »Dritten Schlages« wirkt wie eine folgenreiche Ermahnung. Die zweite Wortmeldung von Frau Dvorcova, ebenfalls eine Museumsführerin des obersten Ranges, kritisierte die fehlende politische Ausrichtung von Leonovas Führung und forderte dabei quasi das Gegenteil ihrer Vorrednerin:

»Die Crundlage der Führung [...] ist die Rede des Cenossen Stalin zum 27. Jahrestag der Oktoberrevolution. [...]. Sie wird weder in der Ausstellung noch in der Exkursion mit ausreichender Klarheit gezeigt. [...] Die Inszenierung der Ausstellung behindert den Cebrauch der Fotos und der Exponate. Die Führung hat kein Ende, weil die Ausstellung auch keines hat. [In der Führung, A.H.] sollte die Winteroffensive von der Sommeroffensive getrennt werden [...]. ${ }^{26}$

In ihren Augen waren nicht die Objekte, sondern der Text - in diesem Fall die Rede Stalins - die Grundlage der Führung. In ihrer Kritik nahm sie die junge Kollegin jedoch gleichzeitig in Schutz und schob den Schwarzen Peter den Kuratorinnen und Kuratoren bzw. der fehlenden politischen Ausrichtung ihrer Ausstellung zu. Sie betonte die Abhängigkeit der èkskurzovody von der Inszenierung: Nur eine Anordnung der Exponate gemäß der Rede ermöglichte eine an politischen Synthesen reiche Führung. In Dvorcovas Kritik zeigt sich die Überzeugung einer Ausstellungspraxis, die zu Gunsten eindeutiger Narrative den Text über die Objekte stellte. Ihr abschließender Ratschlag bezüglich einer inhaltlichen Veränderung der Führung (thematische Trennung der Kriegsepisoden) löste bei einem anderen Kollegen Irritation aus:

»Wenn wir den Weg wählen, den Cenossin Dvorcova in ihrem Beitrag vorgeschlagen hat, wird die Exkursion über 2,5 Stunden dauern [anstelle der gewünschten 1,5 Stunden, A.H.]. Wir dürfen nicht nach Winter- und Sommeroffensive im Jahr 1944 unterscheiden, weil es aus strategischen Cesichtspunkten nicht stimmt. [...] Die Exkursionistin beherrscht ihr Material, und die Exkursion ist mehr oder weniger annehmbar [priemlema]. [...] Ein wesentlicher Fehler ist, dass Genossin Leonova den Befehl vom 1. Mai überhaupt nicht thematisiert hat. Versprecher müssen korrigiert werden und die falsche Aussprache der Namen der Städte, insbesondere der ausländischen, muss verbessert werden. ${ }^{27}$ 
Der Museumsführer Razdorožnij diskreditierte den kühnen Vorschlag einer inhaltlichen Veränderung der Führung (chronologische Trennung der Kämpfe im Jahr 1944) der Kollegin Dvorcova als unüberlegt und wenig sinnvoll. Seine Kritik erwähnte neben der Frage der Relation von Text und Objekt ein weiteres Qualitätskriterium einer guten Führung: fachliche Kompetenz. Seiner Meinung nach sei der Vorschlag einer thematischen Anpassung aus militärstrategischer Perspektive schlicht falsch und sprenge zudem den zeitlichen Rahmen der Führung. Er bescheinigte der Kollegin Leonova eine grundsätzlich gute Führung, aber dass sie die gerade erst zwei Monate zurückliegende Rede Stalins zum 1. Mai 1945 unterschlagen habe, war in seinen Augen ein schwerwiegendes Versäumnis. Hier zeigt sich der hohe Anspruch an ein größtmögliches Fachwissen, das immer auf dem aktuellen Stand sein musste. Dieser Anspruch äußerte sich in scheinbaren Details wie der korrekten Aussprache jener unbekannten ausländischen Städte, die die Rote Armee auf ihrem Vormarsch nach Berlin einnahm. Die èkskurzovody mussten ein enorm hohes und anspruchsvolles Pensum an Wissensverarbeitung in sehr kurzer Zeit bewältigen - diesen Anforderungen wurden sie, wie manche Besucherinnen und Besucher in ihren Gästebucheinträgen bemängelten, nicht immer gerecht.

Grundsätzlich sollten die Ausstellungsabteilung und die Abteilung für Bildung und Vermittlung eng zusammenarbeiten. Die Wortmeldungen drückten zwar den Wunsch nach besserer Abstimmung der beiden Abteilungen aus, betonten aber gleichzeitig die unterschiedlichen Ansprüche, die in der Praxis Widersprüche und Konflikte provozierten. Während die Kuratorinnen und Kuratoren eine möglichst detaillierte Inszenierung der einzelnen Kriegshandlungen anstrebten, waren die ékskurzovody auf ein thematisch zusammenhängendes Narrativ angewiesen, das sie in ihren Führungen zu Synthesen formulieren konnten. Der Museumsführer Rajt formulierte diesen Wunsch nach einer Inszenierung der Objekte, die einem Erzählstrang folgte, so:

»In dieser Ausstellung gibt es eine Reihe von Fehlern. [...] Es dominieren Schemata und Fotos. [...] Für die Besucher wäre es viel besser, wenn Gemälde aus Vogelperspektive von den Kämpfen an den verschiedenen Fronten gezeigt würden. Es wäre zielführender, ein allgemeines Schema der Schläge zu zeigen und sie nicht in einzelne Operationen zu unterteilen. [...] sobald solche Ergänzungen [in die Ausstellung, A.H.] kommen, kann Genossin Leonova ihre Aufgabe verbessern [...]. ${ }^{28}$

Rajt versetzte sich in die Position seines Publikums und vermutete, dass die abstrakte Inszenierung von Tabellen und Fotos Orientierungslosigkeit auslösen könnte. Auch er wünschte sich in der Ausstellung weniger Text und mehr visuell ansprechende Exponate. Aus dieser überlegenen Position - die erfolgreiche Vermittlung 
sollte das höchste Ziel beider Abteilungen sein - überschritt er seinen Kompetenzbereich und formulierte konkrete Vorschläge, wie die Kuratorinnen und Kuratoren die Inszenierung ihrer Ausstellung verbessern sollten. Bei der Kritik an der Kollegin nahmen die muzejščiki kein Blatt vor dem Mund. Die Kritik wurde mitunter in einem schonungslosen Diskussionsklima vermittelt, in dem sie sich sogar gegenseitig die berufliche Qualifikation absprachen:

»[...] Es ist unbedingt nötig die Exponate zu zeigen. Das, was Cenossin Leonova vorgetragen hat, war keine Führung [...]. Ins Museum kommt man, um Exponate anzuschauen und hier, von Seiten der Exkursionistin, eine völlige Ignoranz [polnoe nevnimanie] gegenüber den Exponaten, Reliquien und Vitrinen. ${ }^{29}$

Die Meinung der Museumsführerin Zlygosteva war eindeutig: Eine gelungene Führung musste die Exponate einbeziehen. Selbstbewusst distanziert sie sich von der Meinung der anderen und formuliert die Funktion, die ein Museum ihrer Meinung nach haben sollte: Objekte zu zeigen. Diese Haltung war eine Abkehr von der text- und faktenlastigen Ausstellungspraxis zu Gunsten einer exponatsbezogenen Ausstellungsführung.

Insbesondere der Gebrauch des Begriffes »Reliquie« ist ein interessanter Hinweis auf den veränderten Stellenwert des Objektes in der Vermittlungsarbeit. Der zu Beginn des Krieges in der sowjetischen Museologie vermehrt auftretende Begriff kehrte die Ent-Sakralisierung des Museumsexponates um, die zu Beginn der 1930er Jahre zu einer Produktion von Kopien geführt hatte. Der Begriff betonte die auratische Bedeutung des Ausstellungsstückes, da sich die Reliquie, neben ihrer heilsbringenden Wirkkraft, durch ihre Originalität und Einzigartigkeit auszeichnet.

Die Museumsführerin Leonova hatte offenbar eine rein theoretische Führung über den Kriegsverlauf im Jahr 1944 konzipiert, ohne den Inhalt der Vitrinen oder die Bedeutung der Objekte zu erläutern. Dieses Unvermögen provoziert Zweifel an der Effektivität des eingangs geschilderten Weiterbildungsprogrammes. Der folgende Diskussionskommentar bestätigt diese Vermutung. Der Museumsführer Zlacen betonte, dass der Kollegin Leonova bei der Ausarbeitung die »methodische Führung (metodičeskoe rukovodstvo) gefehlt habe und »keiner der Genossin Leonova geholfen habe.$^{30}$ Die èkskurzovody waren bei der Transformation des politischen Programms in eine sinnvolle Führung überfordert und auf die Unterstützung angewiesen, die sie offenbar nicht erhielten. Die fehlende Leitung führte zu einer großen Unsicherheit, wie die ideologischen Vorgaben und insbesondere die Reden Stalins in die Ausstellungen und Führungen integrieren werden sollten, und die 
muzejščiki der zwei Abteilungen schoben sich gegenseitig die Schuld zu. Ein Kurator meldete sich zu Wort und kritisierte, dass die Museumsführerin Leonova die Rede Stalins an den Anfang ihrer Führung gestellt habe. Das sei "politisch falsch « (političeski neverno), denn die Rede müsste als Fazit der Führung am Ende stehen. ${ }^{31}$ Diese Kritik nahm eine junge Museumsführerin zum Anlass, sich ausgiebig über die schlechte Inszenierung zu beklagen:

»Die Ausstellung behindert die Führerin. Es gibt keine Einführung, keine Zusammenfassung und kein Ende. Die Operationen sind häufig nicht richtig illustriert. Die Karten sind sehr nachlässig angefertigt. Die Bezeichnungen stimmen häufig nicht mit dem Inhalt der Fotos überein. Der Fehler liegt darin, dass Genossin Leonova vor lauter Einzelheiten das Ganze nicht sieht [...].. ${ }^{32}$

In der Diskussion verschob sich die Kritik an der Führung zu einer grundsätzlichen Kritik an der Ausstellung. Die Hinweise auf die dilettantisch angefertigten Exponate (Karten) und die fehlerhaften Beschriftungen der Objekte bestätigen die kriegsbedingt improvisierten und teilweise dilettantisch ausgeführten Inszenierungen. Eine Ausstellung ohne eindeutigen Erzählstrang konnte sich wie ein Dominoeffekt auf die Führungen übertragen. Vor lauter Bäumen sah die Führerin Leonova den Wald nicht mehr und war in den Augen ihrer Kolleginnen und Kollegen nicht in der Lage, eine schlüssige Führung zu konzipieren. An dieser Stelle meldete sich der Chef der èkskurzovody, der Leiter der Exkursionsabteilung Belousov, zu Wort und fasste seinen Eindruck folgendermaßen zusammen:

»Die Exkursion ist zufriedenstellend [udovletvoritel'nij]. Cenossin Leonova hat nicht schlecht gesprochen. Aber das ist nicht alles, was von Cenossin Leonova verlangt wird. Der einzige und große Mangel ist der fehlende Zusammenhang zwischen dem Material und der Theorie. Das, was in der Ausstellung ist, muss benutzt werden. Die Exkursion wird methodisch falsch durchgeführt. Die Aufmerksamkeit der Besucher wird nicht von den Fotografien angezogen - nicht von den Reliquien angeregt. [...]...33

Belousov verlangte eine Führung, die in einer sinnvollen Verknüpfung der Ideologie mit den Objekten lag. Auch wenn die Kuratorinnen und Kuratoren Fehler machten, bestand der Anspruch an die èkskurzovody, die Übersicht zu wahren und in ihrer Führung Bezug auf die Objekte zu nehmen, auch wenn sie an einem falschen Platz standen oder nicht beschriftet waren. Innerhalb der zwei methodischen Lager, die

Ebd. Bei seiner Kritik orientierte sich der Kurator möglicherweise am narratologischen Aufbau der Drehbücher der Historienfilme der 1930er Jahre, bei denen politische Reden den Ausklang bildeten.

32 Ebd.

33 Ebd. I. 11. 
über den Stellenwert des Textes bzw. des Objektes in der Ausstellung diskutierten, war seine Position eindeutig: Die Führung musste auf die Objekte ausgerichtet sein, die die Kraft hatten, die Aufmerksamkeit der Betrachterinnen und Betrachter »anzuregen« (obygrat').

Die Diskussion gibt aufschlussreiche Einblicke in das Klima, in dem die muzejščiki arbeiteten. Diese Sitzungen zeigen klassische Bestandteile jener sozialistischen Kommunikationstheorie, die »Kritik und Selbstkritik (kritika i samokritika) genannt und von Lorenz Erren als »konstitutiver Teil der stalinistischen Öffentlichkeit« gedeutet wurde. ${ }^{34}$ 1927/28 hatten die Bolschewiki das Konzept der »Selbstkritik« als »abstrakte Idealvorstellung einer Kommunikationssphäre propagiert, in der Konflikte so austragen werden sollten, dass gleichzeitig auch die Autorität der Sowjetmacht und der Parteilinie gestärkt würde«. ${ }^{35}$ Konflikte sollten »proletarisch" sein und bestehende Grenzen und Rangunterschiede auflösen. Dieser unmöglich in die gesellschaftliche Praxis umzusetzende Anspruch entwickelte sich »rasch zu einem rhetorischen Imperativ, der von den unterschiedlichsten Akteuren situationsbedingt $\mathrm{zu}$ unterschiedlichsten Zwecken instrumentalisiert werden konnte ${ }^{36}{ }^{36}$ "Selbstkritik« wurde spätestens seit den Parteisäuberungen von 1933 als »Herrschaftsmethode« in der »stalinistischen Öffentlichkeit« verwendet. Diese Öffentlichkeit besaß gemäß Erren einen »schizophrenen Doppelcharakter«, der sich in den widersprüchlichen Erwartungen des Staates an seine Subjekte äußerte: Einerseits sollten sich die loyalen Bürgerinnen und Bürger »an der politischen Willensbildung « beteiligen, andererseits wurden sie gleichzeitig »als Zöglinge in einer fortwährenden Unmündigkeit gehalten «. ${ }^{37}$ Im sowjetischen Museum zeigt sich ein Herrschaftsverhältnis zwischen Vorgesetzten und Angestellten, das einem »Erziehungsverhältnis« glich und sich in der Sprache der »Selbstkritik« ausdrückte. »Im Kampf mit dem Bürokratismus war sie sschonungslos` (bespoščadnaja), im Kampf mit den eigenen Fehlern ’kameradschaftlich`(tovaričeskaja), >mutigく (mužestvennaja) und sehrlich (čestnaja). Wenn sie nach Verbesserungen strebte, war sie ssachlichく(delovaja) und >schöpferisch`(tvorčeskaja). « ${ }^{38}$ Das Protokoll der Besprechung des Führungsskriptes der Museumsarbeiterin Leonova ist ein anschauliches Beispiel für die sozialistische Erziehungspraxis in einer Teilöffentlichkeit, die gleichzeitig eine »Kontroll- und Bewährungszone« war: »Die Obrigkeit organisierte das

Erren, Lorenz: »Selbstkritik« und Schuldbekenntnis, Kommunikation und Herrschaft unter Stalin (1917-1953), München 2008, S. 179.

35 Ebd. S. 94. Lorenz betont, dass das Wort »Selbstkritik« sich anfangs nicht auf das Verhältnis des Einzelnen zum Kollektiv bezog und die Begriffe »Selbstkritik« und »Kritik« synonym verwendet werden sollten. Die Vorsilbe »Selbst« bezog sich nicht auf das kritisierende Individuum, sondern auf die gesamte loyale Sowjetgesellschaft. Ebd. S. 96-97.

37 Ebd. S. 179-180.

38 Ebd. S. 97. 
Kollektiv, um auf einzelne Personen erzieherischen Druck auszuüben. [...] Dabei geht es dann sowohl um deren Besserung wie auch um einen ritualisierten Akt der Unterwerfung. $\ll^{39}$ Die Kritik kam nicht in erster Linie von oben nach unten, also vom Vorgesetzten zu seinen Angestellten, sondern von der Basis selbst. Die »sozialistische Öffentlichkeit « und das Gebot der »Selbstkritik « erwarteten »von allen als loyal eingestuften Sowjetbürgern eine aktive Teilnahme an der politischen Willensbildung «. ${ }^{40}$ Die selbstbewussten Äußerungen weisen auf die »Statusaufwertung des einzelnen Menschen« hin, die dieses Kommunikationsmodell befördert. ${ }^{41}$ Die Sitzungen gaben den Angestellten die Möglichkeit, sich mit ihrem Wissen zu profilieren. Die anwesende Protokollantin verlieh der Diskussion durch ihre Arbeit zusätzliches Gewicht, da den Teilnehmenden bewusst war, dass die Protokolle für allfällige Beurteilungen ihrer Arbeit zu Rate gezogen werden konnten.

Der strittigste Punkt der Sitzung war das Verhältnis zwischen Text- und Objektbezug in der Führung. Hier konnte keine Einigkeit unter den ékskurzovody und der Ausstellungsabteilung erreicht werden. Die Diskussion zeigt, dass alte und neue, durch die >kommemorativen Kriegsausstellungen Ansätze, nebeneinander bestanden. Die jüngere Generation der ékskurzovody beharrte auf der dominierenden Rolle des Textes. Ihm sollten die Objekte untergeordnet werden, er sollte ihre Deutung bestimmen. Im Sinne des ssprechenden Museums der 1930er Jahre forderten die èkskurzovody eine politisch eindeutige Inszenierung. Die ältere Generation der ékskurzovody und ihr Vorgesetzter hingegen sahen in den Relikten des Deutsch-Sowjetischen Krieges Reliquien, die in ihrer Einmaligkeit die Kraft besaßen, die Aufmerksamkeit des Publikums zu lenken. Eine Führung, die diese Verbindung nicht herstellte, war in ihren Augen methodisch falsch. Diese internen Diskussionen um die richtige Darstellung spiegeln das Selbstverständnis des Museums, ein didaktischer Lernort zu sein, an dem mit autoritativem Anspruch Wissen vermittelt wurde.

\section{Armee und Schule im Museum}

Diese Diskussionen blieben dem Publikum als Empfänger dieser Wissensvermittlung verborgen. In der Sowjetunion war der Museumsbesuch weder obligatorisch noch fakultativ, er wurde schlicht vorausgesetzt. Als fester Bestandteil des Alltagslebens war er eine Erfahrung, die die Menschen aus den verschiedenen Gesellschaftsschichten generationsübergreifend verband. Spätestens seit der »Kulturrevolution « besuchten alle Kindergärten und Schulklassen, alle Pionier- und Komsomolverbände, alle städtischen Betriebe und Fabriken, alle politischen und staat- 
lichen Einrichtungen und jede Einheit der Roten Armee mindestens einmal das Museum ihrer Stadt oder ihrer Region. Der Museumsbesuch war in der Regel ein Gruppenbesuch und wurde in regelmäßigen Abständen von den entsprechenden Lehrerinnen und Lehrer bzw. den Abteilungsvorsitzenden als gemeinsamer Bildungsausflug organisiert. ${ }^{42}$

Ein Blick in die Besucherstatistik des Moskauer Armeemuseums gibt Aufschluss über die soziale Zusammensetzung des Museumspublikums in der Hauptstadt. ${ }^{43}$ Seit der Eröffnung der Sonderausstellung »Die Zerschlagung der deutschen Truppen vor Moskau« im Februar 1942 stieg die Besucherzahl stetig an und erreichte im Mai desselben Jahres einen ersten Höhepunkt: In diesem Monat besuchten circa 40.000 Menschen die Ausstellung (Gesamtbesucherzahl im Jahr 1942: ca. 303.780). ${ }^{44} \mathrm{Zu}$ dieser Zeit arbeiteten neun ékskurzovody im Museum, die idealerweise alle Gruppen mit Führungen betreuen sollten. ${ }^{45}$ Doch selbst bei einer maximalen Auslastung konnte das Museum seinem Anspruch im Frühjahr 1942 nur $\mathrm{zu} 30$ Prozent gerecht werden, die restlichen 70 Prozent wurden in den Besucherlisten als Individualbesucher (odinoček) verzeichnet. ${ }^{46}$ Eine maximale Auslastung des Museums bedeutete für jede(n) èkskurzovod bis zu fünf Führungen à 90 Minuten am Tag. Mehr als 45 Führungen täglich mit einer Teilnehmerzahl zwischen 20 und 35 Personen waren räumlich nicht möglich. ${ }^{47}$ In Anbetracht der kleinen

Zu berücksichtigen gilt hier jedoch ein Stadt-Land-Gefälle. Tendenziell adressierten diesen gesellschaftspolitischen Erziehungsmaßnahmen hauptsächlich die Stadtbevölkerung. Die auf dem Land lebende agrarisch geprägte Menschen blieb weitestgehend unberücksichtigt, da kaum Initiativen lanciert wurden, diese Menschen einzubeziehen. Vgl. Akinsha, Konstantin/Jolles, Adam: On the Third Front, S. 206.

43 Im Archiv des Moskauer Streitkräftemuseums befinden sich zufällig überlieferte, das heißt nicht archivierte, Dokumente über Besucherzahlen und Führungen. Die Besucherzahlen erwecken in ihren runden Angaben den Verdacht von Schönungen und sind als tendenzielle Angaben zu verstehen. Mappe: Svody na poseščaemost' CMKA za 1942/43g. (33 Seiten), Mappe: Učet poseščaemosti po muzejam, 1942-1943g. (23 Seiten) sowie Mappe: Grafik učeta, provedennych grupp, 1942-1943g. (22 Seiten). Für das Museum über die Ceschichte des Großen Vaterländischen Krieges in Minsk und das regionalwissenschaftliche Museum in Tscheljabinsk waren keine vergleichbaren Dokumente einsehbar.

44 CMVS, nicht archivierte Bestände: Mappe: Svody na poseščaemost' CMKA za 1942-1943g., I. 3.

45 CMVS, nicht archivierte Bestände: Mappe: Crafik učeta, provedennych grupp, 1942-1943g., I. 20.

46 CMVS, nicht archivierte Bestände: Mappe: Svody na poseščaemost' CMKA za 1942-1943g., I. 3.

47 CMVS, nicht archivierte Bestände: Mappe: Grafik učeta, provedennych grupp, 1942-1943g., I. 20. 
und engen Ausstellungsfläche ist bereits diese Zahl erstaunlich hoch und führte zu Beschwerden über die sich gegenseitig »überschreienden ékskurzovody«. ${ }^{48}$

Für die Statistik wurden die Besucherinnen und Besucher der Gruppe der Militärangehörigen (voennye), der Zivilisten (graždanskie) oder der Schüler (školniki) zugeordnet. ${ }^{49}$ Wenig überraschend stellten die Militärangehörigen mit 70 Prozent, die große Mehrheit des Publikums im Armeemuseum. Die restlichen 30 Prozent verteilten sich zu gleichen Teilen auf die Schulklassen und die kaum differenzierte Gruppe der »Zivilisten «. ${ }^{50}$ Für Gruppenführungen wurde ein niedrigerer Eintrittspreis verlangt und die Führungen wurden individuell an die Besuchergruppen angepasst. Rund 80 Prozent der Führungen waren für das Zielpublikum des Museums, die Armee, bestimmt. Hier wurde zwischen Kommandostab und einfachen Soldateneinheiten unterschieden. ${ }^{51}$ Darüber hinaus verfügte die »Exkursionsabteilung « über ein Set von spezifischen Führungen. Sie boten Führungen für »Mittelschulklassen «, »Studenten«, »Angestellte«, »Arbeiter«, »Kolchosbauern « und »Ausländer« an. ${ }^{52}$ Diese Kategorisierung zeigt das Bemühen der muzejščiki, ihre Führungen auf den sozialen Hintergrund und das Alter ihres Publikums auszurichten. Die Liste sagt bedauernswerterweise nichts über die Geschlechterverteilung aus. Die Schülerinnen, Studentinnen und Arbeiterinnen, die ebenso wie die Rotarmistinnen von ihren Vorgesetzten ins Museum geschickt wurden, gehen in den Gruppenbezeichnungen unter. Nur eine Gruppe von Frauen fand explizit Erwähnung in den Unterlagen der Exkursionsabteilung. Für die »Frauen der Kommandeure « wurden separate Führungen konzipiert. ${ }^{53}$ Aus eher pragmatischen als inhaltlichen Gründen wurden diese Führungen gleichzeitig auch für Seniorengruppen benutzt. ${ }^{54}$

Susan E. Crane hat das Museum als Ort beschrieben, an dem nicht nur Wissen, sondern auch ein »sozialer Verhaltenskodex« weitergegeben wurde: »We learn how to behave in museums, what to expect from them [...] and how to remember them. «55 Während Museen auf der ganzen Welt den Nimbus wissenschaftlicher

48 CMVS, nicht archivierte Bestände: Ėkskursanty o central'nom muzee RKKA, 24.02.1935, I. 1-10, hier I. 1-3.

49 CMVS, nicht archivierte Bestände: Mappe: Svody na poseščaemost' CMKA za 1942-1943g., I. 3.

50 Ebd.

51 CMVS, nicht archivierte Bestände: Mappe: Učet, poseščaemosti po Muzejam 1942-1943g., I. 16.

52 Ebd.

53 Ebd.

54 Ebd.

55 Crane, Susan A.: Memory, Distortion, and History in the Museum, in: History and Theory, Vol. 36, Nr. 4, 1997, S. 44-63, hier S. 46. 
Autorität genießen, ist anzunehmen, das die sowjetischen Museen in der disziplinierten Öffentlichkeit des Stalinismus einen nochmals höheren Status als Hüter der Wahrheit besaßen und mit Respekt und Ehrfurcht besichtigt wurden. Die Exkursion, der geführte Museumsrundgang, verstärkte diese Wahrnehmung noch und war ein selbstverständlicher Teil des von beiden Seiten gelernten und erwarteten Museumsbesuchs, der einen immer gleichen Ablauf hatte. Diese soziale und emotionale Dimension des Museumsbesuchs, die das kognitive Erlernen von Fakten rahmt, spielt für die historische Rekonstruktion der frühen Kriegserinnerung eine wichtige Rolle. Aus der Gedächtnisforschung ist bekannt, dass jene Gefühle, die ein Erlebnis begleiten, die Erinnerung an dasselbe formen. ${ }^{56}$

Abbildung 31: Marija Nazarova bei der Führung einer Mädchenschulklasse im Zentralmuseum der Roten Armee, Moskau Dezember 1946, Fotografin/Fotograf unbekannt (c) CMVS.

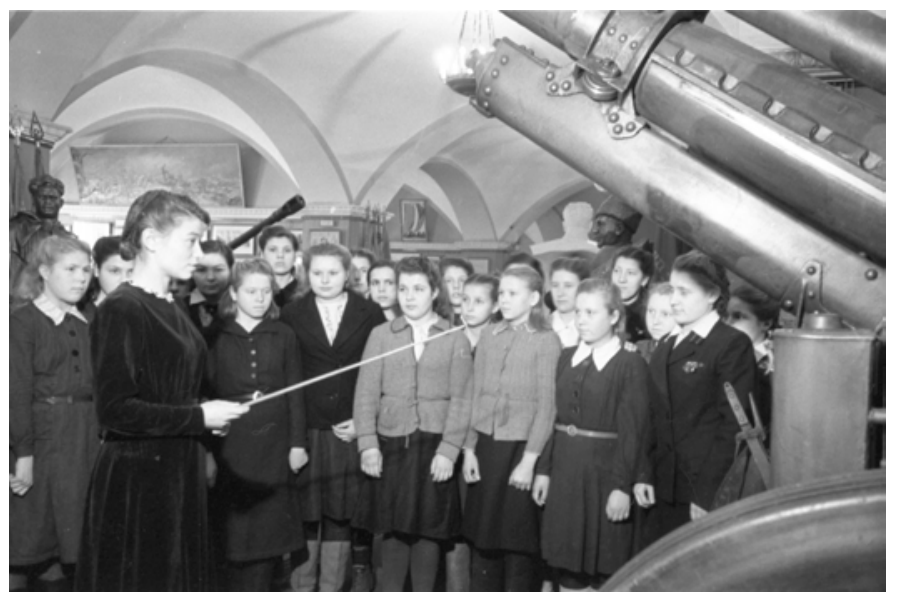

Die Aufnahme zeigt Marija Nazarova bei der Führung einer Schulklasse durch die Ausstellungssäle des Armeemuseums im Dezember 1946 (Abb. 31). ${ }^{57}$ Mit einem langen Zeigestock erklärt die junge Frau den rund zwanzig Mädchen, die sich in einem Halbkreis um sie versammelt haben, die ausgestellten Exponate. Mit ernsten Gesichtern, den Blick auf die Ausstellungsführerin gerichtet, scheinen die Schülerinnen der Erzählung Marija Nazarovas zu folgen. Möglicherweise erzählte sie, wie

Susan A. Crane führt diese Überlegung wie folgt aus: »Personal feelings and memories [...] are always a factor in the contexts in which historical consciousness is made, because they shape how an experience is remembered. "Vgl. Crane, Susan A.: Memory, Distortion, and History in the Museum, S. 48. 
sie die Objekte während des Krieges gesammelt hatte, vielleicht berichtete sie auch von den Heldentaten, die sie an der Front von den Kameraden der gefallenen Soldaten gehört hatte. Als Sammlerin und Dokumentaristin vermochte Marija Nazarova die Ausstellungsobjekte auf eine ganz besonders wirkmächtige Art zum Sprechen zu bringen. Ihre Erzählungen vom Krieg gaben den Kriegsrelikten eine Geschichte, und die visuellen und materiellen Aussagen der Objekte in der Vitrine bestätigten wiederum ihre Berichte. In den Säulengängen des Armeemuseums konnten die jungen Schülerinnen, die den Krieg als Kinder erlebt hatten und von den Erzählungen ihrer Eltern und Verwandten geprägt waren, die Ernsthaftigkeit spüren, mit der Marija Nazarova von der Bedeutung der Objekte sprach. Beim Verlassen des Museums hatten die Schülerinnen nicht nur erfahren, wie groß die Zerstörungskraft eines T-34 Panzers aus »Tankograd« war oder aus welchen Einzelteilen die improvisierten Waffen der Partisaninnen und Partisanen bestanden. Sie hatten ebenfalls gelernt, wie sie diese Objekte betrachten und sich zu ihnen verhalten sollten, vielleicht auch, was sie im Anschluss an die Exkursion ins Gästebuch schreiben sollten. Kurz, sie lernten, wie sie das Gehörte, Gesehene und Empfundene erinnern sollten. Die muzejščiki hatten ihnen damit idealerweise die Verhaltensnormen in Bezug auf den von ihnen gewünschten Umgang mit den Ereignissen des »Großen Vaterländischen Kriegs« vermittelt.

Damit leisteten die muzejščiki einen Beitrag zur geistigen Mobilisierung der Bevölkerung. Während des Krieges bestand im Moskauer Armeemuseum der Anspruch, jede Soldateneinheit vor ihrem Einsatz an der Front durch die Ausstellung »Die Zerschlagung der deutschen Truppen vor Moskau« zu führen. Die Vermittlungsarbeit in den Kriegsmuseen stellt damit einen Beitrag zur stalinistischen Mobilisierung der Gesellschaft im Krieg dar. Dabei scheint insbesondere die Eigenschaft des Museums als Lern- und Erfahrungsort von Bedeutung gewesen $\mathrm{zu}$ sein. In der Anfangsphase des Krieges, in der Aussagen über Ursachen und Verlauf der Ereignisse rar waren, lieferten die Ausstellungsobjekte haptische und visuelle Eindrücke, die die èkskurzovody mit sachlichen und emotionalen Erklärungen $\mathrm{zu}$ den gegenwärtigen Ereignissen sowie siegesgewissen Prognosen zum Ausgang des Krieges kontextualisierten. Als Kultureinrichtung der GlavPURKKA musste das Museum der Roten Armee diese Erwartungen in einem besonders hohen Maße erfüllen.

Die GlavPURKKA war verantwortlich für die Moral, Motivation und die politische Erziehung der Roten Armee. ${ }^{58}$ Ihre Heldenpropaganda formte ein Selbstbild, das sich die Rotarmistinnen und Rotarmisten aneignen sollten. Teil dieser Ideologie war der Aufbau des Feindbildes. Die Behörde politisierte den Krieg, indem sie beispielsweise die Art und Weise beeinflusste, wie man über die Deutschen sprach. Die Erziehung durch die Politoffiziere und die hauseigene Zeitung »Roter Stern« 
wirkten erfolgreich auf das Vokabular ein, was dazu führte, dass aus der individualisierten Bezeichnung wie »Hans« der unspezifische »Deutsche« wurde, der später nur noch »Faschist «, »Besatzer«, »Eindringling « und »Plünderer « genannt wurde. ${ }^{59}$

Jedoch sollte kein automatischer Rückschluss auf eine tatsächliche bzw. generelle Veränderung des Feindbildes in der allgemeinen Wahrnehmung gezogen werden. Die russische Historikerin Elena Senjavskaja weist zu Recht auf die individuelle Prädisposition bei der Aufnahme und Internalisierung von Ideologie hin. Einerseits bestimmten die soziale Herkunft, das Bildungsniveau, kulturelle Spezifika, ethnische und religiöse Hintergründe des einzelnen Rotarmisten, der einzelnen Rotarmistin seine oder ihre Empfänglichkeit für die Feindpropaganda. Gleichzeitig war die "persönliche Kriegsbiografie« von Bedeutung: Hatte er oder sie bereits Familienangehörige verloren, befand sich eine nahestehende Person im von Deutschen besetzten Gebiet, war die Person bereits in deutscher Gefangenschaft gewesen oder hatte er oder sie eine andere Art der persönlichen Begegnung mit dem Feind erlebt? ${ }^{60}$

Einfluss auf die Rezeption der Propaganda der GlavPURKKA hatte die Ausbildung und die Ausstattung der Politoffiziere. Der Beschwerdebrief eines Stabsunteroffiziers an die "Pravda« gibt Einblick in die mangelhafte geistige Mobilisierungsarbeit an der Front im ersten Kriegshalbjahr:

»With respect to propaganda the commissar gives us nothing, nothing is explained about the tactics of the enemy, nothing whatever is understood about the spirit of the soldier. Is it possible there will be no victory? The soldiers are not able to understand anything about this war. One talked about surrendering, others about fleeing from the front, nothing good is expected. It's the same with most of the officers. If this is the sense of the commanders, then what are the soldiers to do without leadership? ${ }^{61}$

Die Politoffiziere an der Front waren angesichts der Niederlagen in den ersten Kriegsmonaten teilweise so demoralisierter als die Armeeangehörigen, die von ihnen motiviert werden sollten. An der Front wurden die Politoffiziere und Reporter nach Informationen und Prognosen über den allgemeinen Kriegsverlauf und die Situation in Moskau bedrängt und oft wussten sie nicht, was oder wie sie auf die kritischen Fragen reagieren sollten. ${ }^{62}$ Sie schienen in Anbetracht ihrer unzureichenden Ausbildung - häufig wurden Soldaten, Parteimitglieder oder Komsomolzen kurzerhand zu Politoffizieren befördert - und des fehlenden Materials zu

59 Reese, Roger: Why Stalin's Soldiers Fought, S. 192.

60 Senjavskaja, Elena: Deutschland und die Deutschen, S. 249.

61 Zitiert nach: Reese, Roger: Why Stalin's Soldiers Fought, S. 194.

62 Ebd. 
improvisieren: »Any time I had a free minute, « erinnert sich ein Komsorg (Organisator im Komsomol) »I visited our batteries, talked about the situation at the front, about the actions of our allies. « ${ }^{63}$

Das belegte Bedürfnis nach Informationen kann für eine grundsätzliche Empfänglichkeit für die Ideologie der GlavPURKKA sprechen. Die individuelle Rezeption ist jedoch schwer zu ermessen. ${ }^{64}$ Hier bietet die Vermittlungsarbeit der Museen neue Einblicke. Die Politoffiziere an der Front erhielten Unterstützung von den ékskurzovody, die mit Wanderausstellungen zu den Armeeeinheiten an die Front fuhren, um in den Feldspitälern und Stützpunkten Vorträge zu halten. Der Tagebucheintrag einer Ausstellungsführerin des Moskauer Literaturmuseums von ihrer ersten Reise an die Front Ende Dezember 1941 zeigt die Mitwirkung der muzejščiki als gestaltende Akteure des Kriegsdiskurses:

»Den ersten Vortrag, über Gorki, hielt ich nach dem Mittagessen in der Mensa. Erschöpfte Gesichter. Müde Augen. Ein Vortrag im trockenen-akademischen Stil [v suchovato-akademičeskom stile] ist hier unbrauchbar, man braucht etwas, das hell, anschaulich und ansteckend ist [čto-to jarkoe, obraznoe, zaražajuščee]. Die heldenhaften Visionen Corkis helfen [...]. Da hellen sich die müden Gesichter der Soldaten auf, die Augen beginnen zu glänzen. Das Ziel des Vortrages - den Kampfgeist der Soldaten, ihren Willen zum Sieg und ihren Hass auf den Feind zu stärken - ist erreicht. [...] Als der Vortrag fertig war, bat mich eine Schwester aus dem Zelt mit den Schwerverletzten, zu ihnen zu kommen. [...] Man möchte die Schwerverletzten von ihrem Leid ablenken. Man nimmt ein Thema aus der fernen Vergangenheit-die Vorbilder der heldenhaften Bogatyr. Zu diesem Thema gibt es auch eine Wanderausstellung, hell und farbig. [Hier fügt die Lektorin zwei Strophen eines Heldenliedes der Bogatyr ein, A.H.].

Im Nachbarzelt hat man scheinbar auch zugehört, von dort kommen Stimmen. >Cenossin Lektorin, kommen sie zu uns ...< Ich gehe hin ... Ein Soldat, noch sehr jung, verwundet am Bauch, aus der lettischen Division, wie es sich später herausstellte, er sagte: `Cenossin Lektorin, erzählen Sie uns von Moskau. Wie ist es? Wir waren noch nie in Moskau ... Den Verteidigern von Moskau so von Moskau zu erzählen, dass die Hauptstadt des Sowjetlandes nicht nur das Recht hat, geliebt zu werden und die Hingabe des ganzen sowjetischen Volkes verdient, sondern auch

63 Šutz, Cennadij: Interview, in: Iremember.ru, zitiert nach: Reese, Roger R.: Why Stalin's Soldiers Fought, S. 195.

64 Ebd. S. 191. Hier bezieht sich Reese auf Elena Senjavskaja, die folgenden Einfluss der heroischen Propaganda auf das »kollektive Bewusstsein «feststellte: »In this sense, unquestionably, the symbols did do their job: they had a strong emotional impact on large masses of people [...]. Vgl. Seniavskaja, Elena: Heroic Symbols, The Reality and Mythology of War, in: Russian Studies in History, Nr. 37, 1998/1, S. 61-87. 
das eigene Leben seiner besten Söhne, ist keine leichte Aufgabe. Die Wanderausstellung > Das heldenhafte Moskau, damals und heute hilft. Ihre Grundlage ist die Zerschlagung der faschistischen Eroberer vor Moskau 1941[...]. Wenn die Zeit und die Umstände es erlaubten, unterhielten wir uns mit den Soldaten. Wir sprechen [...] über ihre Familien, sie zeigen Familienfotos. Die sibirischen Soldaten erzählen über Sibirien, überzeugt davon, dass alles bei ihnen am sallerbesten < ist, die ukrainischen erinnern sich an die Ukraine, ihre Kirschgärten.

Man muss in der Arbeit des Lektoren an der Front eine Besonderheit berücksichtigen. Seine Rolle, die Arbeit und der Austausch mit den Zuhörern, erschöpft sich nicht im Vortrag einer Lektion. Der Lektor an der Front ist ein Vertreter der Heimatfront, der Sprecher [vyrazitel'] der dortigen Stimmung, die Verbindung zur Armee und zu den Ereignissen im Ganzen. Der Lektor nimmt am militärischen Leben der Front nicht nur durch seine Vorträge teil, sondern auch mit seinen ganzen menschlichen Fähigkeiten [vsemi svoimi čelovedčeskimi kačestvami]. Frauen in der Rolle des Lektoren - das ist immer eine Erinnerung an die Familie, an das Zuhause. Der Lektor [...] macht die Politarbeiter mit seinen Vorlesungsmaterialien vertraut, er führt Gespräche mit den Soldaten und den Kommandierenden in der Mensa, im Klub, im Kommandostab, am Sanitätspunkt - er liest gemeinsam mit ihnen die Zeitungen, er liest die Gedichte unserer Dichter, er singt mit ihnen ihre Lieblingslieder, hört ihren Erzählungen über die militärischen Ereignisse zu, schaut Filme, nimmt auch an den improvisierten Tänzen teil, liest die Briefe, die die Soldaten von ihren Verwandten erhalten und erzählt davon, wie im Hinterland gelebt und gearbeitet wird. Das alles verlangt von einem Front-Lektor große physische und moralische Standhaftigkeit [fizičeskoj i moral'noj stojkosti], die Anspannung aller Kräfte, das Vermögen, sich in egal welcher Situation zu orientieren, unter allen Bedingungen geeignet und von Nutzen zu sein [byt' poleznym i nužnym]. « ${ }^{65}$

In dem Tagebucheintrag von K. Vinogradova zeigt sich die bemerkenswerte Empathie der Moskauer Museumsführerin. Als sie im Feldspital auf die Verletzten traf, realisierte sie sofort, dass sie ihren Vortragsstil anpassen musste und anstelle des theoretischen Duktus ihrer Vorkriegsführungen lebendiger und »anschaulicher« sprechen musste. Sie sah ihre Aufgabe in der geistigen Konditionierung und, so stellt sie es zumindest in ihrem Tagebuch dar, hatte dabei Erfolg. Die Museumsmaterialien halfen bei der Wiedergewinnung von Zuversicht. Bei den tödlich verletzten Soldaten hingegen griff Vinogradova auf mittelalterliche russische Sagen zurück, so als wolle sie den Sterbenden suggerieren, dass auch sie nach ihrem Tod in heroischer Erinnerung bleiben würden. Beim Anblick eines schwerletzten jungen Mannes aus einer lettischen Division kam die Lektorin an ihre Grenzen. Ohne

65 Vinogradova, K.: Muzej-frontu, Iz dnevnika lektora, 1942, in: Sovetskaja Rossija (Hg.): Muzejnoe delo v SSSR, Moskva 1976, S. 171-176. 
die Besetzung des Baltikums in Folge des Hitler-Stalin Paktes explizit zu nennen, beschreibt sie ihre Schwierigkeiten, die stalinistische Ideologie des Opfertodes dieser jungen Männer aus Lettland für die Verteidigung von Moskau zu erklären. ${ }^{66}$ Vinogradova schien erkannt zu haben, wie wichtig »normale« Gespräche waren. Voller Sympathie berichtet sie in ihrem Tagebuch von dem Heimweh der Frontsoldatinnen und Frontsoldaten. In der Beschreibung des Selbstbildes der »FrontLektorin« wird deutlich, dass sie sich idealerweise nicht als distanzierte Didaktikerin, sondern im Gegenteil als Teilnehmerin des soldatischen Frontlebens sah, die die Menschen abseits des direkten Kampfgeschehens begleitete. Interessanterweise betonte Vinogradova den Gender-Aspekt, der im Falle einer weiblichen Lektorin eine noch stärkere Sensibilität verlange, da sie Projektionsfläche für Familie und häusliches Leben sei.

Neben der großen Zahl von Armeeangehörigen waren die Schulklassen die zweitgrößte Besuchergruppe in den sowjetischen Museen der Kriegs- und Nachkriegszeit. Die sowjetische Schulbildung litt massiv unter den Kriegsfolgen, und es ist $\mathrm{zu}$ vermuten, dass die Museen den Unterrichtsausfall bzw. die Wissensvermittlung in Sachen militärpatriotischer Erziehung ein Stück weit kompensierten. Die Einberufung in die Rote Armee führte zu einer Halbierung des Lehrpersonals, und zahlreiche Schulen mussten schließen. Die Schulen in den westlichen Gebieten der Sowjetunion, die nicht in der überstürzten Evakuation ins Hinterland gebracht werden konnten, wurden von der schnell vorrückenden Wehrmacht zerstört. Im Hinterland konnten die örtlichen Schulen selten die zusätzliche Betreuung der zahlreichen geflüchteten Schulkinder gewährleisten. Zudem wurden ihre Gebäude häufig für militärische Zwecke beschlagnahmt und es fehlte an dem nötigen Lehrmaterial. ${ }^{67}$ Manche Lehrerinnen und Lehrer gaben ihre Stelle freiwillig auf, um mit ihren Familien zu flüchten oder eine andere Arbeit anzunehmen, die ihnen mehr

66 Vinogradovas Schwierigkeiten waren vermutlich nicht nur moralischer Natur, sondern vielmehr eine auch didaktische Herausforderung: Beim Einfordern des Opfertodes der Menschen aus den Republiken für die Verteidigung von Moskau ging es explizit um eine »imperiale Mission«, die über die gängige und länderübergreifende Kriegsrhetorik »Ehrenhaft ist es, für das Vaterland zu sterben « hinausging.

67 Insbesondere im ersten Kriegsjahr, als die Angst und die Panik vor einer Niederlage am größten waren, diffamierte die Presse dieses Verhalten als»Fall von Demoralisierung«. Die Lehrer und Lehrerinnen, die der Meinung waren, dass »jetzt nicht die Zeit zum Unterrichten « (sejčas ne po učeby) sei, wurden der »politischen Kurzsichtigkeit« beschuldigt und aufgefordert, ihren Beruf auszuüben. Vgl. Dunstan, John: Soviet Schooling in the Second World War, New York 1997. Zu Evakuation und Lehrermangel vgl.: S. 80-98. Die Statistik lässt die sechs besetzten sowjetischen Republiken (Moldawien, Ukraine, Belarus, Litauen, Estland, Lettland) unberücksichtigt. 
Einkommen bzw. Essensrationen sicherte. ${ }^{68}$ Sechs Monate nach Kriegsausbruch, zum Jahreswechsel 1941/1942, besuchten nur noch 51 Prozent der Schulklassen des Vorjahres die Primar- und Sekundarschulen. ${ }^{69}$

Die muzejščiki konnten an die obligatorische politisch-ideologische Bildung und die militärpatriotische Erziehung der sowjetischen Curricula anknüpfen. ${ }^{70}$ Die Aussage einer Lehrerin am Ende des Schuljahres 1937/38 weist auf die patriotische Grundeinstellung hin, die vor dem Krieg im Geschichtsunterricht herrschte:

»Perhaps my children do not know all their historical facts perfectly, but there is one thing I can say for sure: they understand who they are supposed to hate and who they are supposed to love. They hate those who have oppressed our people in the past and those who have interfered with [our] heroic struggle. They love our people and their friends and leaders, Lenin and Stalin. « ${ }^{71}$

Die Einführung der allgemeinen Wehrpflicht am 1. September 1939 führte zu einer Intensivierung der militärpatriotischen Erziehung in den Schulen. Das sogenannte "Militärische Training« (voennaja podgotovka) wurde in Kombination mit dem Sportunterricht als reguläres Schulfach eingeführt und seine Stundenzahl nach dem Überfall der Wehrmacht auf die Sowjetunion ständig erhöht. ${ }^{72}$ Während die Schüler exerzierten und marschierten sowie im Nahkampf trainiert wurden, erhielten die Schülerinnen eine sanitäre Grundausbildung, und die Kinder der Unterstufe lernten, Handgranatenattrappen zu werfen. ${ }^{73}$ Dieser Bildungsplan konnte in der Praxis jedoch häufig nicht durchgeführt werden, da es den Schulen an Übungsmaterial fehlte: Gerade in den Schulen auf dem Land waren keine Attrappen vorhanden, und die Schüler mussten den Umgang mit dem Gewehr und den Nahkampf anhand von Vorträgen erlernen, ohne jemals einen Granatenwerfer oder

68 Zitiert nach: Dunstan, John: Soviet Schooling, S. 96.

69 Beim Jahreswechsel 1942/43 hatte sich die Situation nur minimal verbessert (40 Prozent des Vorkriegstotals). Auch die Oberstufe wurde im ersten Kriegsjahr nur noch von 40 Prozent der Schülerinnen und Schüler besucht. Erst ab dem Jahreswechsel 1934/44 stiegen die Zahlen wieder. Die Statistik lässt erneut die sechs besetzten sowjetischen Republiken unberücksichtigt. Vgl. Dunstan, John: Soviet Schooling, S. 98.

70 Kelly, Catriona: Children's World, Crowing up in Russia 1890-1991, Yale 2007, S. 540-541.

71 Dzjubinskij, S.: Vospitatel'naja rabota na urokach istorii SSSR, in: Belousov, S. (Hg.): Vospitatel'naja rabota v načal'noj škole, Moskva 1939, S. 109-110. Zitiert nach: Brandenberger, David: National Bolshevism, Stalinist Mass Culture and the Formation of Modern Russian National Identity, 1931-1956, Cambridge 2002, S. 76.

72 Der Lehrplan für das Schuljahr 1940/41 beinhaltete zwölf Stunden »Militärische Vorbereitung « pro Woche für die Klassen I-X. Während die Anzahl an Stunden pro Woche gleichblieb, hatte sich drei Jahre später die Anzahl dieser Unterrichtseinheiten auf Kosten von anderen Fächern (Ceschichte, Naturwissenschaften, Literatur) mehr als verdoppelt (28 Stunden/Woche). Vgl. Dunstan, John: Soviet Schooling in the Second World War, New York 1997, S. 118-119. Ebd. S. 119. 
ein Maschinengewehr gesehen zu haben. ${ }^{74}$ Ein grundlegendes Problem war neben dem Mangel an Unterrichtsmaterial die chronische Unterbesetzung der Lehrpersonen für dieses Schulfach, die durch die Vorgabe nach Erhöhung des militärpatriotischen Unterrichts zusätzlich verschärft wurde. Der Unterricht sollte von militärisch ausgebildeten Führungspersonen, den voenruki, durchgeführt werden, die jedoch im fortschreitenden Krieg immer weniger für den Unterricht verfügbar waren. ${ }^{75}$ Vor diesem Hintergrund litt die Qualität des Unterrichts, und die »Pravda« warf im Mai 1942 den Lehrerinnen und Lehrern, »die mit der Kreide in der Hand versuchten, den Krieg zu erklären«, »Formalismus « vor. ${ }^{76}$ Die schlechte Ausbildung der mehrheitlich weiblichen voenruki und die Attribuierung des Fachs als erweiterter Sportunterricht, der neben den hochakademisierten Fächern des sowjetischen Curriculums per se einen schlechten Stand hatte, führte zu Disziplinarproblemen, die sich in fehlender Autorität bzw. fehlendem Respekt der Schulkinder gegenüber ihren Lehrerinnen und Lehrern ausdrückten.

Der militärpatriotische Grundton färbte den ganzen Schultag. Laut dem Lehrplan von 1943 hatten Aufgaben mit Bezug zur Lebenswelt der Kinder, in denen sich die kognitive und die emotionale Wahrnehmungsebene überschnitten, den größten Lerneffekt. Dementsprechend wurden im Biologie-, Chemie- und Physikunterricht Erste Hilfe bei Giftgaseinsätzen erklärt, die Spannung von Telefonleitungen berechnet und im Mathematikunterricht wurden abgeschossene deutsche Flugzeuge bei einem Bombenangriff über Moskau addiert. Im Russischunterricht verfassten sie Essays zum Thema »Sie nahm einen Faschisten gefangen«, und von den Fremdsprachen Französisch, Deutsch und Englisch, die die Kinder ab der fünften Klasse lernten, erhielt Deutsch höchste Priorität. Der Wortschatz wurde angepasst und die Kinder lernten Sätze wie »Die Waffen nieder! Hände hoch! «. ${ }^{77}$

Vor diesem Hintergrund erhielten die regelmäßigen Besuche der Moskauer Schulklassen im Armeemuseum eine noch größere Bedeutung, da hier die Militärtechnik in didaktisch aufbereiteten Führungen präsentiert wurde. ${ }^{78}$ Gerade in Anbetracht der Tatsache, dass die Schulklassen häufig nur eine vage Vorstellung vom Kriegsgeschehen hatten, konnten der Besuch im Armeemuseum und die Betrachtung des eigenen und des feindlichen Kriegsgerätes zu einem prägenden Erlebnis werden. In den Objekten der Ausstellung manifestierten sich die Beschreibungen

74 Ebd. S. 121.

75 Das Kommissariat für Verteidigung, das für die Einstellung der voenruki zuständig war, versuchte den Mangel mit pensionierten Offizieren und kampfunfähigen Veteranen zu kompensieren. Vgl. Dunstan, John: Soviet Schooling, S. 122.

Bis zu einem Drittel der voenruki verfügten nur über eine Primarschulausbildung, und bis zu 50 Prozent von ihnen hatten noch nie im Militär gedient. Vgl. Dunstan, John: Soviet Schooling, S. 122-124.

77 Ebd. S. 127-131.

78 Ebd. S. 120. 
der Erwachsenen und es wurde ein heroisches Deutungsangebot für den Verlust von geliebten Menschen präsentiert.

Während der Ausstellungsbesuch für das Armeepersonal einen motivierenden Effekt haben konnte, war das Museum für die Kinder ein Ort des Lernens und Begreifens, der ihnen in der traumatischen Kriegs- und Nachkriegszeit Orientierung gab. Das Museum war eine »kulturelle Institution«, in der, wie Susan A. Crane schreibt, individuelle Erwartungen mit akademischen Intentionen interagierten. ${ }^{79}$ Dieses Aufeinandertreffen stellte die muzejščiki vor die Herausforderung, diese häufig ambivalenten, individuellen und nicht kongruenten Erfahrungen ihrer Besucherinnen und Besucher einerseits zu berücksichtigen und sie gleichzeitig zu einer vereinigenden take-home-message des Lernortes zusammenzuflechten. ${ }^{80} \mathrm{Bei}$ diesem Prozess spielte das Museumsgästebuch als Medium der Kommunikation zwischen Besucherinnen und Besucher und muzejščiki eine zentrale Rolle.

79 Crane, Susan A.: Memory, Distortion, and History in the Museum, S. 46.

80 Aleida Assmann beschrieb diesen Prozess als »Entkopplung der inkarnierten Erlebniserinnerung und Verkopplung mit dem exkarnierten Mediengedächtnis«. Dieser Vorgang sei laut der Erinnerungsforscherin die zentrale Voraussetzung, damit aus einem individuellem Erfahrungsgedächtnis ein kulturelles Gedächtnis werden kann. Vgl. Assmann, Aleida: Der lange Schatten der Vergangenheit, Erinnerungskultur und Ceschichtspolitik, München 2006, S. 210. 


\section{Das Gästebuch als Medium der Kommunikation}

Die ersten Gästebücher wurden Anfang der 1920er Jahre in den postrevolutionären Museen der Sowjetunion als Mittel der Besucherforschung von den westeuropäischen Museen übernommen. ${ }^{81}$ Jan Plamper, der in seiner Studie zum Stalin-Kult die Frage der öffentlichen Rezeption und Partizipation an der medialen Verehrung Stalins diskutiert, beschreibt das Gästebuch als zentrales Element des sowjetischen Museumsbesuchs. Dieses habe, trotz einer zeitlichen Unterbrechung im Stalinismus, seine große Bedeutung bis heute nicht verloren. In den 1930er Jahren sei das wirkungsvolle Mittel der Besucherforschung jedoch zur »bloßen Kosmetik« verkommen und sein partizipatorischer Charakter sei zur Fassade verkümmert. Erst unter Chruschtschow hätten die Museen das Gästebuch als Zeichen eines demokratischen Wandels reaktiviert. ${ }^{82}$ Ein offensichtliches Zeichen für den Funktionswandel des Gästebuchs im Stalinismus sei der veränderte Einband der Bücher: Die einfachen Notizbücher der 1920er Jahre hätten sich mit der zweiten Generation der sowjetischen Ausstellungen in den frühen 1930er Jahre zu ledergebundenen, rein repräsentativen Büchern mit geprägten Goldbuchstaben entwickelt. Diese qualitative Beobachtung des äußeren Erscheinungsbildes überträgt Plamper auf den Inhalt der Einträge, die sich unter Stalin zu unkritischen, schablonenhaften Lobpreisungen entwickelt hätten. ${ }^{83}$

Die folgende Gästebuchanalyse widerlegt diese Beobachtungen teilweise und erweitert sie auf mehreren Ebenen: Die Beobachtung einer Korrelation zwischen dem äußeren Erscheinungsbild und der Qualität der Einträge trifft lediglich auf die sogenannten »Ehrengästebücher« zu (Vgl.: Abb. 32). Diese meist in glänzendes dunkelrotes Leder gebundenen Bücher wurden Staatsgästen, ranghohen Politikern oder Militärs sowie weiteren VIPs zum Eintrag vorgelegt. Sie hinterließen in der Regel einen lobenden bzw. formelhaften Kommentar, der für das Museum beson-

\footnotetext{
81 Plamper, Jan: The Stalin Cult, S. 205.

82 Ebd. S. 205.

83 Ebd. S. 213.
} 
Abbildung 32: Ehrengästebuch des Belarussischen Museums zur Geschichte des Großen Vaterländischen Krieges, Minsk 1958 @ BDMGVAV.

Abbildung 33: Gästebuch des Tscheljabinsker regionalwissenschaftlichen Museums, Tscheljabinsk 1946-1949 ( O OGAČO.

Abbildung 34: Gästebuch des Zentralmuseums der Roten Arbeiter und Bauernarmee, Moskau 1936-1939 (c) CMVS.
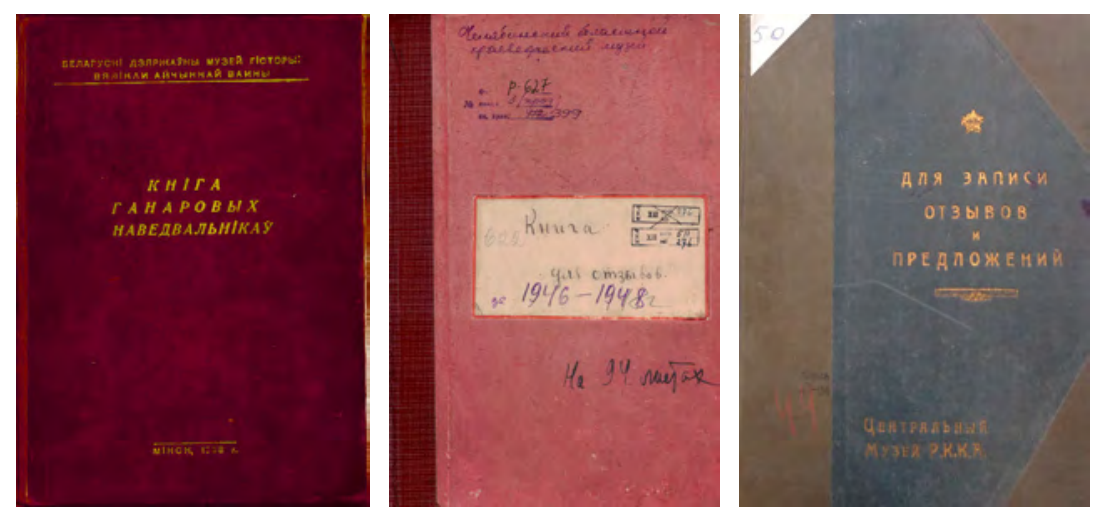

ders wichtig war. ${ }^{84}$ Mit Stolz wurden sie anderen VIP-Gästen vorgelegt, um die Bekanntheit und Beliebtheit des Museums zu demonstrieren. Einträge in nichtrussischer Sprache (Titos vierte Ehefrau Jovanka Broz hinterließ einen serbischen Eintrag im Minsker Museum) wurden ins Russische übersetzt und auf ein separates Blatt geschrieben, das anschließend neben den Eintrag geklebt wurde. Die Einträge in den >normalen` Gästebüchern waren hingegen nicht abhängig vom Erscheinungsbild der Bücher. Auch lässt sich keine zeitlich fixierbare Veränderung des Einbandes feststellen: Seit dem Erscheinen der Ehrengästebücher Anfang der

84 BDMGVAV, Ehrengästebuch (Kniga Ganarovych Navedvalni'kaŭ), September 1958-Juli 1973. Vgl. Eintrag von Josip Broz Tito in fehlerhaftem Russisch: »In Jugoslawien wissen wir viel über den Kampf der belarus[s] Partisanen, aber das, was wir hier im Museum gesehen haben erscheint uns als beeindruckender [impresivnym] Beweis für das große [unleserlich] des weiß$\mathrm{ru}[\mathrm{s}]$ sischen Volkes. Wir [ver] beugen uns vor den Opfern der brutalen faschistischen O[k]kupanten. Dieses Museum erinnert uns, dass es notwendig ist, mit allen Kräften den Frieden zu versichern und den Aufbau des Sozialismus und des Ko[m]munismus zu gewährleisten. 31.06.1965 Josip Broz Tito. « Bei der Übersetzung bzw. der wörtlichen Wiedergabe der Zitate wurde versucht, die grammatikalischen und orthographischen Fehler bzw. die Auffälligkeiten in der Syntax wiederzugeben. Ein großer Dank für ihre Hilfe geht an dieser Stelle an die Linguistin Marina Bulyčeva. 
1930er Jahre bestanden sie parallel zu den handbeschrifteten Notizbüchern (vgl.: Abb. 33 \& 34). ${ }^{85}$

Es scheint, als habe nicht der Einband Einfluss auf den Eintrag gehabt, sondern die Zwanglosigkeit des weißen Blattes, die dem Eintrag keine Form vorschrieb. Im Gegensatz zu den in der Sowjetunion weitverbreiteten Fragebögen, die mitunter auch am Museumseingang auslagen, musste sich der Eintrag keinerlei formalen Vorgaben und gewünschten Angaben beugen. ${ }^{86}$ Die eher ungewohnte Formlosigkeit und Freiheit der weißen, leeren Seiten ließ die Schreiberinnen und Schreibern den Inhalt, die Länge und die Form des Eintrages selbst bestimmen. Sie entschieden, ob und welche Informationen sie mitteilten. Neben kaum leserlichem Gekritzel fanden sich Zeichnungen oder feinsäuberlich geschriebene Einträge, die den Platz einer ganzen Seite einnahmen. Die Unterschriften in den Gästebüchern reichten von einem provokanten »Ich « über den vollständigen Namen samt Herkunftsort und Besuchsdatum bis hin zu persönlichen Adressangaben. ${ }^{87}$ Die Unterschrift konnte den Inhalt des Eintrages unterstützten: Militärs, die die Ausstellung lobten oder kritisierten, gaben beispielsweise ihren Rang an, um ihren Status zu betonen. Die Angabe professioneller Kategorien (Lehrer, Student, Pionier, Arbeiter) anstelle von individuellen Namen weist darauf hin, dass die Zugehörigkeit zu einer sozialer Funktionsgruppe höher gewichtet wurde.

Die Freiheit in der Gestaltung des Gästebucheintrages soll jedoch nicht darüber hinwegtäuschen, dass der Eintrag als solcher eine halböffentliche Praxis und Ritual des Museumsbesuchs war. Während die formalen Besonderheiten des Gästebuchs eine Voraussetzung für die Heterogenität der Einträge darstellten, bestimmte der öffentliche Raum des Museums die mediale Funktion des Buches.

85 BDMGVAV, KP 79359; OCAČO: f. R-627, op. 3, d. 399; CMVS, Nr. 50.

86 CMVS, zwölf ausgefüllte Fragebögen aus dem Jahr 1935, Beilage zum Gästebuch 1935-1936. Auf den Fragebögen mit dem Titel »Helfen Sie mit, die Arbeit des Museums zu verbessern, schreiben Sie ihre Bemerkungen, Wünsche und Vorschläge auf dieses Blatt«, die im Moskauer Armeemuseum auslagen, sollten die Besucherinnen und Besucher folgende drei Fragen beantworten: 1. Was hat Ihnen im Museum am besten gefallen? 2. Schreiben Sie Ihre Eindrücke auf: Was haben Sie gesehen, was haben Sie von dem èkskurzovod gehört? 3. Welche Verbesserungsvorschläge haben Sie? Zuletzt wurden sie aufgefordert, folgende Auskünfte zu geben: Beruf, Wohnort, Parteimitgliedschaft, Alter, Teilnahme am Bürgerkrieg und ob sie das Museum zum ersten Mal besuchten. Zu Fragebögen als Methode der Besucherforschung in Kunstausstellungen siehe: Plamper, Jan: The Stalin Cult, S. $206 \mathrm{ff}$.

87 CMVS, Gästebuch 1936, I. 57-58, Eintrag vom Mai 1936. Ein Besucher beschwerte sich über die schlechte Behandlung, die er durch das Personal des Moskauer Armeemuseums erfahren hatte. In der Hoffnung auf Klärung des Vorfalls hinterließ er seine vollständige Adresse mit Angabe seiner Wohnungsnummer. Bedauerlicherweise kann nicht festgestellt werden, ob bzw. wie das Museumspersonal auf die Beschwerde reagierte. 
Abbildung 35: Eingang in die Ausstellung des Zentralmuseums der Roten Armee, Moskau 1945-1965, Fotografin/Fotograf unbekannt (c) CMVS.

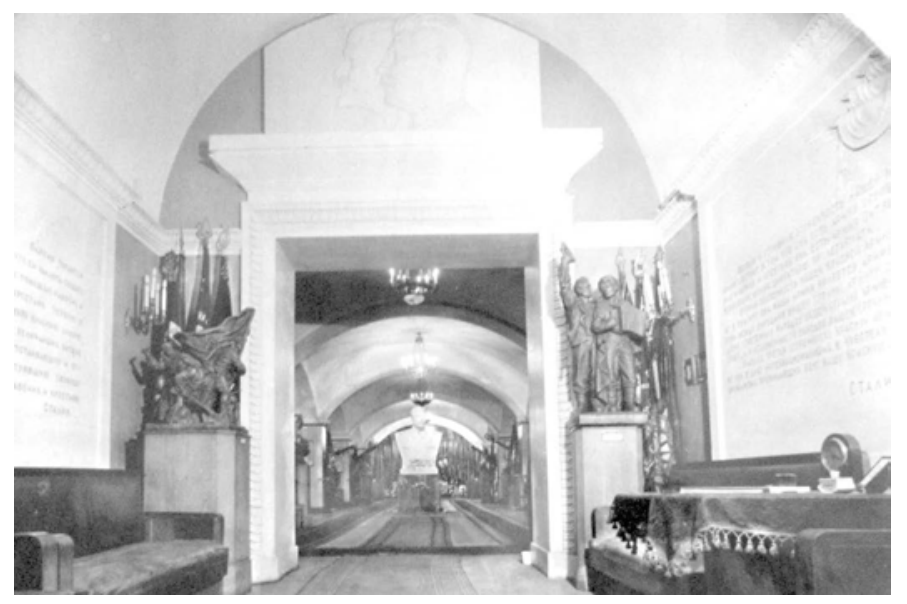

Das Foto (Abb. 35) zeigt den Ein- und Ausgang in die Ausstellung des Moskauer Armeemuseums. ${ }^{88}$ Rechts und links waren Sofas aufgestellt, auf denen die Gruppen auf ihre èkskurzovody warteten. Auf der rechten Seite stand ein Tisch mit einer Tischdecke, auf der neben einer Uhr das Gästebuch lag. Die Besucherinnen und Besucher wurden auf diese Weise an den Eintrag erinnert, den sie nach der Ausstellungsbesichtigung hinterlassen sollten. Auch wenn es keine Verpflichtung für den Eintrag gab, weisen die sich wiederholenden Sätze (wie zum Beispiel »Die Ausstellung hat einen großen Eindruck hinterlassen«; »Vielen Dank für die gute Exkursion«) auf eine etablierte kulturelle Praxis des Gästebuchsschreibens als Teil des Museumsbesuchs hin. Die Gästebücher, die in der Regel Din A4-Format aufwiesen und rund 100 Seiten umfassten, lagen entweder so lange in der Dauerausstellung aus, bis sie vollgeschrieben waren (ein bis zwei Jahre) oder waren für eine spezifische Sonderausstellung gedacht und deckten einen Zeitraum von drei bis sechs Monaten ab. Die abgegriffenen und zerlesenen Seiten weisen darauf hin, dass die Besucherinnen und Besucher vor ihrem eigenen Eintrag die Einträge ihrer Vorgängerinnen und Vorgänger zur Orientierung und als Inspirationsquelle lasen. Im Gästebuch der Tret'jakov-Galerie beschwerte sich ein Besucher im Jahr 1952 über diesen Brauch:

»Not one minute goes by when the visitors' book is lying idle on the table, it is being continually passed from hand to hand. Because of this, it is impossible for 
people to write in it, since it is always occupied by those who simply want to read it. Moreover, not only is it impossible for everyone to write in the book, but if someone succeeds in glancing at it out of curiosity about what others have written, they can consider themselves lucky. $" 89$

Das Lesen der Kommentare animierte, die Einträge der Anderen zu kommentieren. Ausgehend von dieser Beobachtung hat die Historikerin Susan Reid die Forschung mit der Analyse der Gästebücher der Moskauer Kunstausstellung von 1962, die aufgrund von Chruschtschows Wutanfall als »Manege-Affäre« berühmt wurde, angestoßen. ${ }^{90}$ Sie bestimmte eine kommunikative Funktion der Bücher, die sie als »virtual public sphere« beschrieb, vergleichbar mit einem »Internet message board «. ${ }^{91}$ Die Gästebücher seien eine der wenigen überlieferten Quellen, die einen Raum zeigen, den die sowjetische Bevölkerung in »relative independence from the state« nutzte, um sich eine Meinung zu bilden und sich auszutauschen. Ohne externe Einmischung hätten sich die Besucherinnen und Besucher in den Gästebüchern einander mitgeteilt und kollektive Identitäten bzw. ihre Abweichungen und Differenzen davon formuliert. Indem sie die Einträge der anderen kommentierten, überführten sie, laut Reid, die gesellschaftliche Debatte über die revisionistische Kunst des »Tauwetters « in einen geschützten und anonymen Raum und trugen mit ihrer Diskussion zu der Formierung eines Wertesystems im Kontext der Destalinisierung bei. Als Beispiel einer solchen Diskussion zitiert sie folgenden Dialog über den (guten) Geschmack im Gästebuch einer Kunstausstellung: »Remove the Nude by Fal'k from the exhibition. It is not art. " [Der folgende Eintrag war so positioniert, dass er sich auf den ersten Kommentar bezog:] »Don't remove it! Whoever wrote that understands nothing. The exhibition is delightful, incomparable, wonderful! We are for Fal'k. You need to know how to look at his paintings. « ${ }^{92}$

Während die Forscherinnen und Forscher den Gästebüchern im »Tauwetter« diese kommunikative und meinungsbildende Funktion attestieren, verneinen sie dieselbe für die Stalin-Zeit. Die russische Forschung folgt dieser Interpretation und beschreibt die Einträge unter Stalin als »selbstzensierte Formeln und ideologische Klischees ${ }^{93}$ Das gleiche Argumentationsmuster wird bei der Frage nach dem Einfluss der Gästebucheinträge auf die Ausstellungen angewandt: Die Forschung ist

89 Zitiert nach: Johnson, Oliver: Assailing the Monolith, Popular Responses to the 1952 All-Union Art Exhibition, in: Meno istorija i kritika/Art History and Criticism Nr. 3 (special issue »Art and Politics: Case-Studies from Eastern Europe«), 2007, S. 45-52, hier S. 50.

90 Reid, Susan: In the Name of the People.

91 Ebd. S. 680.

92 Zitiert nach: Reid, Susan: In the Name of the People, S. 678.

93 Jankovskaja, G.: Iskusstvo pozdnego stalinizma i ego zriteli, in: Iskusstvo, dengi i politika, Chudožnik v gody pozdnego stalinizma, Perm 2007, p. 215-230, hier S. 221. 
sich einig, dass die Einträge der 1920er Jahre und die der 1950er Jahre die Auswahl und Darstellung des Ausstellungsinhaltes beeinflusst haben, verneint jedoch, dass die Kommentare im Stalinismus diese Wirkung gehabt hätten. ${ }^{94}$ Gleichzeitig wird der unbeobachtete, unzensierte und private Kontext des Gästebuchs unter Chruschtschow betont, der zu einer »candid nature« der Einträge und zu »honest opinions « geführt hätte. ${ }^{95}$

Dieser Widerspruch, der in einer scheinbar unbeobachteten Sphäre im »Tauwetter« bei einer gleichzeitigen Wiederaufnahme der Besucherforschung liegt, wurde bislang nicht adressiert. Auch kann die argumentative Verknüpfung zwischen dem Fokus der Forschung auf Kunstausstellungen in der Zeit der Destalinisierung und der Behauptung des Wegfalls von heterogenen Gästebucheinträgen unter Stalin hinterfragt werden. Die Besuchermeinungen von Kunstausstellungen werden als Ausdruck von persönlichem Geschmack analysiert, die die Forschung als authentische Meinungsäußerungen wertet, während sie den Einträgen in den Museen unter Stalin dieselbe Bedeutung und Relevanz absprechen.

Die Historikerin Francine Hirsch geht in ihrer Analyse der Gästebücher des Ethnographischen Museums in Leningrad aus den 1930er Jahren einen Schritt weiter. Sie betont die doppelte Funktion der Besucherbücher, die erstens dem Museum als »important means of supervision or surveillance« dienten und zweitens ein »important tool of socialist criticism« waren. Dabei führten sie zu einer Selbstermächtigung der Besucherinnen und Besucher: "The ordinary museumgoer thus became more than a student of the Soviet transformative experience; he or she became a participant (consciously or not) in the >revolutionary struggle «. ${ }^{96}$

Hier setzt die Gästebuchanalyse an und argumentiert, dass unter Stalin weder die Heterogenität der Einträge abnahm noch die Gästebücher ihre Funktion als Mittel der Besucherforschung verloren. Die Analyse der Einträge provoziert die Frage nach der Interpretation der individuellen Meinungsäußerungen. In der Diskussion um sowjetische Ego-Dokumente (zum Beispiel Tagebücher oder öffentliche Briefe) gehen die Meinungen über das Verständnis des sowjetischen Selbst und seiner Beziehung zum öffentlichen Diskurs bzw. zu der staatlichen Ideologie stark auseinander. ${ }^{97}$ Die Interpretation von Gästebucheinträgen lehnt binäre Strukturen

94 Plamper, Jan: The Stalin Cult, S. 205, sowie Johnson, Oliver: Assailing the Monolith, S. 50.

95 Johnson, Oliver: Assailing the Monolith, S. 45-52.

96 Die Kontroll- und Überwachungsfunktion beschreibt F. Hirsch anhand der von der Partei für den Zweck der Überprüfung von Gästebüchern gegründeten Behörden. Diese kontrollierten, ob die Menschen die offiziellen Narrative von der sozialistischen Transformation beherrschten. Ab 1931 benutzten diese Behörden die Gästebücher, um bei Sitzungen aus ihnen vorzulesen und beispielsweise Kritik an den Ethnographen zu üben. Vgl. Hirsch, Francine: Empire of Nations, S. 211.

97 Zur Konzeptualisierung der Gästebucheinträge als sowjetischer autobiografischer Praktik vgl. Pinsky, Anatoly: The Diaristic Form and Subjectivity under Khrushchev, in: Slavic Review, 
und totalitäre Terminologien, die den Aussagen widerständiger Dissidenten eine unterdrückte und deswegen lobende Haltung gegenüberstellen, ab. Gleichzeitig betont Susan Reid: »It would be naive to see comment books as unmediated traces of >what the viewer really thought $\iota .{ }^{98}$ Die Gästebuchforscherin erachtet es als unmöglich und nicht sinnvoll, die Einträge nach ihrem Grad von Authentizität zu messen und zieht folgende methodische Schlussfolgerung: »If we cannot calibrate degrees of sincerity of individual comments premised on an essential sself $<$ anterior to language and culture, what we can do is to distinguish different types of socially situated role performances that are entailed in making a certain kind of entry in the visitors' books «. ${ }^{99}$ Indikationen für diese Rollen, die die Besucherinnen und Besucher einnähmen, ließen sich in den Schreibmustern identifizieren, die mitunter den offiziellen Diskurs übernahmen. ${ }^{100}$ Dabei bleibt jedoch die Frage bestehen, ob die Spaltung des sowjetischen Selbst nicht (unfreiwillig) reproduziert wird, wenn die individuellen Äußerungen als Rollenspiel gelesen werden. ${ }^{101}$ Reid schlägt vor, die Perspektive auf die Motivationen zu richten, die möglicherweise hinter dem Eintrag standen. Dieser Ansatz, der bei der folgenden Analyse der Einträge angewendet wurde, macht es möglich, die Einträge als ein eigenes, von kulturellen Grenzen und Konventionen geformtes Genre zu verorten. Dabei gilt es, die Demarkationslinien dieses Genres, die wesentlich von dem speziellen halböffentlichen Charakter des Gästebucheintrags und den Schreibmotivationen der Verfasserinnen und Verfasser bestimmt waren, zu umreißen.

Das wiederholte Auftauchen von bestimmten Ideen und Motiven in den Einträgen kann als ein Anzeichen von geteilten Meinungen und Werten gelesen werden. Sie stehen als Beleg für eine gemeinsame schriftliche sowjetische Kultur, die von den offiziellen Medien und dem staatlichen Diskurs beeinflusst, aber nicht diktiert war. Die Tatsache, dass das Publikum der Kriegs- und Nachkriegsmuseen im Gegensatz zu Besucherinnen und Besuchern der Kunst- oder Ethnographieausstellungen - häufig Teilnehmende der dargestellten Ereignisse waren, unterstützt diese Annahme. Dieser gemeinsam gelebte Diskurs scheint sich in den Gäs-

Vol. 73, Winter 2014, S. 805-827; Dobson, Miriam: Khrushchev's Cold Summer, Gulag Returnees, Crime and Fate of Reform after Stalin, Cornell 2009.

Reid, Susan: Who will beat whom? Soviet Popular Reception of the American National Exhibition in Moscow 1959, in: Kritika, Explorations in Russian and Eurasian History, Vol. 9, Nr. 4, Fall 2008, S. 855-904, hier S. 873.

99 Ebd. 881.

100 Ebd. S. 881.

101 Alexej Yurchak, auf den sich Reid bezieht, weist auf diese hermeneutische Falle hin: »In the mask/truth model the person is first posited and then is involved in the act of wearing masks or revealing truths. «Yurchak bevorzugt ein performatives Modell, in dem der Mensch durch konstitutives und performatives Sprechen konzipiert wird. Vgl. Yurchak, Alexej: Everything was forever until it was no more, The last Soviet generation, Princeton 2005, S. 22. 
tebüchern zu manifestieren. Die Besucherinnen und Besucher schrieben innerhalb dieser Genreregeln, ohne dass sie ihr »Bolschewistisch-sprechen « als strategisches Spiel verstanden. ${ }^{102}$ Beim Gästebucheintrag schrieben sie sich situativ in eine Rollenmöglichkeit hinein, die ihr Selbst performativ mitgestaltete.

Indem nach den Motivationen für einen Eintrag gefragt wird, eröffnet sich eine neue Interpretation der Gästebücher. Dabei ermöglichen die Einträge einen Eindruck von dem Erleben der Ausstellung und der Interpretation bzw. Aneignung der Darstellung auf einer diskursiven Ebene. An welche Abschnitte oder Objekte erinnerten sich die Menschen nach der Führung und wie formulierten sie ihre Eindrücke in dem Gästebuch? Die Einträge verweisen auf Ausstellungsabschnitte und Objekte, die als kommentierbar und kritikwürdig erachtet wurden. Damit identifizieren sie die Bereiche, auf die man aus Sicht der Besucherinnen und Besucher zu reagieren hatte. Inwieweit korrelierten sie mit dem Inhalt der Exkursion und den Schwerpunktsetzungen der èkskurzovody?

Die Einträge waren Produkte einer etablierten Praxis des Museumsbesuchs. ${ }^{103}$ Der Titel der Gästebücher »Buch für Bewertungen und Vorschläge« (Kniga otzyvov i predloženij) wurde ernstgenommen. Häufig übertitelten die Schreiberinnen und Schreiber ihren Eintrag mit dem Wort »Bewertung ${ }^{104}$ Das Museum, die Ausstellungen, die anderen Besucherinnen und Besucher und das Museumspersonal, alles unterlag ihrer Beurteilung und wurde kommentiert. Vergleichbar mit den Schreibprojekten der 1920er Jahre, als die durch die Revolution emanzipierten Menschen ihre Geschichte des Bürgerkrieges und der Industrialisierung niederschrieben, drückten die divergierenden Stimmen in den Gästebüchern den Wunsch zur Teilnahme an der Gestaltung der eigenen Geschichte aus. ${ }^{105}$ Die revolutionäre Ideologie von 1917 hatte sie ermutigt, sich selber als aktive Teilnehmende im sozialistischen Projekt wahrzunehmen. Diese bewusste Selbstrepräsentation führte zu einem Phänomen, das Jochen Hellbeck als »emancipated self of the

102 Stephen Kotkin prägte den Begriff »speaking Bolshevik« und beschrieb damit die Fähigkeit der sowjetischen Bürgerinnen und Bürger, Sprechweisen des Staates für die Erfüllung persönlicher Ziele zu übernehmen. Vgl. Kotkin, Stephen: Magnetic Mountain, Stalinism as a Civilization, Berkeley 1997.

Für diesen Ansatz, die Ego-Dokumente gleichzeitig als Produkte und als Praxis zu lesen, vgl. Peri, Alexis: The War Within, S. 15.

Am 24. Februar 1941 schrieb ein Besucher über seinen Eintrag den Titel »Bewertung« (Otzyv). Zahlreiche folgende Kommentare griffen dieses Gestaltungsmittel auf und betitelten ihre Einträge auf die gleiche Weise. Vgl. Gästebuch des Armeemuseum 1939-1941, S. 76 (Rückseite) -87 (Rückseite), in: CMVS, NA (ohne Signatur).

105 Clark, Katerina: The »History of the Factories « as a Factory of History, in: Hellbeck, Jochen/Heller, Klaus (Hg.): Autobiographical Practices in Russia, Göttingen 2004, S. 251-254. Zu den »Historikern der Avantgarde« vgl. Hellbeck, Jochen: Die Stalingrad-Protokolle, S. 8697. 
1930s « beschrieb. ${ }^{106}$ Die Besucherinnen und Besucher schienen sich selbst als relevante Teilnehmerinnen und Teilnehmer des Krieges zu sehen und nahmen die Einladung des Gästebuchs gerne an, um Meinungen auszudrücken, die ihre aktive Anteilnahme am Museumsleben und der Darstellung ihrer Gegenwart spiegelten.

Es ist kein Zufall und nicht nur eine Folge fehlender Möglichkeiten, wie Reid suggerierte, dass diese >bewussten Repräsentationen des Selbst‘ im Kontext von historischen Ausstellungen offenbar wurden. Die Geschichtswissenschaften und die Literaturwissenschaften haben auf die starke Tradition des Historismus hingewiesen, der die russischen Schreibpraktiken seit dem 19. Jahrhundert beeinflusste. ${ }^{107}$ In der Sowjetunion wurde die Verknüpfung von persönlichem, politischem und historischem Bewusstsein zur entscheidenden Qualität des »Neuen Menschen « stilisiert. Die kommunistische Partei vermittelte dieses Bewusstsein durch Praktiken des Lesens, Schreibens und den mündlichen sowie schriftlichen Ausdruck des Selbst. ${ }^{108}$ Vor dem Hintergrund dieser Tradition konnten das Publikum das Gästebuch benutzen, um sich mit seiner Geschichte auseinanderzusetzen, indem sie sich in diese einschrieben - eine Praxis, die von der Kulturpolitik des Staates unterstützt wurde. Während des Krieges wuchs das gesellschaftliche Bewusstsein der Zeugenschaft einer historischen Epoche an.

So verlockend die These des Gästebuchs als >freie und unabhängige Kommunikationsplattform « sein mag, so zeigt die Empirie die Grenzen dieses Vergleichs auf. Ja, die Einträge der anderen dienten als Richtschnur für die eigene Wahrnehmung der Ausstellung und als Maßstab und Orientierung für den eigenen Gästebucheintrag. Die Deutung des sowjetischen Gästebuchs als Treffpunkt, an dem nach »alternative values« gesucht wurde und diese untereinander abgeglichen wurden, gilt es jedoch in Teilen zu revidieren. ${ }^{109}$

Die folgenden Einträge aus dem Moskauer Armeemuseums zeigen das (politische) Potential und die Grenzen des Gästebuchs als Medium der Kommunikation. Im Herbst 1956 schickte das Moskauer Armeemuseum seine Sonderausstellung »Sowjetische Künstler, Gemälde und Graphiken« nach Wladiwostok, wo sie sich großer Beliebtheit erfreute. Drei Studentinnen und Studenten der örtlichen Kunsthochschule hinterließen folgende Einträge in das Gästebuch:

»Alles in allem hat die Ausstellung einen guten Eindruck hinterlassen. Besonders für uns Primorcy [Selbstbezeichnung der Menschen, die in der Region Primor'e le-

Hellbeck, Jochen: Speaking Out, Languages of Affirmation and Dissent in Stalinist Russia, in: Kritika, Explorations in Russian and Eurasian History, Volume 1, Nr. 1, 2000, S. 71-96.

107 Paperno, Irina: Stories of the Soviet Experience, Memoirs, Diaries, Dreams, Ithaca 2009, S. 9-10; Thaden, Edward: The Rise of Historicism in Russia, New York 1999; Hellbeck, Jochen/Heller, Klaus: Autobiographical Practices in Russia, S. 279-299.

108 Hellbeck, Jochen: Revolution on my Mind, S. 17-19.

109 Reid, Susan: In the Name of the People, S. 679-680. 
ben, A.H.] ist sie wirklich erhellend. Die Gemälde [hier werden sieben Gemälde genannt, A.H.] haben einen guten Eindruck hinterlassen. Es wäre wünschenswert, eine bessere Ausführung der >Rotgardistin` von Korotkova zu sehen. Es ist grau, langweilig und dumpf; genauso [schlecht A.H.] ist die Kopie von Neprinzevs >Ruhe nach dem Kampf ‘ gemalt, wir hatten von diesem Cemälde mehr erwartet. [...] Studenten des 4ten Kurses, Kunsthochschule Wladiwostok. [Drei unleserliche Unterschriften, A.H,]. ${ }^{110}$

Auf der gleichen Seite befinden sich noch zwei weitere Einträge, die sich auf den ersten Kommentar der Studierenden bezogen. Angehörige eines Wladiwostoker Kombinates schrieben: "Den allerbesten Eindruck hatten wir von dem Gemälde Neprinzevs $>$ Ruhe nach dem Kampf $\prec$. Sehr schade, dass die Studenten der Kunsthochschule einen schlechten Geschmack haben. Kb/V. «111 Unter diesem Eintrag befindet sich ein anonymer Kommentar in anderer Handschrift mit folgendem Wortlaut: "Sehr schade, dass das Kb/V [Kombinat Wladiwostok A.H.] einen sehr sehr schlechten, eigentlich überhaupt keinen Geschmack hat. " ${ }^{112}$ Dieses >Gespräch zwischen den drei Parteien gibt uns auf der inhaltlichen Ebene die Information, dass das Moskauer Armeemuseum keine Originale, sondern Kopien der Gemälde nach Fernost schickte. Das ist wichtig, um die Kritik der Studierenden (grau, langweilig und dumpf) einzuordnen. Sie kritisieren nicht die Werke der Künstler, sondern die der Kopisten. Während der erste Kommentar ausgewogen war und neben der Kritik an der Ausstellung einzelne Bilder explizit lobte, argumentierten die zwei anderen Kommentare auf einer persönlichen, abwertenden und offensiven Ebene. Ihnen ging es nicht mehr um die ausgestellten Bilder, sondern um den (schlechten) Geschmack (dieses Wort hat der oder die Schreibende im Eintrag unterstrichen) der Besucherinnen und Besucher. Diese Beobachtung einer Akzentverschiebung von einer Kritik an der Ausstellung zu einer Kritik an den Besuchermeinungen spiegelt die Kollision zweier kontrastierender Wertesysteme in der Ausstellung. Die Kunststudentinnen und Kunststudenten waren frustriert von der schlechten Qualität der Bilder, während die Generation, die die dargestellte Revolution erlebt hatte, dankbar war, dass sich ihre Erfahrungen überhaupt in den Gemälden niederschlugen. Während die Jungen ihre Enttäuschung über die Bilder mit einer künstlerischen Kritik an den Kopisten verbanden, empfanden die Kombinatsangestellten diese Kritik als einen Angriff auf ihr Wertesystem und reagierten mit einer didaktisch motivierten Entgegnung, die die Studentinnen und Studenten die Einträge jedoch bereits am 27. November 1956), unpaginiert. Eintrag vom 27./28. November 1956 . 
eines Besseren belehren sollte. Scheinbar ließ das Kunstverständnis der Arbeiter keine Unterscheidung zwischen einer formalen und einer inhaltlichen Kritik zu.

Diese kollidierenden Meinungsäußerungen zu Beginn des »Tauwetters« erinnern an Reids Analyse des Gästebuchs als Treffpunkt, an dem Wertesysteme diskutiert und abgeglichen wurden. Jedoch scheint der Vergleich mit einem >Internetblog<verfehlt, da die Verfasserinnen und Verfasser die Entgegnungen in der Regel nicht lasen. Das primäre Ziel des Eintrags war die Äußerung der persönlichen Meinung. Ob und wie andere Museumsbesucherinnen und Museumsbesucher auf den Eintrag reagierten, war zweitrangig bzw. in der Regel nicht sichtbar für die Autorinnen und Autoren. Alle, die das Buch vor ihrem Eintrag studierten, positionierten sich im Bewusstsein, dass ihre Einträge von muzejščiki und zukünftigen Gästebuchschreiberinnen und Gästebuchschreibern gelesen werden würden.

Bemerkenswerterweise lasen jedoch nicht nur andere Gäste, sondern auch die muzejščiki die Einträge. Diese kommunikative Funktion der Gästebücher als Bestandteil der Besucherforschung ist bislang nicht adressiert worden. Im Dezember 1940 hinterließ jemand im Namen der Gruppe folgenden Eintrag im Gästebuch des Museums der Roten Armee in Moskau: »Wir waren im Museum und haben unsere Gedanken über die Kämpfe mit den Weiß-Finnen [belofinami] und den Weiß-Polen aufgefrischt. Im Museum ist es sehr schlecht! Ich.« (Abb. 36). ${ }^{113}$

Ein Mitarbeiter des Exkursionsbüros schrieb gut lesbar mit einem andersfarbigen Stift folgende Entgegnung über den Besucherkommentar hinweg: „Schade, dass der Genosse nicht sagt, was schlecht ist, was ihn unzufrieden macht und [schade, dass er A.H.] dem Museum nicht mit seinen Ratschlägen hilft [Unterschrift unlesbar A.H.]. «114 Es wäre zu vermuten, dass die anonyme Unterschrift des kritisierenden Eintrages »Ich« für die muzejščiki eine ärgerliche Provokation darstellte, die sie am besten ignoriert hätten. Das Gegenteil war der Fall: Da sie wussten, dass zukünftige Besucherinnen und Besucher den Eintrag vielleicht lesen würden, konnten die muzejščiki eine derart negative Bewertung ihrer Ausstellung nicht unkommentiert lassen. Für alle sichtbar verwandelten die muzejščiki die Kritik in einen Vorwurf an die schreibende Person, in dem sie ihr oder ihm vorwarfen, dem Museum nicht bei der Verbesserung seiner Arbeit zu helfen. Damit implizierten sie, dass sie oder er die Pflicht zur Verbesserung des Allgemeinwohls beizutragen, vernachlässigt hatte.

CMVS, Gästebuch 1939-1942, I. 530b. Eintrag ohne Datum. Ausgehend von den Datierungen der vorherigen bzw. nachfolgenden Einträge wurde der Eintrag wohl zwischen dem 1. und dem 3. Dezember 1940 verfasst. 
Abbildung 36: Eintrag in das Gästebuch des Zentralmuseums der Roten Armee Armeemuseums mit Kommentar eines Museumsmitarbeiters, Moskau Dezember 1940 ○ CMVS.

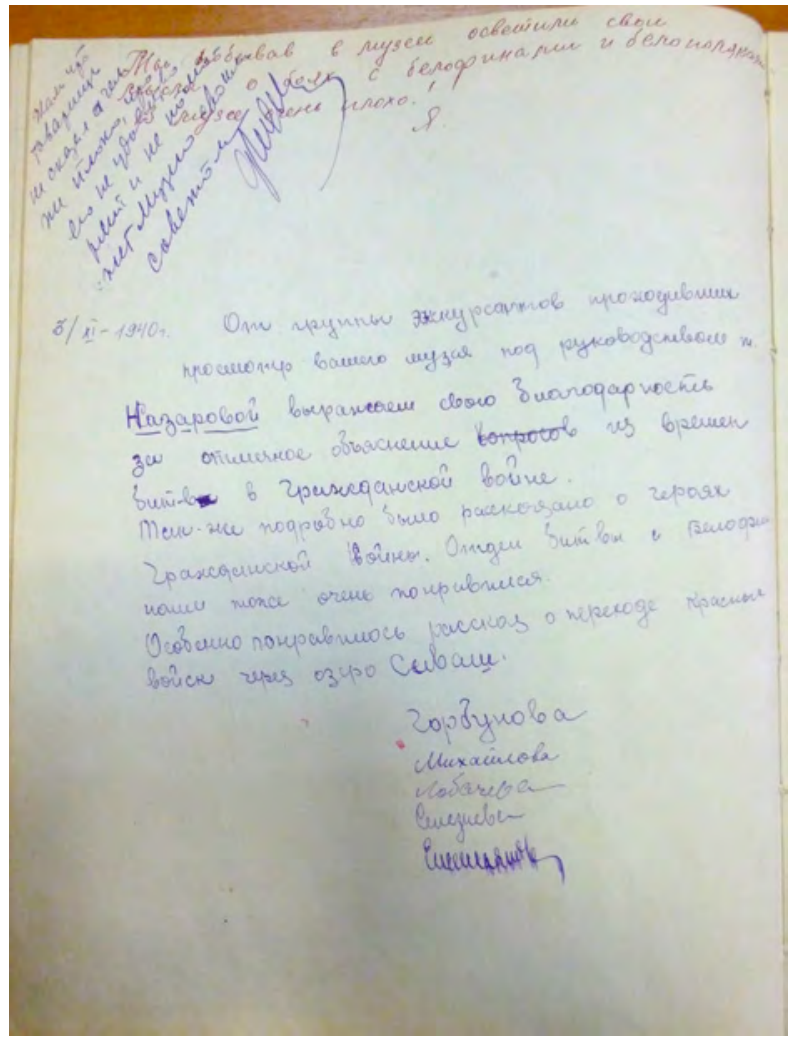

Dass manche Besucherinnen und Besucher genau diese Funktion im Gästebuch sahen, zeigt der Eintrag, den ein Offizier im November 1940 hinterließ: »Das englische Maschinengewehr >Lewis< ist mit >Chauchau beschriftet, bitte korrigieren Sie [diesen Fehler A.H.].«"115 Auch dieser Eintrag wurde kurze Zeit später demonstrativ von den muzejščiki kommentiert. Der stellvertretende Museumsdirektor persönlich reagierte mit nur einem Wort auf die Kritik: »Korrigiert«. ${ }^{116}$

115 CMVS, Gästebuch 1939-1941, unpaginiert, 18. November 1940. Bei den genannten Gewehren handelt es sich um Waffen, die von der britischen bzw. der französischen Armee im Ersten Weltkrieg benutzt wurden und mit denen die Rote Armee im Bürgerkrieg kämpfte. 
Auch die roten Häkchen am Ende vieler Einträge zeugen davon, dass die $m u-$ zejščiki das Buch sorgfältig lasen. Die Schreiberinnen und Schreiber wussten bzw. sahen, dass die Einträge gelesen werden würden. Interessanterweise hemmte sie dieses Wissen nicht, Kritik zu äußern. Unter Berücksichtigung der internalisierten Grenzen des Sagbaren der stalinistischen Diktatur lässt sich sogar argumentieren, dass dieses Wissen sie zusätzlich zur Niederschrift motivierte. Diese Grenzen und die Angst vor einer verdeckten Überwachung und anschließenden Bestrafung durch den NKVD verboten grundsätzliche Kritik an der Kriegsführung oder die Äußerung von Zweifeln an der Überlegenheit des sowjetischen Gesellschaftssystems. Die Quellen lassen keinen Rückschluss auf den Grad der Überwachung im Museum zu. Doch möglicherweise erschien es den Besucherinnen und Besuchern auch gar nicht angebracht, sich mit Fragen oder Kritik dieser Art an die muzejščiki zu wenden? In den Gästebüchern lassen sich jedenfalls keine derartigen Äußerungen finden, und es erscheint wahrscheinlicher, dass sich die Besucherinnen und Besucher an der Funktion des »Buchs für Bewertungen und Vorschläge« orientierten und die muzejščiki für ihre Arbeit im Museum lobten oder kritisierten. ${ }^{117}$

Bei der Genrebestimmung des sowjetischen Gästebuchs hilft der Vergleich mit dem sogenannten "Beschwerdebuch« (Kniga žaloby). Die Auslage dieser Bücher, beispielsweise in Bahnhöfen, war bereits im 19. Jahrhundert eine weitverbreitete Pflicht gewesen. ${ }^{118}$ Möglicherweise liegt hier der Ursprung des sowjetischen Gästebuchs, der es in dieser Traditionslinie von seinem westeuropäischen Gegenstück unterscheidet. Bis heute sind die »Beschwerdebücher in vielen öffentlichen Institutionen wie der Metro oder in Tankstellen zu finden. Sie liegen an einer gut sichtbaren Stelle aus und sind für alle zugänglich, die die Produktqualität, den Service oder die Kundenbetreuung der entsprechenden Einrichtung monieren oder, seltener, loben wollen. Der folgende Eintrag aus dem Gästebuch des Armeemuseums vom Dezember 1940 erinnert stark an die Kommentare in den Beschwerdebüchern:

\section{»1. Dezember 1940}

In Ihrem Museum gibt es sehr schlechte Putzfrauen, die die Besucher mit nassen und schmutzigen Lappen schlagen. Ich bitte Genossin Sorokina, dies zur Kenntnis zu nehmen.

Exkursantengruppe der Roten Armee [dreiteilige nicht lesbare Unterschrift A.H.]. $^{119}$ tor Participation in Soviet War Museums during Stalinism, in: Journal of Educational Media, Memory, and Society, 3, 2021, S. 13-32.

118 Schenk, Frithjof Benjamin: Russlands Fahrt in die Moderne, S. 270-271. 
Es ist $\mathrm{zu}$ vermuten, dass Frau Sorokina die verantwortliche Museumsführerin der Gruppe war. Ihr Name muss den Rotarmisten zuerst entfallen sein, er wurde nachträglich zwischen die Zeilen eingeschoben. Auf den ersten Blick erscheint der Eintrag wie eine Zweckentfremdung des Gästebuchs, von dem man gemeinhin Kommentare zum Ausstellungsinhalt erwartet. Die Untersuchung der Gästebücher zeigt jedoch, dass ein Eintrag in Form einer Beschwerde - unabhängig davon, ob die Beschwerde den Ausstellungsinhalt oder den Umgang mit Besucherinnen und Besucher betraf - integraler Bestandteil des Gästebuchs war, das von dem Museumspublikum als Möglichkeit genutzt wurde, sich öffentlich sichtbar über die schlechte Behandlung durch eine Institution zu beschweren. Die Rotarmisten beschwerten sich über die unangebrachte Behandlung im Museum und meldeten einen schwerwiegenden Vorwurf: Sie seien mit schmutzigen Lappen geschlagen worden und insistierten auf einer Klärung des Vorfalls. Dafür nannten sie den Namen der Person, an die sie sich noch erinnern konnten, und formulierten die Erwartung nach einer Klärung des Vorfalls.

Diese Namensnennung lässt eine Denunziation vermuten. Insbesondere im Kontext des Stalinismus hat die Forschung gezeigt, dass Beschwerden häufig zu diesem Zweck genutzt wurden. Marianna Murav'eva wies jedoch unlängst darauf hin, dass die »Kultur der Beschwerde« als etablierte Kommunikationsform zwischen der Gesellschaft und den Autoritäten eine Konstante in der russischen Geschichte darstellt. ${ }^{120}$ Dabei betont sie den legalen Aspekt des Beschwerdeprozesses. Bereits in vorrevolutionären Petitionen wurde ein Missstand angeklagt und ein Prozedere zur Lösung vorgeschlagen. Hier bestehen Parallelen zwischen dem Beschwerdebuch und dem Gästebuch des Museums. Auch im Eintrag der Rotarmisten stand nicht primär die Denunziation im Vordergrund, sondern vielmehr der Hinweis auf einen Missstand mit der Bitte, diesen zu beheben. Einträge wie dieser, den eine Person im Namen einer Gruppe schrieb, sind typisch. Die Kollektivautorschaft, bei der die anderen Gruppenmitglieder ihre Namen unter den Eintrag setzten, verlieh dem individuellen Anliegen mehr Gewicht und ermöglichte es Einzelnen, in der Anonymität der Gruppe unterzutauchen. Die Gruppe beschrieb eine Unrechtmäßigkeit und forderte vom Museumspersonal, konkret vom Exkursionsbüro, Konsequenzen. Auf den schwerwiegenden Vorwurf über handgreiflich werdendes Reinigungspersonal musste umgehend reagiert werden, sonst lief das Museumspersonal selbst Gefahr, wegen Untätigkeit zur Verantwortung gezogen zu werden. Noch am gleichen Tag schrieb ein Mitglied des Exkursionsbüros demonstrativ mit rotem Buntstift, scheinbar routiniert und abgeklärt, folgende Entgegnung quer über den Eintrag der Soldaten: »Die Prüfung hat ergeben, dass der hier 
beschriebene Vorfall nicht stattgefunden hat und der Fantasie entspringt. 1. Dezember 1940 [Unterschrift unleserlich A.H.]. « ${ }^{121}$ Für alle sichtbar entledigte sich er oder sie der Verantwortung, indem dokumentierte wurde, dass der Vorfall überprüft sei. Er wurde der Fantasie der Rotarmisten zugeschrieben und der Vorwurf war damit Makulatur. Nicht nur der Gebrauch des Rotstifts, sondern auch die Entscheidung, die Erwiderung über den Eintrag hinweg zu schreiben, ist Ausdruck für die Annahme eines Kommunikationsangebotes, dessen Regeln beide Seiten kannten. Es zeigt eine didaktisch motivierte Handlung. Der Besucherkommentar wurde öffentlich korrigiert. Durch die Überschreibung war er nun schwer lesbar und die Besuchermeinung entwertet. Die Entgegnung annullierte die Beschwerde auf zwei Ebenen: auf einer inhaltlichen und auf einer Handlungsebene, denn das Überschreiben des Eintrages gleicht einem Außerkraftsetzen der Handlungsmacht der Schreiberinnen und Schreiber

Das Beispiel aus dem Moskauer Armeemuseum zeigte, dass das Museumspersonal die Einträge, in erster Linie die kritischen, kommentierte, um sich vor seinen gästebuchlesenden Besucherinnen und Besucher und vor der Museumsleitung zu rechtfertigen. ${ }^{122}$ Schrieben die Gäste unangenehme Vorwürfe (wie zum Beispiel der Kommentar über die schlechte Ausstellung über den Winterkrieg) in das Gästebuch, so warfen die muzejščiki den Ball zurück und konfrontierten sie mit ihrer Plicht an der Teilnahme des sowjetischen Projekts. Das Gästebuch war das Medium einer spannungsreichen Kommunikation. Mit der Aufforderung, sich am Lernort Museum zu beteiligen, stellten sich die muzejščiki einer potentiellen Kritik. Der öffentliche Charakter des Buches wiederum zwang die muzejščiki, auf die Kritik ihres Publikums zu reagieren. Dies konnte in Form von rechtfertigenden und klärenden Entgegnungen geschehen oder sogar zu Anpassungen bzw. Korrekturen des Ausstellungsinhaltes führen. Diese Beobachtungen widerlegen die rein »kosmetischen Funktion« des Gästebuchs im Stalinismus.

\section{Besucherforschung im Museum}

Seit Beginn der 1930er Jahre publizierten Zeitungen unter dem Titel »Aus den Seiten des Gästebuchs« (in der Regel lobende) Einträge für Werbezwecke oder als Ankündigung von neuen Sonderausstellungen. Auch ist bekannt, dass sowohl Künstlerinnen und Künstler als auch ihre Kritikerinnen und Kritiker die Gästebücher la-

\footnotetext{
121 CMVS, Gästebuch 1939-1941, I. 57. Eintrag vom 1. Dezember 1940.

122 F. Hirsch hat in den Gästebüchern des Leningrader Ethnographischen Museums (1931-1932) Entgegnungen auf Gästebucheinträge festgestellt, die von Parteimitgliedern an den Rand der Besucherkommentare geschrieben wurden, um vermeintliche Abweichungen von der offiziellen Linie zu korrigieren. Vgl. Hirsch, Francine: Empire of Nations, S. 214-215.
} 
sen, um daraus zu zitieren. ${ }^{123}$ Eine darüber hinausgehende museumsinterne Verwendung der Einträge oder eine Veränderung des Inhalt oder der Inszenierung der Ausstellung als Konsequenz eines Eintrages war bislang ein Forschungsdesiderat und wurde generell als unwahrscheinlich betrachtet.

Ein erster Hinweis auf konkrete Auswirkung der Gästebuchkommentare auf die èkskurzovody zeigt sich in den Listen mit (positiven) Kommentaren, die in Moskau für jede Museumsführerin und jeden Museumsführer angefertigt wurden. Hier wurden Gästebucheinträge aufgeführt, die die jeweiligen èkskurzovody namentlich erwähnten. ${ }^{124}$ Es lässt sich vermuten, dass diese Listen Eingang in die Personalakte der Mitarbeitenden fanden.

Abbildung 37: Vera Romanovskaja liest gemeinsam mit Mitarbeiterinnen und Mitarbeiter des Museums der Geschichte des Großen Vaterländischen Krieges in Minsk das Gästebuch, Minsk Anfang 1950er Jahre, Fotografin/Fotograf unbekannt (c) BDMGVAV.

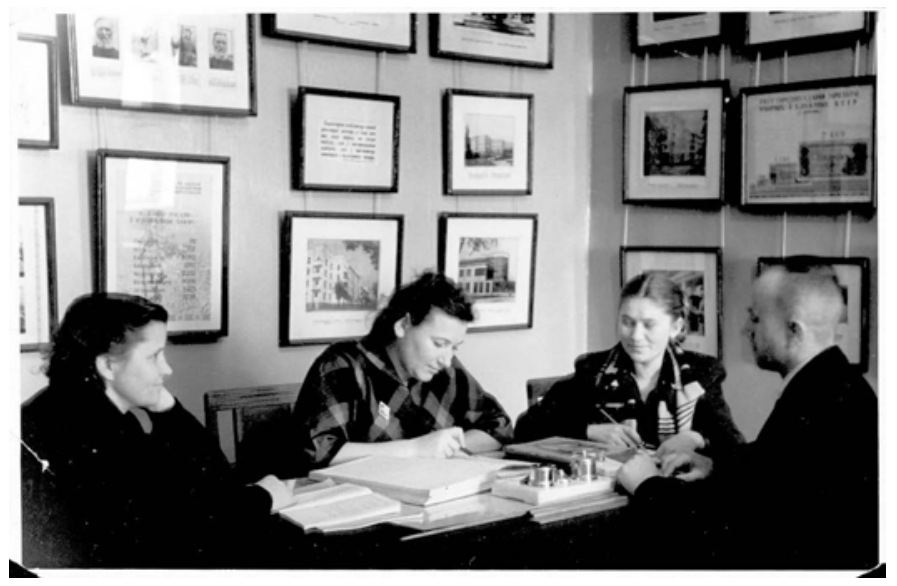

Einen weiteren Hinweis liefert eine Aufnahme aus dem Minsker Museum (Abb. 36), die auf der Rückseite folgendermaßen beschriftet ist: »Romanovskaja, V.S. (in der Mitte) führt Aufzeichnungen im Gästebuch durch «. ${ }^{125}$ Links und gegenüber

S. Reid und O. Johnson wiesen auf den Einfluss von Gästebucheinträgen im Kontext der Kunstkritik hin. Vgl. Reid, Susan: In the Name of the People, S. 675; Johnson, Oliver: Assailing the Monolith, S. 50.

CMVS, Gästebuch 1935. Zwei solcher Listen - Cenosse Alekseev« und »Cenosse Abrosimov« - mit 12 bzw. 13 wörtlichen Gästebuchzitaten sind ebenfalls zufällig überliefert. 
von ihr saßen eine wissenschaftliche Mitarbeiterin und ein wissenschaftlicher Mitarbeiter und an ihrer linken Seite, bereit zum Mitschreiben mit dem Stift in der Hand, die Museumsführerin Vera Petrovič. Das Bild ist Ende der 1940er, Anfang der 1950er Jahre im Büro der stellvertretenden Direktorin des Museums aufgenommen worden. ${ }^{126}$ Der Verwendungszweck dieses Fotos lässt sich nicht feststellen. Aber auch, wenn die Szene etwas gestellt wirkt, so wurde dem Sujet ein hoher Symbolwert zugesprochen. Vor der ehemaligen Untergrundkämpferin Vera Romanovskaja, die inzwischen zur stellvertretenden Museumsdirektorin und Leiterin des Exkursionsbüros befördert worden war, liegt das dicke Gästebuch, dessen Einträge sie aufmerksam, mit einem Stift in der Hand, liest und kommentiert. Auch die wissenschaftliche Mitarbeiterin hat ein aufgeschlagenes Buch vor sich liegen - möglicherweise überprüft sie, ob sich die Kommentare auf ihren Führungstext bezogen. Häufig nannten die Besucherinnen und Besucher in ihren Kommentaren die ékskurzovody beim Namen, deshalb mussten diese bei der Sitzung anwesend sein. Das (inszenierte) Foto zeigt den hohen Stellenwert, den Gästebücher im Museum hatten. Die Tatsache, dass die stellvertretende Museumsdirektorin die Besucherkommentare persönlich las und die verantwortlichen wissenschaftlichen Mitarbeitenden sowie eine Vertreterin der Abteilung Bildung und Vermittlung bei dieser Kontrolle anwesend waren, belegt die museumsinterne Relevanz, die den Gästebucheinträgen zugesprochen wurde.

Ein Zufallsfund im Archiv des Moskauer Museums eröffnet ein empirisches Beispiel für einen weiteren internen Gebrauch der Gästebucheinträge. Das Exkursionsbüro war für die Museumspädagogik und die statistische Erfassung des Besucherspektrums zuständig. Die Historiker Akinsha und Jolles verglichen ihre Arbeit mit einer frühen Form des "politischen Profiling «, die dem Exkursionsbüro geholfen hätte, ihre Führungen zu verbessern. ${ }^{127}$ Ein Museumsführer namens Guščin schrieb im Februar 1935 im Auftrag seines Vorgesetzten einen zehnseitigen Bericht mit dem Titel »Die Exkursanten [Exkursionsteilnehmerinnen/Exkursionsteilnehmer A.H.] über das Zentralmuseum der Roten Armee ${ }^{128}$ In diesem Papier, das an alle Museumsangestellten gerichtet war, aber in erster Linie die èkskurzovody adressierte, zitierte Guščin direkt aus dem Gästebuch und führte die Kommentare als Indikatoren für die Qualität der Arbeit seiner Kolleginnen und Kollegen an. $\mathrm{Zu}$ Beginn nannte Guščin eine Vielzahl von Einträgen an, die er »schmeichelhafte Beurteilungen « (lestnye otzyvy) nannte. Hier wurden die Führungen mit den Kommentaren »sehr gefallen«, »verständlich und schön gesprochen«, »gut erklärt«,

126 Beschriftung auf der Rückseite des Fotos.

127 Akinsha, Konstantin/Jolles, Adam: On the Third Front, S. 206. Diese Studie wurde von S. Reid und J. Plamper in ihrer Forschung zu der sowjetischen Besucherforschung nicht berücksichtigt. 
»alles verstanden« beurteilt. Diesen lobenden Einträgen stellte Guščin die Kommentare gegenüber, die »Opfer [!] von qualitativ schlechten Führungen« geworden waren. Guščin zitiert folgende Besuchermeinungen: »monoton, fad, schlecht vorbereitet «, »unzusammenhängend, unverständlich, zu schnell, wir haben gar nichts verstanden «. ${ }^{129}$ Wurde eine Museumsführerin oder ein bestimmter Museumsführer auffallend oft erwähnt machte Guščin die Mitarbeiterin oder den Mitarbeiter als Positiv- bzw. Negativbeispiel museumsintern bekannt.

Für Guščin waren die Gästebucheinträge eine Interpretationsgrundlage, um Schlussfolgerungen für die zukünftigen Entwicklung der Vermittlungsarbeit zu ziehen. Einträge, die die unzureichende Qualität der Exkursionen kritisierten, sah er als ein Zeichen für das gewachsene Bewusstsein des Museumspublikums, das nach größerem Wissen strebte. Deshalb müssten die èkskurzovody mehr leisten; sie müssten in Zukunft zu »Methodikern « (metodisty) werden, damit sie fähig sein würden, ihr Niveau an die jeweilige Gruppe anzupassen. ${ }^{130}$

In seinem Bericht zitiert Guščin nicht nur Einträge aus dem Gästebuch, sondern nimmt die Besucherbewertungen der Fragebögen hinzu, die am Museumsausgang auslagen. ${ }^{131}$ Ohne die geschlossene Fragestruktur der Bögen in seiner Auswertung zu berücksichtigen, interpretiert Guščin die Einträge als repräsentative Beurteilungen: »Die Bewertungen über das Museum sind ehrlich gesagt nicht schlecht, [sie sind A.H.] tiefgründig, lebendig und wenn man auch die negativen Kommentare hinzunimmt, spiegeln sie die Museumsarbeit umfassend. «32 Der Bericht schließt mit den Rubriken: »Was [sich A.H.] die Massen von dem Museum wünschen « und »Vorschläge der Exkursionsteilnehmer in Bezug auf ihre Betreuung«. Hier werden einerseits organisatorische Verbesserungsvorschläge zitiert (»kleinere Gruppen, längere Führungen«) und andererseits zahlreiche inhaltliche Ergänzungsvorschläge der Besucherinnen und Besucher wiedergegeben (»die Rolle der Frau und des Komsomol im Bürgerkrieg ausstellen«). Damit deutlich wurde, aus welcher sozialen Schicht die Bedürfnisse und Verbesserungsvorschläge stammten, hatte Guščin die Angaben des Verfassers hinzugefügt: »A. Poplev, 20 Jahre, Mitglied des Komsomol «. ${ }^{133}$ Auch pragmatische Vorschläge wie die Bitte an die Putzfrauen, »nicht während einer Führung zu putzen« oder jene, einen Kiosk mit Postkartenverkauf sowie ein Buffet mit Wasserausschank einzurichten, erachtete Guščin als relevant und nahm sie in seine Liste auf.

Ebd. I. 1-3.

Ebd. S. 4. Hier führte Guščin ein Negativbeispiel an: »[...] nicht so, wie es die Genossin Malyščeva gemacht hat, Schüler des Hauses Nr. 15 haben sie gebeten, die Karte mit der schematischen Darstellung der Fronten von 1919 zu erklären, aber sie weigerte sich und sagte: >Davon versteht ihr überhaupt nichtsく.«

CMVS, Gästebuch 1935, zwölf ausgefüllte Fragebögen aus dem Jahr 1935. CMVS, nicht archivierte Bestände, Ėkskursanty o central'nom muzee RKKA, I. 7.

Ebd.: I. 7-10 
Neben der Erkenntnis, dass die Gästebucheinträge für die muzejščiki, insbesondere für das Exkursionsbüro, Konsequenzen hatten, gibt der Guščin-Bericht Einblick in den Museumsalltag. Dieser hatte Mitte der 1930er Jahre offenbar mit schwierigen Bedingungen und Mängeln (fehlende Cafeteria, verschmutzte Ausstellungsräume) zu kämpfen. Mit dem Hinweis, dass sonst ein »Basar« entstünde, auf dem sich die èkskurzovody gegenseitig überschrien, bat ein Besucher darum, bitte nicht zwei Führungen gleichzeitig in einem Saal oder einer benachbarten Abteilung stattfinden $\mathrm{zu}$ lassen. ${ }^{134}$

Der Guščin-Bericht zeigt, dass die Gästebuchkommentare ernst genommen wurden und dass sie, gemeinsam mit den Besucherfragebögen, für die Besucherforschung genutzt wurden. Der Museumsführer Guščin befand sich dabei an einer einflussreichen Schnittstelle zwischen dem Museumspublikum und den $m u$ zejščiki. Er wählte die Einträge aus, entzifferte die Handschriften und tippte die Kommentare ab. Anschließend, und das mag der bedeutendere Arbeitsschritt gewesen sein, gruppierte und interpretierte er die Einträge nach seinem Gutdünken. Dabei wurden aus individuellen Wahrnehmungen eine kollektive Ausstellungserfahrung konstruiert. Wörtlich, aber vor allem ohne den Zwischenschritt einer Reflexion über eine mögliche Schreibintention interpretierte Guščin die Einträge als Belege für die Qualität der Arbeit. In seinem Bericht, der vom Exkursionsbüro an den Museumsdirektor weitergeleitet wurde, sparte Guščin die negativen Besucherkommentare nicht aus, sondern deutete sie als Ansporn für das Museumskollektiv, seine Arbeit zu verbessern.

\section{Ein sdissonanter Chor` im Museumsgästebuch der Kriegsausstellungen}

Bemerkenswerterweise sind in zwei der drei untersuchten Museen die Gästebücher aus dem Jahr ihrer Eröffnung (1919) bis in die Gegenwart beinahe lückenlos in den hauseigenen Archiven des Moskauer und Minsker Museums überliefert. ${ }^{135}$ Die Gästebücher des Tscheljabinsker Museums befinden sich im Gebietsarchiv der Region. Die Tatsache, dass die Museen ihre Gästebücher bis heute selbst aufbewahren, während sie andere interne Dokumente längst an die entsprechenden staatlichen Archive übergeben haben, weist auf ihre anhaltende Bedeutung für die

Ebd.: I. 9.

135 In dem Moskauer Armeemuseum sind die Gästebücher von der Eröffnung im Jahr 1919 bis in die Gegenwart im hauseigenen Archiv überliefert (CMVS). Das hauseigene Archiv des Staatlichen Belarussischen Museums der Geschichte des Großen Vaterländischen Krieges archiviert alle Gästebücher seit seiner Eröffnung 1944 (BDMGVAV). Die Gästebücher (geführt seit der Eröffnung des Museums 1919) des Tscheljabinsker regionalwissenschaftlichen Museums befinden sich im OCAČO. 
Museumsleitung hin. ${ }^{136}$ Ihre Überlieferungsgeschichte, die Archivierung und die handschriftliche Nummerierung der Seiten (oder der Einträge) belegen den internen Gebrauch des Gästebuchs als Quelle der Besucherforschung und den Anspruch des Museums an eine umfassende Dokumentation der Besucherrezeption. ${ }^{137}$ Das widerspricht der These, die Gästebücher seien zufällig und nur in kleiner Anzahl überliefert worden. ${ }^{138}$ Eine repräsentative Auswahl von Einträgen zu den hier untersuchten Ausstellungen in Moskau, Minsk und Tscheljabinsk in der Kriegs- und Nachkriegszeit (1941-1949) offenbart einen vielstimmigen Chor von Besucherstimmen aus ganz unterschiedlich vom Krieg betroffenen Gebieten (Frontstadt, befreite Stadt und Hinterland). ${ }^{139}$

\section{Moskau}

Die Informalität der weißen Seiten konnte die Besucherinnen und Besucher dazu ermutigen, sich spontan Raum für die kreative Gestaltung ihrer Einträge zu nehmen. Ein Beispiel für die Nutzung dieser Freiheit ist der Eintrag, den eine Gruppe kurz nach der Eröffnung der Ausstellung »Die Zerschlagung der deutschen Truppen vor Moskau« im Gästebuch des Moskauer Armeemuseums im März 1942 hinterlassen hatte (Abb. 38). ${ }^{140}$

136 Die Cästebücher haben, im Gegensatz zu den Ausstellungsplänen und den Führungstexten, keinen Stempel der zentralen Zensurbehörde (ClavLit). Das ist ein weiterer Hinweis darauf, dass sie bereits zu sowjetischen Zeiten in der exklusiven Verantwortung der Museen lagen. Zur Forschung, die archivalische Klassifikationssysteme in ihre Überlegungen einbezieht, vgl. Luehrmann, Sonja: Religion in Secular Archives, Soviet Atheism and Historical Knowledge, Oxford 2015, S. 3.

138 Reid, Susan: In the Name of the People, S. 680.

139 Aus den Cästebuchbeständen des Moskauer Armeemuseums wurden sieben Bücher des Zeitraums 1936-1965 analysiert. Sechs Gästebücher (von 1944 bis 1965) aus dem Minsker Museum und zwei Gästebücher $(1946-1948,1949)$ aus dem Tscheljabinsker regionalwissenschaftlichen Museum liegen der vorliegenden Analyse zugrunde. Auf den Din-A4-Seiten fanden je nach Länge und Schreibstil der Einträge 3-5 Kommentare Platz. 
Abbildung 38: Eintrag des Schriftstellers Samuil Maršak im Gästebuch des Zentralmuseums der Roten Armee, Moskau März 1942 (c) CMVS.

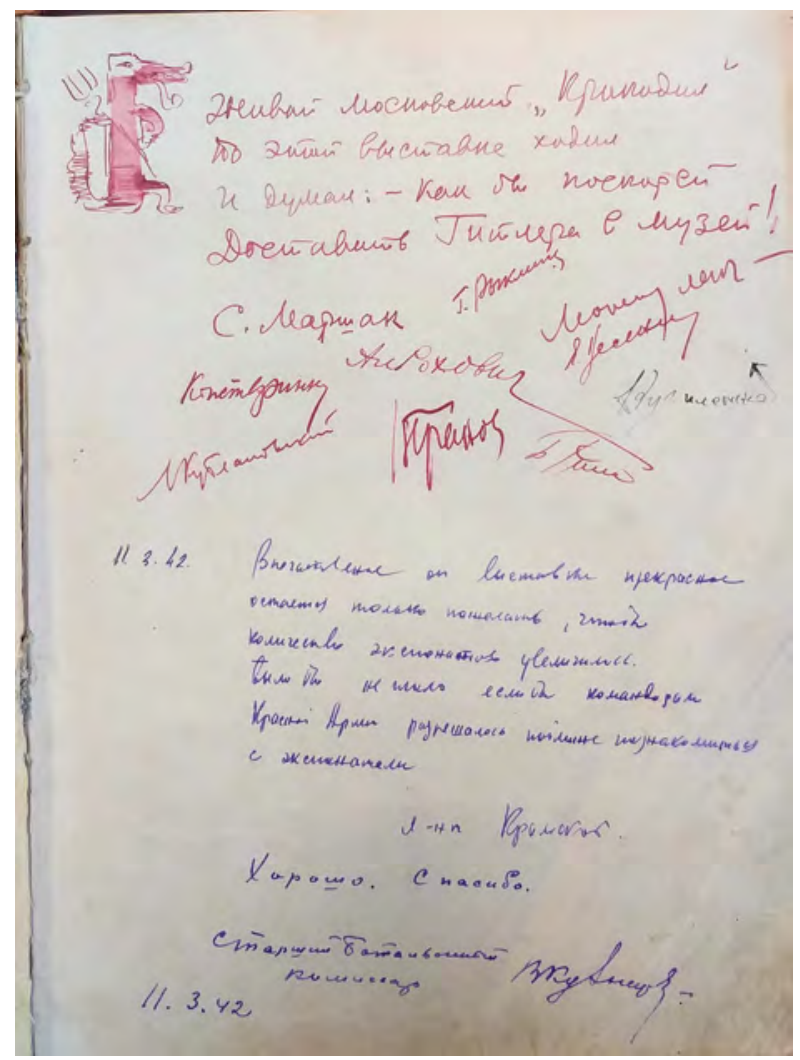

Im Anschluss an ihre Führung schrieb der Herausgeber des Satiremagazins »Krokodil« einen Reim in das Gästebuch, den die acht Mitglieder der Gruppe unterschrieben: »Das lebendige Moskauer >Krokodik ist durch diese Ausstellung gegangen und dachte: >Wie kann Hitler möglichst schnell ins Museum gestellt werden! [Živoj moskovskij >Krokodil po ètoj vystavke chodil i dumal: - Kak by pobystrej dostavit' Gitlera v muzej!] «. ${ }^{141}$

Die erste Unterschrift oben links stammt von dem für seine Kinderliteratur berühmten jüdisch-russischen Schriftsteller Samuil Jakovlevič Maršak (1887-1964). 
Die Übereinstimmung der Unterschrift mit dem Text verrät uns, das er den Eintrag verfasste. Er schien seinen eigenen, roten Stift $\mathrm{zu}$ benutzen (die vorangehenden und folgenden Einträge im Gästebuch sind in blauer Tinte verfasst). Samuil Maršak, dessen Gedichte über die »Deutschen Faschisten« berühmt waren, nahm sich nicht nur die Zeit, einen Vierzeiler zu dichten, sondern malte zusätzlich das Maskottchen des Magazins mit seinen typischen Attributen Mistgabel und Pfeife neben den Eintrag. ${ }^{142}$ Das Krokodil, die Hauptfigur des Magazins, erlebte stellvertretend für die Moskauer Bevölkerung die alltäglichen Freuden und Sorgen der Menschen in der Hauptstadt. Kurz nach der Eröffnung der neuen Sonderausstellung war das Krokodil nun in das Museum gegangen und hatte sich die Schau über den »Großen Vaterländischen Krieg« angesehen. Im Namen der anderen Besucherinnen und Besucher rekapitulierte es die Eindrücke seines Museumsbesuches und formulierte die drängendste Frage: Wie kann Hitler möglichst schnell in ein Museumsobjekt verwandelt werden? Maršak ließ seine literarische Figur den Diskurs der Ausstellung in Form eines künstlerischen Reimes reproduzieren. Dabei sprach er (unbewusst oder nicht) den Musealisierungsprozess an, bei dem materielle Überreste gegenwärtiger Ereignisse in tote Museumsexponate transformiert wurden. Das Krokodil drückte seinen Wunsch nach Frieden aus, indem es den Auslöser des Krieges, Adolf Hitler, als totes Ausstellungsobjekt imaginierte. Maršak, der für die Teilnahme an »literarischen Abenden« mehrmals selbst an der Front gewesen war, wurde zum Sprachrohr der Bevölkerung und nahm Stellung zu den Kriegsereignissen. Es ist zu vermuten, dass die Leserinnen und Leser des Gästebuches an der roten Zeichnung mit hohem Wiedererkennungswert, die aus dem üblichen Duktus der Kommentare herausfiel, hängenblieben. Das Ziel, Aufmerksamkeit zu wecken, hat der prominente Gästebuchschreiber nicht zuletzt über seine bekannte Unterschrift erreicht. Für das Museum bedeutete dieser Eintrag kurz nach Ausstellungseröffnung eine öffentliche Aufwertung durch eine berühmte Persönlichkeit.

Einträge dieser Art waren nicht die Regel, sondern die Ausnahme. Die meisten Einträge glichen standardisierten Phrasen und Sätzen, die das Genre des Gästebucheintrages charakterisieren. Ein solcher Eintrag eröffnete das Gästebuch der ersten Kriegsausstellung "Die Zerschlagung der deutschen Truppen vor Moskau« im Armeemuseum. Der Leiter einer Gruppe von Bergarbeitern rahmte seinen Kommentar mit einem Titel und einem Schlusswort. Auf seine Unterschrift folgten die Signaturen seiner vier Angestellten, die mit ihm von der Museumsführerin Dvorcova durch die Ausstellung geführt worden waren:

Das Gedicht im Gästebuch entspricht dem Stil von Maršaks Kriegsgedichten. Vgl.: »V nojabre sezon zakryt« (Im November geht die Saison zu Ende), Krokodil, Nr. 44, 1943. Die Mistgabel ist das Symbol für den Abschnitt des Magazins mit dem Titel »Vyly v bok « (Gabelstich in die Rippen), das Nachrichten und Rezensionen enthielt. Die Pfeife und die Mistgabel waren unverkennbare Attribute des Krokodils. 
»Bergarbeiter, auf zu noch größerer Stoßarbeit.

Wir sprechen Cenossin Dvorcova unseren großen-riesengroßen [bol'šuju-prebol'šuju] Dank aus. Sie hat uns einfach, klar und klug [prosto, jasno, umelo] über die heldenhafte Verteidigung unserer heimatlichen Hauptstadt erzählt.

Lebe und sei gesund, Moskau! [živi i zdravstvuj]

Leiter der Bergarbeiter-Delegation und Abgeordneter des Höchsten Rats der RSFSR [Name nicht lesbar A.H.]

Delegierter: Al. Ionov

Bergmann des Schachtes `Komsomol'skaja Prvada<: [Name nicht lesbar A.H.]

Vorarbeiter des Schachtes benannt nach Krasin: Lorskij

Bauleiter des Schachtes benannt nach Artem: [Name nicht lesbar A.H.].« ${ }^{143}$

Dieser Eintrag erfüllt den gewünschten Zweck des sowjetischen Gästebuchs vorbildlich. Zum Einstieg appellierte der Bergmann solidarisch an alle zukünftigen Bergarbeiter, die das Museum besuchen würden, es seinen Männern gleich zu tun und noch härter für den Sieg zu arbeiten. Der eigentliche Kommentar ist der Ausspruch eines Dankes, der in seinem umgangssprachlichen Ausdruck (großriesengroß) nach einem aufrichtigen Lob für die gute Ausstellungsführung von Frau Dvorcova klingt, die die Gruppe durch ihre prägnante Erzählung beeindruckt hatte. Das Schlusswort sollte die Verbundenheit der Bergarbeiter mit ihrer Hauptstadt Moskau zeigen. Der Imperativ »Lebe und sei gesund, Moskau«, ein Grußwort, das in der Regel zum Abschied naher Menschen geäußert wird, drückt die Vermenschlichung der Stadt aus. Womöglich waren die Bergarbeiter von der Ausstellungserzählung, die von der bevorstehenden Einnahme der Hauptstadt Moskaus durch die Wehrmacht berichtete, ergriffen und wollten aufbauende Worte für die von Bomben zerstörte Stadt finden. In diesem Eintrag bestimmte der Verfasser, der gleichzeitig der Vorgesetzte der Gruppe war, die Form der Unterschriften. Er selbst gibt sich nicht nur als Gruppenvorsteher zu erkennen, sondern dokumentierte seine politische Funktion als Delegierter im obersten Sowjet der RSFSR. Nach gebührendem Abstand zu seiner Unterschrift listete er die vier Berufsbezeichnungen (Delegierter, Bergmann, Vorarbeiter, Bauleiter) und die jeweiligen Namen ihrer Schächte auf und legt den Eintrag seinen Angestellten zur Unterschrift vor. ${ }^{144}$ Dieser Kommentar zeigt die angesprochene Betonung von Zugehörigkeit zu einer sozialen Funktionsgruppe. Die Bergarbeiter gehörten einer sehr angesehenen Ge-

143 CMVS, Gästebuch 1942-1943, Eintrag ohne Datum, ca. 10. März 1942.

144 Die Vorstrukturierung des Eintrages durch den Delegationsleiter ist aus dem Schriftbild abzuleiten. Hier zeigt sich erneut der Erkenntnisgewinn, der aus der Analyse der handschriftlichen Einträge zu ziehen ist. 
sellschaftsschicht an und nannten, anstelle ihres Namens, die einzelnen Schächte: Komsomol'skaja Pravda, Krasin und Artem. ${ }^{145}$

Am 7. Juni 1942 besuchte eine junge Moskauer Soldatin vor ihrer Abfahrt an die Front das Museum und schrieb folgenden Eintrag ins Gästebuch:

\section{»7. Juni 1942}

Heute war ich zum ersten Mal in diesem Museum. In seinen Exponaten spiegeln sich alle Ereignisse des Großen Vaterländischen Krieges hell wider, sie zeigen seine Helden. Wenn du dir die Exponate anschaust, erscheinen vor den Augen die harten und verlustreichen [krovoprolitny] Kämpfe vor Moskau - die Hauptstadt, meine Heimat. Die zukünftigen Generationen werden sich mit dem Gefühl von Stolz auf ihre Väter und Brüder und mit einem brennenden Hass auf den verfluchten deutschen Faschismus, auf die deutsche Räuberarmee erinnern. Wenn ich aus dem Museum gehe, nehme ich den Hass auf den Feind mit, und wenn ich bald an der Front bin, werde ich gemeinsam mit den Soldaten der heldenhaften roten Armee den Feind ohne Mitleid vernichten und die Ehre und Unabhängigkeit meiner Heimat verteidigen.

Kadett Dzrjakova, L.N. ${ }^{146}$

Die Forschung hat das schablonenhafte Aufgreifen offizieller Versatzstücke, hier beispielsweise die Referenz auf die sogenannte »Hass-Kampagne« des Sommers 1942, als Indiz dafür gelesen, dass Stalins Propaganda im Gästebuch reproduziert wurde. Diese Deutung unterstellt eine verfälschte Äußerung, ohne zu berücksichtigen, dass die Wiederholung eines offiziellen Diskurses auch als Evidenz des beachtlichen Nachhalls, den die Ausstellung und ihre Führungen genossen, gelesen werden kann. ${ }^{147}$ Der Ausstellungsbesuch bzw. die Betrachtung der Exponate bestätigte die Kriegspropaganda, die die junge Rotarmistin außerhalb des Museums rezipiert hatte. Die Betrachtung der Exponate suggerierte der Soldatin eine Würdigung, die künftige Generationen der Roten Armee, und damit auch ihr selbst,

Die Schächte waren benannt nach der Zeitung der staatlichen Jugendorganisation (»Komsomol'skaja Pravda«), dem Ingenieur und früheren Mitglied der Bolschewiki Leonid Krasin (1870-1926), und nach Fëdor Sergeev, genannt Artem (1883-1921), der im Donbas einen Sozialdemokratischen Zirkel gegründet hatte.

147 In ihrer Neubewertung der Tauwetterperiode kritisiert Polly Jones einen zu starken Kontrast zwischen offiziellem und nichtoffiziellem Diskurs. Sie hinterfragt die hartnäckige Annahme, die öffentliche sowjetische Kriegserinnerung sei durchweg verfälscht gewesen und habe die Erinnerung der Menschen unterdrückt, und betont den beachtlichen Teil der Menschen und Institutionen, die einen wesentlichen Anteil und eine fest etablierte Rolle im Kulturleben unter Stalin hatten. Vgl. Jones, Polly: Myth, Memory, Trauma, Rethinking the Stalinist Past in the Soviet Union, 1953-1970, New Haven 2013. 
entgegenbringen würden. Angesichts der Niederlagen der Roten Armee im Sommer 1942 konnte dieses Gefühl möglicherweise Mut und Kampfgeist in der jungen Frau auslösen. Durch den Gästebucheintrag, in dem sie ihren emotionalen Aufruhr beschrieb und ihre Absichten zur Erfüllung ihrer Pflicht an der Front beschrieb, konnte die Kadettin ihr sowjetisches Selbst produzieren. Dieser Eintrag zeigt anschaulich die von Jochen Hellbeck in den Tagebüchern der 1930er Jahre beobachtete Motivation der Menschen, sich selbst in die Geschichte einzuschreiben: »[They A.H.] revealed an urge to write themselves into their social and political order. They sought to realize themselves as historical subjects defined by their active adherence to a revolutionary common cause. Their personal narratives were so filled with the values and categories of the Soviet revolution that they seemed to obliterate any distinction between a private and a public domain. ${ }^{148}$ Dabei wird die Ideologie als eine das »sowjetische Selbst« formende Kraft sichtbar.

Formelhaft wirkende Einträge, die von Schulkindern oder Pioniergruppen unterschrieben wurden, können Indikatoren dafür sein, dass Erwachsene, oder Lehrpersonen den Kindern die Einträge diktiert hatten. ${ }^{149}$ Schließlich, das lässt sich bis heute in allen Gästebüchern beobachten, griff man gerne auf bekannte Muster zurück, wenn man selbst nicht wusste, was man schreiben sollte. Dementsprechend kann der Gebrauch von Schablonen bzw. die Niederschrift von stark individualisierten Einträgen ein Hinweis dafür sein, dass die Person zum ersten Mal in das Gästebuch schrieb. ${ }^{150}$ Gästebucheinträge, in denen sich die Schreibenden auf einzelne Ausstellungsexponate bezogen und sie in ihren eigenen Erfahrungskontext einordneten, können die Wirkmacht von Exponaten und Führungen belegen. Im März 1942 besichtigte ein Kollektiv des inländischen Geheimdienstes das Armeemuseum:

148 Hellbeck, Jochen: Revolution on my Mind, S. 4-5.

149 BDMCVAV, Gästebuch 1944, unpaginiert. Eintrag vom 2. Juli 1959. Ljudmila Jabloševskaja schrieb, dass sie in den Ferien nach Minsk gefahren war und das Museum besucht hatte. Sie benutzte die hochtrabenden Ausdrücke der offiziellen Rhetorik: »]a očen vooduševlena geroiymom našego naroda v bor'be za nezavisimost' nasej Rodiny.«Sie schloss ihren Eintrag mit dem Versprechen, ihren Klassenkameraden von den »Heroischen Taten des belarussischen Volkes« zu erzählen.

150 OGAČO, f. R-627, op. 3, d. 399, Gästebuch 1946-1948. Eintrag vom 26. Februar 1948. Schwer zu entziffernder Eintrag, der im Gästebuch des Tscheljabinsker regionalwissenschaftlichen Museums eine ganze Seite einnimmt. Der Schreiber gibt sich als Frontsoldat zu erkennen (»]a frontovik«). Die auffällig hohe Zahl der Rechtschreib- und Grammatikfehler zeigt den schlechten Ausbildungshintergrund. Er wiederholt Wort für Wort die Propaganda-Phrasen, die er bei der Museumsführung gehört hat. Der Eintrag endet mit dem Hinweis des Autors, dass dies sein erster Besuch im Museum sei, womit er bekennt, ein Novize in der Praxis des Gästebuchschreibens zu sein. 
14. März 1942. Die Ausstellung hinterlässt einen einmaligen Eindruck und ruft tiefen Hass gegenüber den Hitler-Schurken hervor. Alle werden sagen: >In solchen Ersatz-Filzstiefeln [érsac-valenki] werden sie nur russische Eichenkreuze erobern kënnens.

Gruppe von NKVD-Mitarbeitern. ${ }^{151}$

Der Kommentar nahm Bezug auf die Vitrine mit den ausgestellten Uniformen der Wehrmacht. Das Exponat, die handgeflochtenen Stiefel aus gepresstem Stroh, hatten sich die Wehrmachtsoldaten aufgrund fehlender Winterausrüstung angefertigt, als sie im Winter 1941/42 vor Moskau steckenblieben. Als es keine Kleidung mehr gab, die man der Bevölkerung in den eroberten Gebieten hätte stehlen können, ordnete die deutsche Versorgungsabteilung an, nach russischem Vorbild Filzstiefel sogenannte »Valenki« anzufertigen. Da jedoch kein Filz, geschweige denn Maschinen zum Nähen von Stiefeln zur Verfügung standen, flochten die deutschen Soldaten gepresstes Stroh zu Stiefeln, die zum Schutz vor Kälte und Nässe über die eigentlichen Stiefel gezogen wurden. Als die Rote Armee die Wehrmachtssoldaten gefangen nahm, brachten muzejščiki die »Ersatz-Valenki«als Exponat in ihr Museum. ${ }^{152}$

Die Stiefel schienen die Geheimdienstmitarbeiterinnen und Geheimdienstmitarbeiter bei ihrem Rundgang besonders beeindruckt zu haben, da sie sie in ihrem Eintrag erwähnten. Es ist anzunehmen, dass insbesondere der große Kontrast zwischen der hochentwickelten militärischen Ausrüstung der deutschen Wehrmacht und diesen selbstgeflochtenen Stroh-Überziehern, die so offensichtlich unzweckmäßig für den Wintermatsch waren, Belustigung und Hohn hervorrief. Ihre Schadenfreude drückten sie in einer Metapher aus, bei der aus den Eisernen Verdienstkreuzen, die die Wehrmachtsoldaten als Auszeichnung für die Eroberung Moskaus bekommen sollten (Exponate, die ebenfalls in der Ausstellung gezeigt wurden), russische Friedhofskreuze wurden. ${ }^{153}$

An diesem Eintrag wird erneut der empirische Erkenntniswert handschriftlicher Selbstzeugnisse deutlich. In einer ersten Version hatte die schreibende Per-

CMVS, Gästebuch 1942-1943, unpaginiert. Eintrag vom 14. März 1942.

Das diese Stiefel den Weg ins Museum gefunden haben, scheint ein Glücksfall gewesen zu sein. Auf einer Aufnahme der Kriegskorrespondentin der »Krasnaja Zvezda«, Natal'ja Bode, sieht man, wie im Winter 1942/1943 Rotarmisten in Stalingrad »Trophäen-Ersatz-Valenki« an ihre Pferde verfüttern. https://fr.wikipedia.org/wiki/Natalia_Bode\#/media/File:Красноар мейцы_пустили_на_корм_лошадям_трофейные_эрзац-валенки_Сталинград,_СССР_Зим а_1942_1943_Наталья_Боде.jpg (Stand: 31.07.2021).

Am 17. März 1942 erhielt das Museum von der GlavPURKKA 644 fabrikneue deutsche Eisenkreuze mit Ordensbändern, die als Auszeichnung für die Eroberung Moskaus bestimmt waren. Vgl. Pečen, N./Povesmo, P.: V gody surovych ispytanij 1941-1945, S. 63. Es ist anzunehmen, dass die Kuratorinnen und Kuratoren diese Eisenkreuze 10 Tage nach dem Erhalt bereits ausstellten. Möglicherweise übernahm der NKVD-Mitarbeiter die Metapher aus einer Führung. 
son die Metapher von der Eroberung der russischen Eichenkreuze im Konjunktiv (»können«) formuliert. Später schien er oder sie es sich anders überlegt zu haben, strich die Möglichkeitsform durch und machte die Aussage damit zu einer feststehenden Regel, einem Sprichwort gleich. In der Formulierung "alle werden sagen « drückt sich eine gewisse Selbstsicherheit aus. Er oder sie schreibt sich in eine allgemein bekannte Wahrheit ein.

Zwei Wochen später schrieb ein Besucher im Namen seiner Gruppe den ersten Kommentar auf eine neue Seite des Gästebuchs, der in seiner sauberen Schönschrift auffällt. Verfasst mit blassem Bleistift, scheint er im starken Kontrast zu seinem überaus kritischen Inhalt zu stehen:

»28. März 1942. Die Ausstellung ist zweifellos von großer Bedeutung. Aber was uns absolut nicht zufrieden gestellt hat, sind die Erläuterungen [der Museumsführerinnen/Museumsführer A.H.] in den Sälen. Sie erzählen nur bekannte Wahrheiten. Und wenn man zum Beispiel etwas über die Konstruktion eines Waffenstücks oder eines Panzers herausfinden möchte, ist das absolut unmöglich. Hier sind militärische Spezialisten vonnöten und keine Dilettanten. Von diesen hat man überhaupt keinen Nutzen.

Stellvertretender $\mathrm{p}-\mathrm{ka}$ [Unterschrift unleserlich A.H.]. ${ }^{154}$

Die Gruppe war enttäuscht von der Führung. Sie hatte sich von der Ausstellung Erkenntnisse erhofft, die über die täglichen Radio- und Zeitungsmeldungen hinausgingen. Nach der Führung formulierten sie ihren Ärger über das nicht vorhandene Fachwissen der Personen, deren Aufgabe es war, Fragen zu Ausstellungsobjekten zu beantworten. Diese Kritik ist ein direkter Angriff auf die (schlechte) Ausbildung der ékskurzovody, die als Vermittlerinnen und Vermittler der (politischen) Botschaft des Museums fungieren sollten. ${ }^{155}$ Sie wurden als »Dilettanten « (diletanty) bezeichnet, und die Gruppe verlangte, diese durch »militärische Spezialisten« (voennye specialisty) zu ersetzen.

Die Besucherinnen und Besucher präsentierten sich als informiert und gebildet. Sie wollten mit ihrer Kritik zu einer Verbesserung der musealen Vermittlung und damit zur Entwicklung des Gemeinwohls beitragen. Ihr abschließender Kommentar, dass die Erläuterungen »überhaupt keinen Nutzen« (net nikakoj pol'zy) für

154 CMVS, Gästebuch 1942-1943, unpaginiert. Eintrag vom 28.03.1942.

155 Die Museumsführung betrieb einen großen Aufwand, um eine sachkundige Ausbildung des Führungspersonals zu gewährleisten. Ab dem Frühjahr 1942 wurde ein spezielles Ausbildungsprogramm eingeführt, um die Museumsangestellten auf dem nahegelegenen Schießplatz mit der Funktionsweise der deutschen Waffen vertraut zu machen. Jede und jeder sollte die deutschen Waffen auseinandernehmen, wieder zusammensetzen und mit ihnen schießen können. Ein gefangener deutscher Offizier wurde beauftragt, mit Hilfe eines Übersetzers, die Unterschiede zwischen den deutschen Orden und Auszeichnungen zu erklären. Vgl. Pečen, N./Povesmo, P.: V gody surovych ispytanij 1941-1945, S. 63. 
die Gruppe gehabt hätten, könnte für die entsprechende Person Konsequenzen gehabt haben. ${ }^{156}$ Der Eintrag belegt die großen fachlichen Herausforderungen, die sich den èkskurzovody bei der Beherrschung des ständig wachsenden Wissensstandes stellten. Das betraf bei Kriegsanfang, als dieser Eintrag verfasst wurde, insbesondere die erbeuteten Waffen der Deutschen, zu denen die muzejščiki häufig keinerlei Informationen besaßen.

Mit den zunehmenden militärischen Erfolgen der Roten Armee bot das Gästebuch eine Möglichkeit, sich in den politischen Siegesdiskurs einzuschreiben:

»Es lacht der [am besten A.H.], so geht ein französisches Sprichwort, der am letzten lacht. Und als Letzter lacht der Sieger. In Teilen sind wir das und unsere Alliierten. Aber wir lachen nicht: Wir stellen die Folgen unserer Siege objektiv zur Betrachtung aus - die Trophäen der deutschen Räuberarmee, diese Trophäen werden unserem Volk lange davon erzählen, wie sinnlos Ceist, Energie und Material verschwendet wurden, nur um den Nachbarn zu überfallen und ihn danach zu töten im Namen der wahnsinnigen Träume eines Nietzsches und seinesgleichen, dass auf der Erde angeblich nur der >Übermensch< [sverchčelovek] und die reine, >Kulturrasse< [kulturnaja rasa] leben soll, die in Europa die >Neue Ordnung< [novyj porjadok] einführen wird und die der Menschheit, und allen voran den Deutschen, das Lebensglück bringen soll. Wir wünschen den Deutschen dieses Glück, wenn sie es nur erreichen könnten.

8. März 1944 L. [Familienname unleserlich A.H.].

P.S. Die Ausstellung ist gut eingerichtet und macht einen kultivierten [kul'turnoe] Eindruck. ${ }^{157}$

Auf den ersten Blick fällt dieser Eintrag durch seine Länge auf. Selbstbewusst wurde der Platz einer ganzen Seite in Anspruch genommen und mit großem Zeilenabstand geschrieben. Auf den zweiten Blick erstaunt die Rhetorik des Kommentars. L. begann mit dem Zitat eines französischen Sprichwortes, nur um dessen Regelhaftigkeit im Folgesatz zu widerlegen. ${ }^{158}$ Die Autorin oder der Autor demonstrierte das eigene Wissen über die Propaganda des faschistischen Deutschlands, indem sie oder er die Begriffe »Übermensch«, »Kulturrasse« und »Neue Ordnung« verwendete. Damit wurde die eigene Bildung und soziale Stellung betont. Der Kommentar

156 Quellen, die über mögliche (repressive) Konsequenzen für die Moskauer Museumsmitarbeitenden seitens der Museumsleitung Auskunft geben könnten, sind nicht bekannt. Im Minsker Fall wurden jedoch Dokumente gesichtet, die die Museumsangestellten für nachlässiges Verhalten (zum Beispiel Inszenierung falscher Exponate, Vernachlässigung der Aufsichtspflicht, Verlust von Museumseigentum etc.) in einem dreistufigen Verfahren verwarnten. CMVS, Gästebuch 1943-1950, I. 13. Eintrag vom 3. März 1944.

158 Dieses Sprichwort existiert auch im deutschen Sprachgebrauch. Evt. war dem Autor das bewusst und er betonte explizit den französischen Ursprung der Redewendung, um seine Selbstdarstellung vom Feind abzugrenzen. 
schließt mit einem ironisch-fatalistischen Grußwort, in dem sie oder er den Deutschen viel Glück bei ihren Plänen wünscht.

Der deutsche Überfall traf auf ein spezifisches Bild, das die Menschen in der Sowjetunion von den Deutschen und dem Krieg hatten. Der Anblick der Museumsexponate konnte ihr Feindbild, die Vorstellung von dem, was sie zu verlieren hatten und wozu die Deutschen fähig waren, verändern. Der Ausstellungsrundgang bereitete die Bühne für die Wahrnehmung und Erinnerung an den Sieg. Der oder die Schreibende war durch die Betrachtung der Trophäen zum Gästebuchschreiben angeregt worden. Der Museumsbesuch hatte ein Nachdenken über den Krieg ausgelöst, welches in wertgeladenen binären Oppositionen mündete. Die Betrachtung der Kriegsrelikte führte zu dem Ausdruck von Unverständnis über den Überfall Deutschlands auf die Sowjetunion.

Aus der heutigen Perspektive erscheint es möglicherweise überraschend, dass die Überlegenheit der Sowjetunion nicht in triumphalistischen Siegesfeiern imaginiert wurde, sondern im didaktischen Gebrauch der »objektiven Trophäen «, die ausgestellt wurden, um das Scheitern des deutschen Angriffs zu zeigen. Wie die Ausnahme von der sprichwörtlichen Regel würde die Sowjetunion nicht über die Besiegten lachen, sondern die Kriegsrelikte am Lernort Museum für Erziehungszwecke nutzen. In den Augen der Besucherin oder des Besuchers entsprach dieser Ansatz der kulturellen Überlegenheit der Sowjetunion. Der Sieg über die Deutschen oder, präziser ausgedrückt, die Befreiung der Völker vom Faschismus machte die Sowjetunion zum moralischen Sieger. Das Postskriptum wirkt, als hätte sich die Schreiberin oder der Schreiber plötzlich an den konventionellen Gebrauch des Gästebuches erinnert. Das Lob des »kultivierten Eindrucks« von der Ausstellung, unterstützte das Argument der eigenen moralischen Überlegenheit. ${ }^{159}$

Die Sagbarkeitsgrenzen des Gästebuchs hatten ihren Ursprung in den kulturell-militärischen Konventionen der Sowjetunion. Kriege wurden hier traditionell in einen feierlichen und heldenhaften Diskurs gefasst. Deshalb wurde selten über Angst oder Leiderfahrungen geschrieben. Man könnte nun meinen, dass nur triumphalistische und heroische Kommentare Eingang ins Gästebuch fanden. Der zuvor zitierte Kommentar aber erweitert diese Vorstellung, indem er zeigt, dass eine anders konnotierte Aneignung der zukünftigen Betrachtung von gewonnenen Kriegen vorgeschlagen werden konnte.

An dieser Stelle muss beachtet werden, dass sich der russische Gebrauch des Adjektivs »kulturell« (kultur'nij) leicht von unserem Verständnis unterscheidet und am ehesten mit »kultiviert« übersetzt werden sollte. Das Nomen »kultur'nost'« war ein Schlüsselbegriff des sowjetischen Diskurses. Die Enzyklopädie von 1940 beschrieb »kultur'nij «als gutes Benehmen, das sich von der angenommenen Rückständigkeit der Landbevölkerung unterschied. Vgl. Brown, Kate: A Biography of no Place, From Ethnic Borderland to Soviet Heartland, Harvard 2005, S. 58. 


\section{Minsk}

Während das Museumspublikum in der Hauptstadt Kriegsepisoden präsentiert bekam, die in großen Teilen dem allgemeinen Diskurs entsprachen, bot die Darstellung im Minsker Museum dem Publikum eine andere Erzählung. Der hier gewählte Fokus auf den Partisanenkampf und das Leid der Zivilbevölkerung unter der Besatzungsherrschaft war für die Besucherinnen und Besucher ein Teil ihrer eigenen Lebenswelt gewesen. Für Menschen aus anderen Teilen der Sowjetunion bedeutete diese Darstellung jedoch eine neue Facette der Kriegserzählung.

Abbildung 39: Gästebuch des Belarussischen Museums der Geschichte des Großen Vaterländischen Krieges, Minsk 1944 (c) BDMGVAV.

Abbildung 40: Erste Seite des Gästebuchs mit geschwärzten Stellen, Minsk Oktober 1944 (C) BDMGVAV.
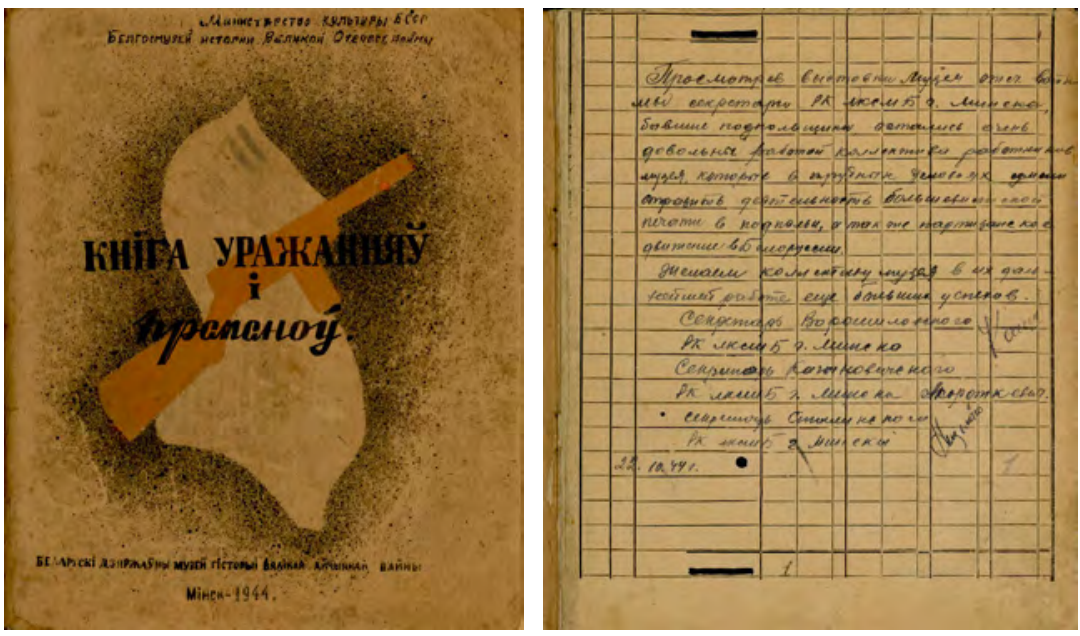

Das bemerkenswerte Äußere des ersten Gästebuchs des Minsker Museums verdient Beachtung (Abb. 39). Da in der befreiten, aber völlig zerstörten Stadt alltägliche Gebrauchsgegenstände wie beispielsweise Gästebücher nicht vorhanden waren, improvisierten die jungen muzejščiki und verwendeten die Hinterlassenschaften der geflohenen Besatzungsbehörden: In diesem Fall ein Rechnungsheft. ${ }^{160}$ Das Deckblatt des deutschen Hefts im Format A5 wurde mit einem Siebdruckverfah- 
ren verziert und beschriftet, so dass der deutsche Aufdruck nicht mehr zu sehen war. $^{161}$

Den ursprünglichen Zweck dieses Heftes verraten die zur Addierung von Beträgen gedachte Linierung der Blätter und die deutschen und belarussischen Überschriften über den Spalten: »Übertrag« (peranos), »Zusammen«(razam). Dieser Hinweis auf den ursprünglichen Gebrauch des Heftes wurde (allerdings nur auf den ersten 10 Seiten) unkenntlich gemacht, indem die deutsch-belarussischen Spaltenbezeichnungen des Rechnungsbuchs geschwärzt wurden. Am Tag der Museumseröffnung wurde das Gästebuch als erstes den Ehrengästen vorgelegt. Der lobende Gruppeneintrag der drei Parteivorsitzenden der Minsker Stadtkreise, die während der deutschen Besatzung im Untergrund den Komsomol geleitet hatten, verlieh der Arbeit der muzejščiki politische Legitimität. ${ }^{162}$ An zweiter Stelle wurde ein hoher Militär gebeten, seinen Besuch im Museum zu verewigen:

Nachdem ich die Exponate angeschaut habe, die in der Ausstellung des Museums des Vaterländischen Krieges in Minsk gezeigt werden, bin ich bis zum Grund meiner Seele begeistert über die Arbeit des Künstlerkollektivs und der anderen Museumsmitarbeiter, über die Gründung eines solch reichhaltigen Ortes, der alle ewigen Verdienste unserer Brüder, Schwestern, Väter und Mütter um das Vaterland zeigt, die in den Reihen der Volksrächer gegen die verfluchten, faschistischen Finsterlinge gekämpft haben.

Ich muss offen gestehen, dass das Museum meine Vorstellung von der Partisanenbewegung nachdrücklich erweitert hat.

Von ganzem Herzen danke ich den mutigen Volksrächern für ihren engagierten Kampf unter den schwierigen Bedingungen im Hinterland des Feindes und dem Kollektiv der Museumsarbeiter, dass sie es geschafft haben, das zu zeigen.

Oberleutnant a/sl Turkin 22.10.1944. ${ }^{163}$

In seiner Unterschrift gab sich Oberleutnant Turkin bewusst als Militär zu erkennen. Sein Rang verlieh dem Eintrag Gewicht. Jedoch hatte Turkin nicht in den Reihen der Partisaninnen und Partisanen gekämpft und stammte scheinbar auch nicht aus der sowjetischen Republik Belarus. Er bekannte seine Unkenntnis über das Ausmaß des Partisanenkampfes, um im gleichen Atemzug die Taten dieser

161 BDMGVAV, KP 79433, S. 1. Im Museum ist man sich heute des Wertes dieses ersten Gästebuchs bewusst. Es ist in der aktuellen Dauerausstellung (2016) im Saal 9. zu Wiederaufbau und Erinnerungsgeschichte (»Belorus' posle osvoboždenija 1944-1950, Pamjat' o vojne«) ausgestellt. Allerdings ist das Buch in der Vitrine geschlossen, so dass die nur das Deckblatt zu sehen ist und die vormalige Verwendung des Heftes durch deutsche Besatzungsbehörden nicht erkennbar ist (Besuch der Ausstellung am 27. Juli 2016).

BDMCVAV, Gästebuch Oktober 1944-Januar 1945, I. 1, Eintrag der Sekretäre der Bezirke Vorošilov, Kaganovič und Stalin vom 22. Oktober 1944. 
sogenannten »Volksrächer« als Verdienste vor dem Vaterland zu loben. In seinem Dank verbindet er den kuratorischen Erfolg des Museumskollektivs mit den militärischen Leistungen der Partisaninnen und Partisanen zu einer gemeinsamen Sache, die dem Oberleutnant imponiert hatte. Der Eintrag erfüllte offenbar mehrere Schreibmotivationen zugleich. Indem er erstens die Schwierigkeiten des Kampfes im besetzten Gebiet anerkannte und die Partisaninnen und Partisanen als »Brüder und Schwestern « in die sowjetische Familie der Kriegsteilnehmenden aufnahm, wertete er ihren Kampf auf und hob ihn auf eine Ebene mit den Kämpfen der Roten Armee. Zweitens spricht er dem Museumskollektiv das größtmögliche Lob aus: In den Augen des Oberleutnants war es ihnen gelungen, den Widerstandskampf gegen die deutschen Besatzer so darzustellen, dass das Publikum genau diese Gleichwertigkeit mit der Roten Armee erkannte. Der Ausstellungsrundgang hatte den Oberleutnant »bis auf den Grund seiner Seele beindruckt « und löste offenbar ein Gefühl von Solidarität mit den belarussischen Partisaninnen und Partisanen aus. Die Objekte und die Ausstellungsnarrative hatten ihm die Ähnlichkeit des Kampfes an der Front und im besetzten Gebiet vor Augen geführt, und in seinem Gästebucheintrag drückt er die Wiederaneignung entfremdeter Beziehungen mit den Menschen der besetzten Gebiete aus.

Die Teilnahme am Krieg war zur Wasserscheide geworden, die über die Integration in der sowjetischen Nachkriegsgesellschaft entschied. Dies war besonders zentral für die Menschen, die während des Krieges unter deutscher Besatzung gelebt hatten und unter dem politischen Generalverdacht der Kollaboration standen. Der Eintrag des Leutnants kann als Beispiel dafür gelesen werden, wie Menschen ihr Leben innerhalb der sowjetischen Ideologie verorten konnten. Das universale Projekt der kommunistischen Gesellschaft wurde im Krieg wiedergeboren und erfuhr insbesondere nach dem Krieg, der die Kriegsteilnehmerinnen und Kriegsteilnehmer in einem multiethnischen und klassenunabhängigen Kampf vereint hatte, eine neue Wirkmächtigkeit. ${ }^{164}$

Gut zwei Wochen später dokumentierte ein weiterer Leutnant im Gästebuch seinen Ausstellungseindruck:

Amir Weiner beschrieb den »Croßen Vaterländischen Krieg« als neuen sowjetischen Cründungsmythos. VgI. Weiner, Amir: Making Sense of War, The Second World War and the Fate of the Bolshevik Revolution, Princeton 2002. Für die Rezeption dieses breit anerkannten Konzeptes durch die russische Forschung vgl. Budnickij, Oleg: Making Sense of War, The Second World War and the Fate of the Bolshevik Revolution, by Amir Weiner, Review, in: Ab imperio, 4 2002, S. 464-481. Ein Vergleich der von A. Weiner untersuchten Region Winnyzja (Ukraine) mit der Republik Belarus im Deutsch-Sowjetischen Krieg unter deutscher Besatzung und in der direkten Nachkriegszeit erscheint in Hinblick auf die von ihm diskutierten Themen (Rolle der Partisanenverbände, der Roten Armee und der Erinnerung an den Holocaust und an den Sieg) vielversprechend. 
9. November 1944. Beim Betrachten der Ausstellung hinterließen die Waffen der Partisanen einen besonderen Eindruck. Anhand dieser Waffen wird deutlich, welch großer Drang zum Kampf mit den deutschen Eindringlingen bei unseren sowjetischen Menschen vorherrschte. Sie rüsteten sich selber mit Waffen aus, die die Deutschen im Kampf zurückgelassen hatten. Und sie haben mit ihren eigenen Kräften selber welche hergestellt. Um das größte Feuer unter dieser braunen Schlange zu legen, die in unsere Erde hineingekrochen ist. ML [Unterschrift nicht lesbar A.H.]. ${ }^{165}$

Bemerkenswert ist der direkte Bezug des Schreibenden auf die Ausstellungsstücke. Auch er schien die Partisanenwaffen zum ersten Mal gesehen zu haben und begründet sein Interesse für die Exponate: Die improvisierten Waffen belegten den Widerstandsgeist der Menschen, die nicht mit der deutschen Besatzung kollaboriert hatten. Aus eigenem Antrieb war es ihnen gelungen, aus den häufig zerstörten Überbleibseln der erbeuteten deutschen Trophäen eigene neue Waffen zu bauen. Der Leutnant bewunderte das handwerkliche Geschick und die Kreativität und stand damit in Einklang mit dem allgemeinen Narrativ der Ausstellung. In seinem Kommentar wiederholte der Leutnant Auszüge aus der Ausstellungsführung, mit der die Exponate beschrieben wurden. Die Metapher der »braunen Schlange« weist auf die Verwendung des Vokabulars der die Medien dominierenden Kriegspropaganda hin.

Im Gegensatz zu diesen zwei lobenden Kommentaren, in denen die Erwartungen an die Ausstellung von den muzejščiki übertroffen wurden, schien der Verfasser des folgenden Kommentars elementare Dinge zu vermissen und äußerte drei sehr konkrete Verbesserungswünsche:

»Neben all den überaus positiven Seiten der Ausstellung müssen auch ihre Nachteile erwähnt werden:

1) Die Ausstellung zeigt zu wenig vom Heldenmut und Alltag einzelner Partisanen (ihre Heldentaten, ihre persönlichen Dinge und ihre persönlichen Waffen).

2) Die Waffen sind unachtsam ausgestellt, schlecht geölt, sie rosten.

3) Reichtümer wie die handgemalten Partisanenzeitschriften sind nutzlos, [wenn A.H.] sie offen daliegen und jedem in die Hand gegeben werden.

Oberleutnant [Unterschrift nicht lesbar] 1. April 1945. «166

Die Strukturierung des Eintrages anhand einer Nummerierung kann als Hinweis darauf gelesen werden, dass sich der Oberleutnant den Text vor dem Eintrag gut überlegt hatte. Unter Betonung seines grundsätzlich positiven Eindrucks von der 
Ausstellung zählte er drei konkrete Nachteile auf und offenbarte dabei ein differenziertes Wissen über die Partisanenbewegung. ${ }^{167}$ Sein erster Punkt kritisierte die Ausstellung als zu oberflächlich. Er warf den muzejščiki vor, den Partisanenalltag zu trivial und ohne direkten Bezug auf die einzelnen Kämpfer auszustellen. Sein zweiter Kritikpunkt bezog sich auf das Versagen des Museums im Hinblick auf den Schutz bzw. die angemessene Aufbewahrung und Pflege der Waffen. Da sie das Kernstück der Ausstellung waren, wog der Vorwurf ihrer unzureichenden Pflege und der Hinweis, dass die Exponate rosteten, besonders schwer. Auch hier präsentiert sich der Verfasser gegenüber den als unwissend, fahrlässig und unprofessionell dargestellten muzejščiki als militärisch gebildeten Fachmann. Im dritten Kritikpunkt zeigt sich eine weitere Steigerung dieser Reflexion über die Arbeit der Kuratorinnen und Kuratoren. Bemerkenswerterweise erkannte der Oberleutnant im Gegensatz zu den muzejščiki den historischen Wert der Partisanen-Almanache. ${ }^{168}$ Es scheint, als verfolgte er ein persönliches Anliegen als er erneut das Museumspersonal für seine Unwissenheit und Unachtsamkeit kritisierte. Die Motivation dieses Eintrags liegt in der öffentlichen Selbstdarstellung eines Experten, der sich in militärhistorischen, restauratorischen und musealen Fragen als versiert und den muzejščiki überlegen darstellte. Als Teilnehmer der Ereignisse schilderte er in dem Gästebucheintrag seine Vorstellung von der musealen Inszenierung und Bewahrung der Erinnerung an den Partisanenkampf. Der Besucher hatte offenbar bereits zukünftige Generationen im Auge, für die die Exponate professionell konserviert werden mussten. Damit hatte er den Sinn des Museums - die Bewahrung der materiellen Erinnerung - verinnerlicht.

$\mathrm{Zu}$ Beginn des Jahres 1945 besuchte die Schule Nr. 13 das Museum. Eine der Lehrerinnen schilderte den Eindruck ihrer Klasse:

»Die 13. Schule hat gemeinsam das Museum des Vaterländischen Krieges besucht. Den Kindern hat alles sehr gut gefallen. Etliche haben sich an ihre Vergangenheit erinnert, als sie bei den Partisanen gekämpft haben.

4. Januar 1945, Rodina. ${ }^{169}$

Der geführte Rundgang durch die Ausstellung und die Erzählungen der ékskurzovody hatten die Schülerinnen und Schüler offenbar animiert, ihrer Lehrerin mitzuteilen, welche Exponate sie wiedererkannten oder welche Erinnerungen diese in ihnen weckte. Es ist vorstellbar, dass die Jugendlichen dabei ihre ehemalige Zugehörigkeit oder Nähe zu den Partisaninnen und Partisanen erinnerten. Die Kriegs-

167 Vermutlich handelt es sich hier um den Kommandeur der Partisaneneinheit »Patriot«Aleksandr Azončik. spät erkannt. Vgl. Azaronok, S. I. (Hg.): Partizanskij al'manch 1944-2009, Minsk 2009. 
erfahrung, die die Schülerinnen und Schüler mit einem Teil der Gesellschaft, die das Museum öffentlich als Kriegshelden anerkannte, teilten, kreierte ein Gemeinschaftsgefühl und half den Jugendlichen möglicherweise bei der Verarbeitung ihrer häufig traumatischen Vergangenheit. Die Nachkriegszeit war für die Kinder und Jugendlichen, die die deutsche Besatzung überlebt hatten, von großer Not geprägt. Viele von ihnen, insbesondere die jüdischen Kinder, waren Waisen, deren Alltag von Hunger, Armut und Krankheit bestimmt war. Viele beschrieben ihre Unfähigkeit, sich nach dem mehrjährigen Aussetzen der Schulbildung auf den Unterricht zu konzentrieren. Zugleich boten Schulen und Universitäten Möglichkeiten, dem Alltagsleid zu entkommen und wurden zu Räumen, in denen die Vergangenheit überwunden und eine Zukunft aufgebaut werden konnte. ${ }^{170}$ Vielleicht half ihnen auch der Museumsbesuch, sich in die Nachkriegsgesellschaft zu integrieren.

Während in Minsk bereits die Verarbeitung des Kriegserlebnisses begonnen hatte, wurden in anderen Regionen der Sowjetunion weiterhin junge Männer und Frauen an die Front geschickt. Im Februar 1945 besuchten drei junge Unterleutnants, die gerade die Offiziersschule beendet hatten, auf ihrer Fahrt nach Westen das Minsker Museum. Sie beschrieben die Gefühle, die der Ausstellungsbesuch in ihnen ausgelöst hatte:

»2. 2. 1945. Im Namen der Offiziers-Absolventen, die zur Front fahren.

Die Besichtigung der Ausstellung über den Partisanenkampf in Belarus hat uns sehr zufriedengestellt; der Hass auf den Faschismus und der Wunsch, die Fahne schneller über Berlin zu hissen, kocht [vskipela] noch stärker in uns.

MI. L-nt. [drei unleserliche Unterschriften A.H.]. «171

Die drei jungen Männer widmeten ihren Eintrag den Kameradinnen und Kameraden, die ebenso wie sie an die Front fuhren. So betonten sie das Gemeinschaftsgefühl mit den kampferprobten und gesellschaftlich hochangesehenen »frontoviki«, zu denen sie in Kürze selbst zählen sollten. Der Eintrag zeigt, dass die Minsker Ausstellung einen ähnlichen Effekt auf Rotarmistinnen und Rotarmisten hatte wie die Ausstellung im Moskauer Armeemuseum. Die Präsentation der Folgen der deutschen Besatzungsherrschaft und des Widerstandskampfes motivierte die Soldatinnen und Soldaten, denen der erste Fronteinsatz noch bevorstand, zum Kampf. Die Rhetorik des »überkochenden Hasses « überlagerte bestehende Ängste und förderte den sehnlichen Wunsch, zum Sieg über den Faschismus beizutragen. Die Einträge im Gästebuch des Minsker Museums zeigen die Bedeutung, die die Ausstellung sowohl für die belarussische Bevölkerung als auch für die Besucherinnen und Besucher aus anderen Republiken der Sowjetunion hatte. 
Die Minsker muzejščiki hatten sich bewusst entschieden, ihr Museum mit zwei Sonderausstellungen $\mathrm{zu}$ eröffnen, die erstens den kommunistischen Widerstand (»Bolschewistische Presse im Untergrund«) und zweitens die Spezifik des belarussischen Partisanenkampfes (»Selbstgebaute Waffen der belarussischen Partisanen«) zeigten. Die Gästebucheinträge spiegeln die Wirkung, die die improvisierten Waffen auf das Publikum hatten, und bestätigen die Aussage des Museumsdirektors Stal'nov, der diesen Ausstellungsstücken die größte Beliebtheit attestierte.

Für Besucherinnen und Besucher von außerhalb bot die Ausstellung neue Ansichten auf den »Großen Vaterländischen Krieg«. Erstmals konnten die Menschen der Sowjetunion eine konkrete Vorstellung vom Widerstandskampf und dem Leid der Besatzungserfahrung entwickeln. Die improvisierten Waffen, von denen keine der anderen glich, beeindruckten die auswärtigen Gäste, da sie die handwerkliche Begabung und Kreativität der Partisaninnen und Partisanen zeigte. Die Unikate betonten die lokale Spezifik des belarussischen Anteils am Krieg und lösten insbesondere bei den militärisch versierten Publikum Respekt aus. Diese Wertschätzung ließ den Partisanenkampf in den Augen der Militärs als gleichwertig mit ihrem eigenen Kampf erscheinen und konnte dazu führen, dass die durch die deutsche Besatzungszeit belasteten Beziehungen innerhalb der sowjetischen Vielvölkerfamilie wieder gestärkt wurden. Die Besucherinnen und Besucher konnten die Ausstellung über den Widerstand gegen die deutsche Besatzungsmacht und die Darstellung über das erfahrene Leid in den allgemeinen Diskurs über den »Großen Vaterländischen Krieg « integrieren und verfügten damit über eine alternative Deutung angesichts der Gerüchte über Verrat und Kollaboration. Kritik übten die ehemaligen Partisaninnen oder Partisanen selbst. Sie präsentierten sich im Gästebuch als Expertinnen und Experten für den Inhalt und die Inszenierung ihrer Erfahrung. Als Teil einer gesellschaftlich hochangesehenen Schicht der Nachkriegszeit forderten sie mit ihrer expliziten Kritik die muzejščiki heraus. ${ }^{172}$

Innerhalb der belarussischen Gesellschaft vermochte die Ausstellung einen Beitrag zur Verarbeitung der traumatischen Besatzungserfahrung zu leisten. Davon profitierten insbesondere diejenigen, die bei den Partisanenverbänden gekämpft hatten, unter ihnen auch Kinder und Jugendliche, die in den Einheiten überlebt hatten. Die offizielle Geschichtspolitik, die unter dem Stichwort »Partisanenrepublik« den Partisanenkampf als allgemeinen Widerstandskampf auf die heterogene Kriegserfahrung des ganzen Volkes übertragen sollte, adressierte auch die Kinder und Jugendlichen. Diese positive Konnotation des Partisanenkampfes sollte andere

172 Mark Edele betont die öffentlich sichtbare Vorzugsbehandlung von Veteranen durch den Staat, die sich durch leichteren Zugang zu Wohnraum, Ausbildung und angesehenen Arbeitsplätzen direkt in der Nachkriegszeit äußerte. Edele, Mark: Soviet Veterans of the Second World War, A Popular Movement in an Authoritarian Society, 1941-1991, Oxford 2008, S. 133 sowie S. $195 \mathrm{ff}$. 
Erinnerungen der belarussischen Nachkriegszeit verdrängen - die Partisanenverbände hatten die Bevölkerung immer wieder zu Opfern deutscher Strafaktionen gemacht, von den Dorfbewohnern Nahrungsmittel geraubt und ihre Kinder als Kämpfer zwangsrekrutiert.

Mit den Kapiteln über die deutsche Besatzungsherrschaft, die im Winterhalbjahr 1944/45 den zwei Eröffnungsausstellungen hinzugefügt wurden, stellten die Minsker muzejščiki die Erfahrung des Holocausts und das Schicksal der sowjetischen Kriegsgefangenen neben den Partisanenkampf. Im Gästebuch lässt sich kein Eintrag finden, der explizit Bezug auf diese Ausstellungskapitel nimmt. In dem zuletzt erwähnten Eintrag der drei Unteroffiziere taucht die Leiderfahrung der belarussischen Bevölkerung jedoch indirekt auf. Die Darstellung der deutschen Kriegsverbrechen löste in den Militärs ein Rachebedürfnis aus, das sie mitteilen wollten.

\section{Tscheljabinsk}

Auch die Menschen im Süd-Ural setzten ihre eigenen Erfahrungen an der »Heimatfront « in Beziehung zu den Eindrücken, die sie bei ihrem Ausstellungsbesuch gesammelt hatten. Als das im Krieg »konservierte« regionalwissenschaftliche $\mathrm{Mu}$ seum im Frühjahr 1946 mit der Ausstellung »Die Rolle Tscheljabinsks im Großen Vaterländischen Krieg« wieder eröffnen konnte, hinterließ eine Lehrerin einen ausführlichen Eintrag im Gästebuch, der eine ganze Seite in Anspruch nahm:

»25. Mai 1946. Die Ausstellung >Die Rolle Tscheljabinsks im Großen Vaterländischen Krieg، hat mich in ihrer Aussagekraft überrascht - alle Abteilungen. Alles ist hier hervorragend ausgewählt und auf seine Art besonders [svoeobraznij]. Auf mich, eine ehemalige Untertanin [poddannaja] Polens, haben folgende Abteilungen großen Eindruck hinterlassen: Die Produktion der militärischen Fabriken, die Bomben, die Sprengkörper, die Schrapnelle, die Granaten, Minen und besonders die Modelle der Panzer - mit denen wir - den bösesten Feind der Menschheit den Faschismus zerstört haben. Das System der Panzer, die Berlin eingenommen haben, diese >Höhle des blutdürstigen Menschenfressers Hitler<- das ging mir besonders nahe [byla po duše].

Kossovska, E. I., Lehrerin der 22. Schule in der Stadt Zlatoust. « ${ }^{173}$

Offenbar hatte die Lehrerin Kossovska vor ihrem Besuch keine großen Erwartungen an die Ausstellung. Nach dem Rundgang war es ihr jedoch ein Bedürfnis, ihrer positiven Überraschung Ausdruck zu verleihen. Sie betont, dass die Ausstellung sie insgesamt sehr beeindruckt und ihr Inhalt eine unerwartete Wirkung auf sie gehabt habe. Sie lobt die muzejščiki für die »hervorragende« Auswahl der Objekte, die ihr aufgrund ihrer Einzigartigkeit gefallen haben. Frau Kossovska bleibt jedoch 
nicht bei diesem allgemeinen Lob, sondern beschreibt, welche Ausstellungsabschnitte ihr besonders "nahegingen«. Dabei offenbart sie ihre ursprüngliche Herkunft. Sie benutzt den Ausdruck »poddannaja« (Untertanin), was als negative Wahrnehmung ihrer ehemals polnischen Staatsbürgerschaft interpretiert werden kann. Damit bediente sie möglicherweise das politische Argument für den Molotov-Ribbentrop-Pakt, das in der Befreiung Ostpolens von den polnischen Unterdrückern lag. Diese biografische Randbemerkung dient ihr als Überleitung zu der detaillierten Beschreibung jener Ausstellungsabschnitte, die ihr am besten gefallen haben: die Darstellung der Waffenproduktion. Dabei bezieht sie sich gerade auf den Ausstellungsabschnitt, den Museumsdirektor Ivan Gorochov in der Inszenierung vernachlässigt hatte. Die Lehrerin zählt die ausgestellten Objekte auf und unterscheidet dabei präzise zwischen den verschiedenen Waffengattungen. Ihre ideologisch aufgeladenen Definitionen »Faschismus, der böseste Feind der Menschheit « und »Berlin, die Höhle des blutdürstigen Menschenfressers Hitler« zeigen erneut, wie auch außerhalb des Museums bestehende omnipräsente Propagandaformeln auf die Ausstellungsnarrative übertragen wurden. Frau Kossovska unterschreibt ihren Eintrag und fügt ihren Beruf und Wohn- bzw. Arbeitsort als zusätzliche Informationen hinzu. Mit der Bezeichnung »Lehrerin« identifizierte sich die Gästebuchschreiberin als Angehörige einer angesehenen sowjetischen Berufsgruppe. Durch das elaborierte Lob der Ausstellung, das im übertragenen Sinne den Leistungen der Waffenproduktion im Süd-Ural und dem Sieg der Roten Armee galt, positionierte sich die ehemalige Polin als patriotische sowjetische Bürgerin. Die Betonung ihrer Biografie könnte die Motivation für diesen Eintrag gewesen sein: Die Bekennung ihrer Herkunft und die stolze Erwähnung ihres Berufs. Diese rhetorischen Elemente lassen sich als Bestandteile eines sozialistischrealistischen Narrativs deuten, in der der Mensch eine bewusste Entwicklung von einem schlechten Leben hin zu einem neuen (sozialistischen) Leben erfuhr. ${ }^{174}$ Diese Selbstbeschreibung im Gästebucheintrag reflektiert das Bedürfnis nach Selbstdarstellung und Loyalitätsbezeugung zur UdSSR, ein Akt, der von den neueingebürgerten Menschen und insbesondere von Lehrerinnen und Lehrern erwartet wurde.

Die Ausstellung der Bodenschätze fand großen Anklang unter den Kindern, Jugendlichen und Erwachsenen. Mit ihrem Lob konnten sie zugleich ihre Verbundenheit mit ihrer Region ausdrücken. Eine Gruppe von Schülerinnen der siebten Klasse schrieb beispielsweise: 
»12. März 1949. Die Erzählungen von Vera Fëdorovna haben uns sehr gefallen. Wir sind ihr sehr dankbar für die guten Erklärungen. Jetzt können wir uns den Reichtum unseres Urals deutlich vorstellen und wir hoffen, dass das Museum bald mit neuen Exponaten ergänzt wird.

Schülerinnen der 7. Klasse der 18. Schule.

Traktorozavodnyj Rayon, Tscheljabinsk. ${ }^{175}$

Die muzejščiki des Tscheljabinsker regionalwissenschaftlichen Museums waren sich über den Zusammenhang zwischen dem Vorkommen der Bodenschätze und der wirtschaftlichen Entwicklung bzw. der Rüstungsindustrie ihrer Region im Klaren. Die Allokation der Industriebetriebe am Ort der Rohstoffförderung und Verarbeitung hatte in den 1930er Jahren zu einem Bevölkerungszuwachs geführt. Mit dem Ziel, neben dem Donbas in der Ukrainischen Sowjetrepublik im Süd-Ural ein zweites metallurgisches Industriezentrum aufzubauen, wurden allein zwischen 1930 und 1931 ungefähr 134.000 Bauern unter dem Vorwurf, Kulaken zu sein, von den sowjetischen Behörden in den Ural deportiert. ${ }^{176}$ Ein bedeutender Teil der lokalen Bevölkerung lebte noch nicht lange in der Region und war erst seit kurzem Teil dieser spezifischen Geschichte des Tscheljabinsker Gebietes. Sie wussten, dass sie wegen der Verarbeitung der Mineralien und Metalle hier lebten, und die Bodenschätze in der Sonderausstellung konnten eine identitätsstiftende Bedeutung für sie haben. Der Eintrag der Schülerinnen »Jetzt können wir uns den Reichtum unseres Urals deutlich vorstellen«, spiegelt die erfolgreiche Vermittlung dieser lokalen Bedeutung durch die Museumsführerin Vera Fëdorovna.

Ein knappes Jahr nach der Eröffnung hinterließ ein Besucher oder eine Besucherin am 20. März 1947 folgenden ausführlichen Eintrag im Gästebuch, in dem der Krieg, dem die Sonderausstellung in erster Linie gewidmet sein sollte, mit keinem Wort erwähnt wurde:

OGAČO, f. R-627, op. 3, d. 409, I. 1ob. Gästebuch 1949, Eintrag vom 12. März 1949. Auch die vorangegangenen und folgenden Einträge loben die Ausstellung der örtlichen Mineralien und drücken den Wunsch nach weiteren Exponaten dieser Art aus: »10.03.1949 [...] Wir wünschen [dem Museum], dass es in Zukunft weitere Reichtümer des Urals erhält. Schülerinnen der 7. Klasse, 37. Schule, Leninskij Rayon, Tscheljabinsk«, in: OCAČO, f. R-627, op. 3, d. 409, I. 10 . »Uns ha[t] besonders die [...] Vielfalt der Mineralien des Urals gefallen. Schülerinnen der 5 . Klasse, 33. Schule«, in: OGAČO, f. R-627, op. 3., d. 409, I. 2. »16.03.1949 [...] Von ihr [der Ausstellung] erfuhren wir über unsere Reichtümer im Ural. Schüler der 27. Schule«, in: OGAČO, f. R-627, op. 3., d. 409, I. 3. »17.03.1949 [...] Vera Fëdorovna berichtete uns auf eine einfache und reichhaltige Weise über die Schätze unserer Region [...] «, in: OGAČO, f. R-627, op. 3, d. 409, I. 30 .

176 Khlevniuk, Oleg: The History of the Gulag, From Collectivization to the Great Terror, New Haven, 2004, S. 16. 
»Die Ausstellung hinterlässt einen guten Eindruck, insbesondere hat mich die Abteilung >Bodenschätze des Tscheljabinsker Cebietes` erfreut. Die Stellwände zu diesem Thema sind mit großem Sachverständnis erstellt. Die Bedeutung und die Perspektiven des Gebietes werden deutlich gezeigt [unleserlich A.H.]. Nur schade, dass keine geologischen und industriell verarbeiteten mineralischen Rohstoffe vorgestellt werden.

Ich bedauere, dass ich mich in der Ausstellung nicht mit der Landwirtschaft des Gebietes, der städtischen Wirtschaft und der Wohnkultur Tscheljabinsks und seiner Geschichte vertraut machen konnte. In der Ausstellung ist [folgendes A.H.] nicht ausgestellt: a) die Kultur und der Alltag des Tscheljabinsker Gebietes, b) die örtlichen Handwerkerbetriebe, c) die Ural-Kusnezk-Magistrale und ihre gesamtstaatliche Bedeutung, d) die Perspektiven des Tscheljabinsker Gebietes unter dem Gesichtspunkt des vierten Fünfjahresplans, e) die Perspektiven des Tscheljabinsker Cebietes in Bezug auf die nächsten zwei bis drei Jahrespläne.

Schade, dass die Schwerindustrie des Tscheljabinsker Cebietes so unzureichend gezeigt wird. Über sie könnte man bedeutend mehr sagen. Überhaupt nichts wird über den Waldreichtum der Region gesagt. Abgesehen von den genannten Lücken verdient die Ausstellung Beachtung. Die Ausstellung sollte in der Presse und im Radio beworben werden, damit sie von den Studierenden und der ]ugend [unleserlich] besucht wird.

20. März 1947. [Unterschrift unleserlich A.H.]. «"177

Der Besucherin oder dem Besucher gefiel die Ausstellungsabteilung zu den Bodenschätzen des Tscheljabinsker Gebietes besonders gut. Dieses Lob konnte der Museumsdirektor auf seine eigene Arbeit beziehen, denn das genannte Ausstellungskapitel hatte nicht die Stadtverwaltung, sondern Gorochov selbst erstellt. Auf dieses positive Urteil folgte eine ausführliche Kritik der zahlreichen Unzulänglichkeiten der Ausstellung, die interessanterweise an die Kritik des Museumsinstitutes an der ausgebliebenen Darstellung des sozialistischen Aufbaus erinnert. Der oder dem Schreibenden waren nach dem Ausstellungsrundgang große Lücken in der Ausstellung des regionalwissenschaftlichen Museums aufgefallen. Sie oder er nannte über zehn thematische Bereiche (von der Landwirtschaft über den Alltag und den Waldreichtum des Gebietes), die die Ausstellung vernachlässigte oder gar nicht repräsentierte. Dabei wird das große Wissen der Autorin oder des Autors offenbar. Die alphabetische Aufzählung und die systematische Nennung der thematischen Lücken sollte die Kritik strukturieren. Indem die oder der Schreibende die eigene Kenntnis der Region als Ergänzungsvorschlag für die Ausstellung formulierte, erfüllte sich der wörtliche Sinn des »Buches für Ratschläge und Meinungen«. Die Kritik wurde in einen höflichen Ausdruck des Bedauerns (»schade, 
dass ... «, »ich bedauere, dass ...«) verpackt. Damit suggeriert die Besucherin oder der Besucher, dass sie oder er gerne noch mehr von dem Museumsbesuch profitiert hätte. Geäußert wird damit implizit auch der Vorwurf einer unzureichenden Museumsarbeit. ${ }^{178}$ Leider lässt sich keine Reaktion auf diesen Eintrag feststellen. Auf Gorochov jedoch, der das Gästebuch regelmäßig las, mag dieser Eintrag wie eine Bestätigung der Moskauer Forderungen gewirkt haben, die thematische Ausrichtung seines Museums zu erweitern. ${ }^{179}$ Gleichzeitig liefert die Aufzählung der Mängel eine Beschreibung des (wirtschaftlichen) Potentials der Region. Es wurde eine Ausstellung gewünscht, die die lokale Entwicklung spiegelte und unterstützte. Motiviert durch den Ausstellungsrundgang, drückte die Verfasserin oder der Verfasser die Verbundenheit zu dem Tscheljabinsker Gebiet aus. Die wiederholte Erwähnung der stalinistischen Wirtschaftspläne (vierter Fünfjahresplan und die darauffolgenden Pläne) sind weitere Hinweise darauf, dass der sozialistische Aufbau eine Leerstelle der Ausstellung war.

Auch im Tscheljabinsker Museum interagierten die muzejščiki mit dem Publikum. Im Februar 1948 schrieb vermutlich ein Schulkind folgende anonyme Frage in das Gästebuch: „28. Februar 1948. Ich habe das Museum besucht und es hat mir sehr gefallen. Aber warum gibt es überhaupt keine Bären und bei den Hasen steht "Schneehasen«, aber beide sind grau. «180 Dieser Eintrag befindet sich im gleichen Gästebuch wie die zuvor zitierten Einträge. Doch im letzten Drittel des Buches wurde eine formale Änderung vorgenommen. Ein Fünftel der leeren Seite wurde mit einem vertikalen Strich abgetrennt und die schmale Spalte an der rechten Blattseite mit der Überschrift »Für Antworten« versehen. Dieser Platz wurde von den muzejščiki genutzt, um mit zwei kurzen Strichen die Registrierung des Eintrages zu vermerken oder um eine Entgegnung niederzuschreiben. Die wissenschaftliche Mitarbeiterin Frau Surach fühlte sich von der spontanen Frage des Kindes angesprochen und antwortete: »Der Schneehase wird im Winter weiß, das heißt sein Fell wird im Winter heller. Im Sommer ist es wieder grau, das heißt nach seinem Haarwechsel im Frühling wächst ihm ein graues Fell. Wissenschaftlicher Mitarbeiter C. Surach. ${ }^{181}$

178 In den Cästebüchern der Ausstellung »Die Neue Ukraine« im Leningrader Ethnographischen Museum äußerte das Publikum ein ähnliches Detailwissen aus erster Hand über Fehler, Lücken und die unzureichende Darstellung des Landes in der Ausstellung. Vgl. Hirsch, Francine: Empire of Nations, S. 212.

179 OGAČO, f. 627, op. 3, d. 401, S. 9. I. Gorochov fügte dem Arbeitsbericht, den er jährlich an das zentrale Museumsinstut des Narkompros schickte, eine Liste mit sechs abgetippten (lobenden) Gästebuchkommentaren bei.

180 OCAČO, F. 627, op. 3. d. 399, ohne Seitenzahl. Gästebuch 1946-1948, Eintrag vom 28. Februar 1948.

181 Ebd. 
Die Frage und die Antwort betrafen einen Kernbereich der wissenschaftlichen kraevedenie: die Flora und Fauna der Region. Die ausführliche Antwort der Mitarbeiterin gerade zu dieser Frage (andere Fragen und Einträge auf den vorhergehenden und nachfolgenden Seiten wurden nicht beantwortet) zeigt, dass das Interesse und die Expertise der muzejščiki insbesondere in diesem Bereich lagen. Während des Krieges war neben den naturwissenschaftlichen Expeditionen die öffentliche Beratung in Alltagsfragen (beispielsweise zu Formen der Subsistenzwirtschaft) das zweite Standbein der Museumsaktivität gewesen.

Im Tscheljabinsker Gästebuch lassen sich weitere Einträge von Kindern finden, die zum Teil von Museumsdirektor Gorochov persönlich beantwortet wurden. ${ }^{182}$ Manche kamen sogar in Erwartung einer Antwort wieder ins Museum und schrieben neben ihre Frage >Warum gibt es keine Sammlungen von historischen und aktuellen Briefmarken?` vorwurfsvoll in die dafür vorgesehene Sparte des Gästebuchs: »Warum bekomme ich keine Antwort, wenn Platz dafür gelassen wurde? « ${ }^{183}$ Diese Vernachlässigung in der Besucherbetreuung kann nicht darüber hinwegtäuschen, dass die muzejščiki unter Gorochov an die Traditionen des "Goldenen Jahrzehnts der kraevedenie« anknüpften. Mit der bewussten Hinwendung zu einer intensiven Beratungstätigkeit sollte das Museum wieder zu einem Forschungszentrum werden, das mit seiner lokalen (naturwissenschaftlichen) Expertise die Bewohner über ihre Umwelt aufklärte.

182 Vgl.: Eintrag vom 31. Januar 1948, Schüler der Schule Nr. 107, Klasse »B«, »Warum gibt es keine Abteilung >Insekten«? Antwort I. Gorochovs: »Wegen Platzmangel kann die Abteilung >Umwelt« nicht vollständig inszeniert werden. Direktion«. Direkt darunter befindet sich eine weitere Frage: »Warum gibt es keine Münzensammlung?« Antwort I. Gorochovs: »Einzelne Münzen sind ausgestellt, aber eine umfassende Präsentation ist im Plan nicht vorgesehen. Direktion«. Vgl.: Gästebucheinträge vom 31.01.1948, in: OGAČO, f. 627, op. 3, d. 399, ohne Seitenzahl. Vgl.: Gästebucheintrag vom 31.01.1948, in: OCAČO, f. R-627, op. 3, d. 399, ohne Seitenzahl. 


\section{Kapitelfazit}

Das Kapitel »Besichtigen« stellt die Besucherinnen und Besucher der sowjetischen Museen ins Zentrum. Die èkskurzovody waren verantwortlich für ihre Betreuung und für die Vermittlung der Ausstellungsinhalte. Interne Sitzungsprotokolle zeigen die »selbstkritischen « Diskussionen innerhalb des Exkursionsbüros über die Form und den Inhalt der Führungen. Die Objekte des »Großen Vaterländischen Krieges« und die beliebten Ausstellungen hatten offenbar ein Umdenken bei den Moskauer ékskurzovody ausgelöst: Entgegen der Praxis der 1930er Jahre bezogen sie sich nun explizit und stärker auf die Objekte. Damit erhöhten sie den Status des Museumsexponates in der Vermittlung der Inhalte. Die muzejščiki stellten hohe Ansprüche an ihre Arbeit: Die Gäste sollten im Museum visuell ansprechende Exponate betrachten können, die von den ékskurzovody durch einen fortlaufend aktualisierten Stand des Kriegsverlaufs kontextualisiert werden sollten.

Der regelmäßige Museumsbesuch war ein traditioneller und relevanter Bestandteil im Leben der Menschen in der Sowjetunion. Im Museum erlebten die Besucherinnen und Besucher sowohl auf der kognitiven als auch auf der emotionalen Ebene eine Deutung, die sie in ihre persönliche Kriegsbiografie integrieren konnten. Diese Funktion der sowjetischen Kriegsausstellung als Lernort wurde bislang nicht ausreichend berücksichtigt. Sowohl der Stellenwert des Museumsbesuchs im sowjetischen Schulalltag als auch der Einfluss des Museums auf die kulturpolitische Bildung der Rotarmistinnen und Rotarmisten ergänzen die Wahrnehmungsmuster, mit denen die Menschen der Sowjetunion den Krieg deuteten und erinnerten.

Die Untersuchung der Rezeption sowjetischer Kriegsausstellungen trägt $\mathrm{zu}$ dem Verständnis von Ideologie im Stalinismus bei. Ausgewählte Eindrücke ihres Ausstellungserlebnisses teilten die sowjetischen Museumsbesucherinnen und Museumsbesucher ihren Mitmenschen und den muzejščiki im Gästebuch mit. Ein über Werbezwecke hinausgehender museumsinterner Gebrauch dieser Besucherrezeption wurde für die Stalinzeit bislang als unwahrscheinlich erachtet. Die Empirie der Museen in Moskau, Minsk und Tscheljabinsk eröffnet jedoch neue Dimensionen im Verhältnis zwischen dem Museumspersonal und ihren Gästen.

Grundsätzlich zeigen die Gästebücher den Wunsch, an der Kriegserinnerung im Museum zu partizipieren. Diese Mitsprache äußerte sich in Bezug auf die Museumsarbeit und besonders häufig auf die Führungen. Die scheinbar trivialen Kritik- und Änderungswünsche waren politisch, da sie den autoritativen Deutungsanspruch des Museums in Frage stellten. Den Einträgen in den drei Museen ist gemein, dass sie den Grad der Aneignung der Ausstellungsnarrative spiegeln. Ihre Einträge konnten den muzejščiki ein unspezifisches Lob aussprechen oder sie konnten in die Tiefe des Ausstellungsinhaltes gehen und Lücken oder besonders gute Inszenierungen benennen. Insbesondere die Bezugnahme auf ein- 
zelne Ausstellungselemente gibt Aufschluss über die Akzeptanz bzw. Beliebtheit, die die Objekte beim Museumspublikum genossen. Darüber hinaus können die Einträge Hinweise auf die Schreibmotivation der Verfasserinnen und Verfasser geben. Diese lag häufig in dem Impuls begründet, sich in das allgemeine Narrativ einzuschreiben.

Die Interpretation der Gästebücher aus Moskau, Minsk und Tscheljabinsk erlaubt verschiedene Rückschlüsse, die die Forschung zu Gästebüchern in folgenden Punkten erweitern. Während sich das Gästebuch erkenntnisreich als Medium der Kommunikation analysieren lässt, so muss doch der situative Kontext stärker berücksichtigt werden: Unter welchen Umständen kommunizierte hier wer mit wem und wer las wessen Kommentare? Die Museumsgäste nahmen die Einladung des "Buchs für Bewertungen und Vorschläge« wörtlich und präsentierten sich gemäß der sozialistischen Forderung als engagierte und verantwortungsvolle Bürgerinnen und Bürger mit einer differenzierten Mitsprache, die ihren Wunsch nach Teilhabe am sozialistischen Projekt zeigt. Deshalb sollten die Meinungen eher als Stellungnahmen und weniger als ein Dialog gelesen werden. Man war durchaus animiert, auf die Kommentare der anderen Besucherinnen und Besucher zu reagieren; dahinter stand jedoch eher die Motivation, die eigene Position festzuschreiben, als in einen Austausch mit ihnen zu treten. Gemäß des ideologischen Anspruchs nach "self-transformation «, der die Menschen, zu >neuen, sich ihrer sozialistischen Geschichte bewussten Menschen machen wollte und diesen Prozess mit repressiven Strafmaßnahmen überwachte, wurde das Schreiben über sich selbst zu einer von mehreren »intensely politicized activities «. ${ }^{184}$ Mit ihren Einträgen im halböffentlichen Raum des sowjetischen Museums konnten sie sich in das sowjetische Narrativ einschreiben. Ihre Einträge können als ein Ausdruck »of the making of an illiberal, socialist subjectivity« gelesen werden. ${ }^{185}$

Die Adressaten der Einträge waren jedoch nicht nur zukünftige Besucherinnen und Besucher, sondern auch die muzejščiki. Die Angestellten des Exkursionsbüros, die èkskurzovody, waren auf zwei Ebenen in den Gästebucheintrag involviert. Auf einer expliziten Ebene mischten sie sich in die Bewertungen ein - wenn ein Kommentar in seiner Kritik Grenzen überschritt, d.h., einen schlechten Eindruck auf die Leserschaft machte, wurde er für alle sichtbar entkräftet. Die Präsenz der $\dot{e} k s-$ kurzovody bzw. das Wissen um die Resonanz ihres Eintrages beeinflusste die Schreibenden indirekt, da sie sie scheinbar nicht hemmte, sondern im Gegenteil motivierend wirken konnte. Die Signaturen unter den Einträgen (zum Teil vollständige Adressen) und die Bekanntgabe des beruflichen oder sozialen Hintergrundes weisen darauf hin, dass die Schreibenden sich als hörbare Kritikerinnen und Kritiker 
wahrnahmen, die den Eintrag in Erwartung einer Antwort verfassten. In Tscheljabinsk manifestierte sich diese in der Museumswelt einzigartige kommunikative Funktion des Gästebuchs darin, dass eine Spalte »Für Antworten« angelegt wurde. ${ }^{186}$

Das sowjetische Gästebuch war allen zugänglich und lud zur Mitsprache ein. Die oder der Schreibende erlangte durch den öffentlichen Eintrag Aufmerksamkeit und das Museumspersonal nutzte das Buch zur Besucherforschung. Der öffentliche Charakter des Buches zwang die muzejščiki, auf offensichtlich scherzhafte und vorwurfsvolle Einträge (»Im Museum ist es sehr schlecht. Ich.«oder »Die Putzfrauen schlagen die Besucher!«) zu reagieren. Indem das Museum diese Kritik für alle sichtbar entkräftete (»Schade, dass der Genosse dem Museum nicht mit Ratschlägen hilft « und »Der Vorfall wurde überprüft und entspringt der Fantasie«), bekräftigte es seine überlegene Position. Herrschaft zeigt sich hier in einer informellen Form, die nicht (nur) auf die Logik des Befehlens und Gehorchens reduziert werden kann. Die Vorstellung von Herrschaft als sozialer Praxis, die auf Prozesse des Gebens und Nehmens und des Kompromisses angewiesen ist, kann die Duldung der Museumsautoritäten, die stark abwertende und provozierende Kommentare tolerierten (»Hier sind Spezialisten nötig und keine Dilettanten«), erklären. Die Besucherinnen und Besucher wiederum wussten um die Regeln dieses Machtverhältnisses und nutzten das Gästebuch, um ihre Deutung, Aneignung und Bewertung des musealen Vergangenheitsdiskurses zu artikulieren.

Für die Museumsseite stellten die Einträge eine Art Kapital dar, das sie auf verschiedene Weise nutzten. Die wohlmeinenden Besuchermeinungen publizierten sie zu Werbezwecken in Zeitungen oder zum Beweis ihrer guten Arbeit in der Korrespondenz mit dem Museumsinstitut im Bildungsministerium. Die Einträge in den VIP-Gästebüchern (z.B. von Josip Tito) stellten in dieser Interpretation eine besonders wertvolle »Währung « dar, mit ihnen konnte man - und so ist es bis heute - die (internationale) politische Relevanz des Museums beweisen. Die negativen Kommentare hingegen hatten internen Nutzen: Sie wurden als Indikatoren für eine mangelhafte Arbeit der ékskurzovody interpretiert und in Aufsätzen und Berichten über die Qualität der muzejščiki zitiert.

Die Beispiele aus dem >dissonanten Besucherchor zeigen, dass die Stimmen im Stalinismus über formelhafte Loyalitätsbekundungen hinaus gingen. Die Analyse der Gästebucheinträge der Museen in Moskau, Minsk und Tscheljabinsk präsentiert ein breites Spektrum von individuellen Schreibmotivationen, das das Bedürfnis nach Mitsprache an dem Ausstellungsdiskurs spiegelt. Mit ihren Beiträ-

186 Diese kommunikative Dimension des sowjetischen Museumsbesuchs steht im starken Kontrast zu den westeuropäischen Museen, die diesen Austausch im Gästebuch nicht kannten. Susan A. Crane schreibt: „Visitors are interlocutors without discussion partners in the museal conversation«. Crane, Susan A.: Memory, Distortion and History in the Museum, S. 48. 
gen eigneten sie sich den musealen Gegenwarts- bzw. Vergangenheitsdiskurs auf unterschiedliche Weise an: mit spontaner Kreativität (»Das lebendige Moskauer Krokodil ...«), mit Schadenfreude (»Sie werden nur russische Eichenkreuze ernten«), mit der Wiedergewinnung entfremdeter Beziehungen zu den Partisaninnen und Partisanen (»Von ganzem Herzen danke ich den Volksrächern«), mit Bewunderung (»Die Waffen hinterließen einen großen Eindruck«), mit versierter Expertenkritik (»Nachteile der Ausstellung 1.-3.«), durch die Identifizierung und Loyalitätsbezeugungen mit dem sozialistischen Projekt (»Mich, als ehemalige Polin, hat die Waffenproduktion besonders beeindruckt«), mit Enttäuschung (»Ich bedauere, dass ich mich nicht mit ... vertraut machen konnte«) oder mit Unverständnis (»Graue Schneehasen?«). Die Besichtigung konnte gleichzeitig Gefühle der Dankbarkeit (»großer-riesengroßer Dank«), des Ärgers (»Die Erläuterungen haben uns absolut nicht zufriedengestellt«), des Stolzes (»Hier werden alle ewigen Verdienste unserer Brüder, Schwestern, Väter und Mütter gezeigt«) und der Rache (»ich nehme den Hass mit«) auslösen. Während des Krieges konnten sie motivieren (»Der Wunsch kocht noch stärker in uns«) und in der Nachkriegszeit der Selbstvergewisserung und der positiven Deutung der eigenen Erfahrung dienen (Schulkinder erinnern sich an ihre Zeit bei den Partisanenverbänden).

Diese Schreibmotivationen existierten nicht exklusiv oder unabhängig voneinander. Im Gegenteil, sie zeigen, dass Einzelne einige Ausstellungsinhalte annahmen, während sie gleichzeitig andere ablehnten. Der komplexe Kommentar (»Aber wir lachen nicht«) zeigt, dass binäre Entweder-Oder-Deutungen nicht immer sinnvoll sind, da Kritik und Lob miteinander verflochten sein konnten. Generell zeigen die Einträge, wie die Ideologie als eine lebendige und adaptive Kraft der sowjetischen Kultur benutzt wurde, um die Gegenwart kreativ zu bewerten und die Geschichte mit Bedeutung zu versehen.

Das Museumspersonal im Stalinismus hatte das Interesse an den Meinungen ihrer Gäste keinesfalls verloren. Die Markierung der Einträge und die schriftlichen Entgegnungen des Exkursionsbüros im Gästebuch beweisen den intensiven internen Gebrauch als Mittel der Besucherforschung. Der Guščin-Bericht erweitert unser Wissen über eine naheliegende Verwendung der Gästebucheinträge: Die Kommentare wurden als Interpretationsgrundlage für die Bewertung der èkskurzovody und für die Vermittlungsarbeit des Museums im Allgemeinen benutzt. Inwieweit diese Kommentare zu einer Veränderung im Text der Führung oder sogar im Ausstellungsinhalt führen konnten, muss noch erforscht werden. Ein Vergleich von Überarbeitungen der Ausstellungspläne unter Berücksichtigung der Besucherkritik könnte hier weiteren Aufschluss geben. Auch ein Vergleich mit verwandten Institutionen (z.B. Bibliotheken, Kinos oder Theater) und ihrer Besucherforschung 
bietet sich an. ${ }^{187}$ In Bezug auf die Gattungsfrage erscheint das sowjetische Gästebuch als ein Genre, das mehr von den Spannungen der sozialistischen Öffentlichkeit als von strikten formalen Grenzen geprägt ist. Der vielseitige Gebrauch des Mediums weist auf ein Verständnis hin, das eine doppelte Interpretation verlangt: Die Einträge können als kulturelle und kommunikative Schreibpraxis, die Teil des Museumsbesuchs war, und als Produkte einer literarischen Form von EgoDokumenten gelesen werden. Dadurch sind die Einträge unauflöslich mit der Subjektivität des Schreibenden verbunden, welche sich in dem Entwurf des jeweiligen Selbstverständnisses im Eintrag zeigt.

187 Evgeny Dobrenko konnte für die sowjetischen Bibliotheken zeigen, dass die Ergebnisse der Besucherforschung die Bücherproduktion vorstrukturierten und beeinflussten. Vgl.: Dobrenko, Evgeny: The Making of the State Reader, Social and Aesthetic Contexts of the Reception of Soviet Literature, Stanford 1997. Für das sowjetische Kino vgl. Kenez, Peter: Cinema and the Soviet Society, 1917-1953, Cambridge 1992. 